\title{
La información gubernamental y el acceso a la información pública
}




\section{La presente obra está bajo una licencia de:}

\section{http://creativecommons.org/licenses/by-nc-sa/3.0/deed.es MX}

\section{Atribución-No Comercial-Licenciamiento Reciproco 3.0 Unported}

Eres libre de:

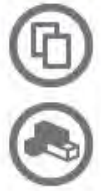

copiar, distribuir y comunicar públicamente la obra

hacer obras derivadas

Bajo las condiciones siguientes:

Atribución - Debes reconocer la autoría de la obra en los términos

especificados por el propio autor o licenciante.

No comercial - No puedes utilizar esta obra para fines comerciales.

Licenciamiento Recíproco - Si alteras, transformas o creas una obra a

partir de esta obra, solo podrás distribuir la obra resultante bajo una licencia

igual a ésta.

\section{Esto es un resumen fácilmente legible del: texto legal (de la licencia completa)}

En los casos que sea usada la presente obra, deben respetarse los términos especificados en esta licencia.
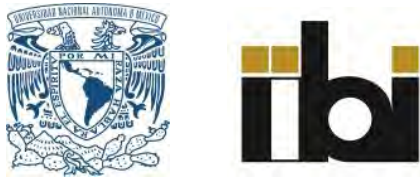
La información gubernamental y el acceso a la información pública 
Investigación realizada gracias al Programa UNAM-DGAPA-PAPIIT IN 403113 


\title{
La información gubernamental y el acceso a la información pública
}

\author{
Coordinador \\ Egbert John Sánchez Vanderkast
}

Universidad Nacional Autónoma de México 2015 


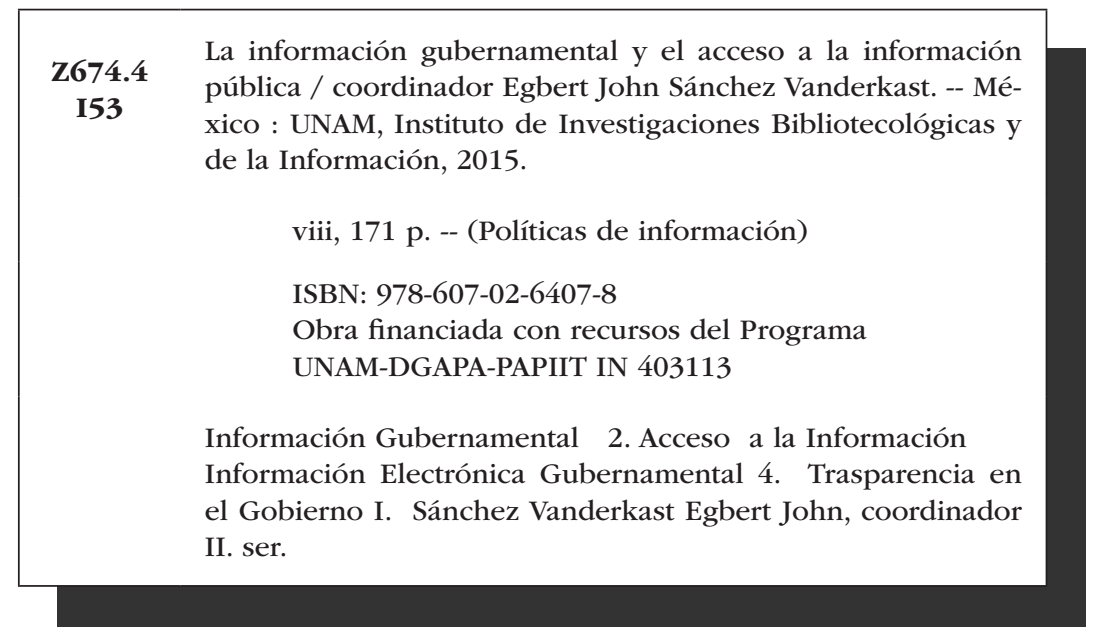

Diseño de portada: SPAFA

Primera Edición 2015

DR (C) UnIVERSIDAd NACIONAL AUTÓNOMA DE MÉXICO

Ciudad Universitaria, 04510, México D.F.

Impreso y hecho en México

ISBN: 978-607-02-6407-8

Obra financiada con recursos del Programa

UNAM-DGAPA-PAPIIT IN 403113 


\section{Tabla de contenido}

Presentación ....................... vii

Norma Aída Manzanera Silva

Introducción . . . . . . . . . . . . . . . . . 1 Egbert John Sánchez Vanderkast

DATOS PÚBLICOS EFICIENTES: WEB OFICIAL, PORTAL DE REUTILIZACIÓN

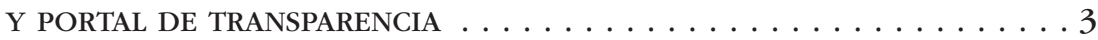
Luis Fernando Ramos Simón

LAS PUBLICACIONES OFICIALES DE LA ADMINISTRACIÓN PÚBLICA DE Bogotá, Colombia . . . . . . . . . . . . . . . . 15

Wilson E. Colmenares Moreno

LOS PORTALES LATINOAMERICANOS DE DATOS ABIERTOS: NUEVAS HERRAMIENTAS PARA EL ACCESO Y LA REUTILIZACIÓN DE LA . . . . . . . 39 INFORMACIÓN GUBERNAMENTAL

Silvia Cobo Serrano

EL PORTAL DE DATOS ABIERTOS DE LA UNIÓN EUROPEA EN EL CONTEXTO DEL OPEN DATA GOVERNMENT . . . . . . . . . . . . 51

Rosario Arquero Avilés y Gonzalo Marco Cuenca

HACIA UNA TRANSPARENCIA ACTIVA FOCALIZADA EN EL ÁMBITO

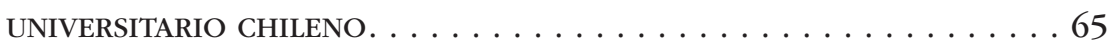
Jorge Pérez Pérez 
MEDIOS PARA EL ACCESO A LA INFORMACIÓN PÚBLICA

EN VENEZUELA . . . . . . . . . . . . . . . . . . . . . . . . 77

Dionnys Peña Ocando y Nelly Primera Mendoza

EL CIUDADANO BIEN INFORMADO Y LA MEDIACIÓN BIBLIOTECARIA. . . . 93 Verónica Araiza Díaz

APORTES DEL PROYECTO "COSTA RICA HACIA LA SOCIEDAD DE

LA INFORMACIÓN: DE TODOS PARA TODOS” PARA LA CONSTRUCCIÓN

DE UNA POLÍTICA NACIONAL DE INFORMACIÓN EN COSTA RICA . . . . 109

Marcela Gil Calderón y Magda Sandi Sandi

ARCHIVOS, BIBLIOTECAS Y CENSURA . . . . . . . . . . . . . . . 127

Rosa María Martínez Rider, Perla Itzamná Navarro Sánchez

y Rosa María López Martínez

PUBLICACIONES OFICIALES, INSTRUMENTO FUNDAMENTAL PARA LA

TRANSPARENCIA DEL ESTADO DE DERECHO . . . . . . . . . 147

Juan Ricardo Montes Gómez

LA IMPLEMENTACIÓN DE POLÍTICAS DE INFORMACIÓN EN LA

DISEMINACIÓN DE LA INFORMACIÓN GUBERNAMENTAL . . . . . . . . . . 159

Nayeli Gervacio Mateo 


\section{Presentación}

7 odo texto bibliotecológico trata de alguna manera sobre el fenómeno de la información, de ahí que esta obra no sea la excepción; sin embargo, su cualidad primera es que constituye una recopilación de reflexiones en torno a la información gubernamental y a sus modalidades de disposición y acceso, desde el conocimiento experto, con énfasis en la necesidad de centrar la mirada en el usuario.

Los autores abordan la importancia del usuario-ciudadano informado, como requisito para una participación activa en la toma de decisiones que contribuya en la construcción de regímenes democráticos, alejados de los esquemas totalitarios, cuyo sustento ideológico ha sido la censura y la secrecía.

En los escritos se analizan los rasgos particulares de las colecciones oficiales en sus diferentes soportes y formatos, sobre todo la tendencia a su disposición en la Web, y de manera centralizada en portales de acceso abierto y su importancia como elementos para una rendición de cuentas expedita y oportuna que, de manera anticipada -sin interpósita solicitud expresa del ciudadano-, conlleve a la comparación de promesas contra resultados, a la necesaria autoevaluación por parte de los sujetos obligados y a la evaluación ciudadana, para permitir la mejora de las políticas públicas. 
Las contribuciones, provenientes de diferentes latitudes, principalmente de Latinoamérica y Europa, enriquecen el panorama sobre la constitución y las tendencias de las políticas de información; asimismo, se vislumbra la imprescindible ubicación de dichas políticas en los primeros lugares de toda agenda gubernamental como elemento estratégico para la concreción de iniciativas de dependencias y entidades de la administración pública, en sus diferentes niveles: federal, estatal y municipal.

Este conjunto de escritos representa un ejercicio transdiciplinario en el cual se manejan términos y materias propias de la bibliotecología, tales como control bibliográfico, competencias informativas, mediación bibliotecaria, organización y diseminación de la información, en el marco de las políticas públicas.

La información gubernamental y el acceso a la información pública es un esfuerzo pionero en el estudio de la intersección de la bibliotecología y la administración pública, cuya lectura invita a continuar con la reflexión académica, y que veladamente reclama, en el campo laboral, la participación activa de los especialistas en el tratamiento de la información. 


\section{Introducción}

T a paulatina transformación de las sociedades ocasiona que surjan temas de investigación y campos de estudio novedosos, comunidades epistémicas dinámicas y creativas, y una praxis profesional focalizada. Estos cambios, además, enfatizan la cohesión, las nuevas formas de actuar y estructurar el uso del poder informacional y una forma de argumentar diferente. Todos estos factores van acondicionando el camino que conduce al estado informacional.

En este sentido, los estudios sobre políticas de información han ganado terreno, principalmente las temáticas que giran alrededor de las políticas de información; para ser más exacto, las indagaciones que tienen que ver con la diseminación de la información gubernamental. La información es vista desde diferentes ángulos, como un recurso económico, como un bien (se puede comprar o vender), como dador de un contexto y de una estructura predefinida, o como un agente y una fuerza constitutiva que contribuye a que la sociedad consiga sus propósitos de acuerdo con la normativa vigente.

Desde la perspectiva de la bibliotecología y los estudios de la información, el campo de acción de los estudios sobre 
políticas de información tiene una historia muy reciente, ya que sus temas han sido tratados de manera transversal en los discurso de las humanidades y de las ciencias sociales. Es evidente que las leyes y la economía han sido promotores de una larga tradición de trabajos sobre este tema. Sin embargo, los estudios de la información ofrecen una visión particular relativa al acceso a la información pública y a la información gubernamental en general.

Cabe mencionar que las políticas de información transitaron de un tema o discurso de bajo impacto, o de menor importancia, a uno de un alto impacto por el reconocimiento de la información a través de las legislaciones y las regulaciones que promueven su uso. Mientras, en el ámbito de la información gubernamental, resaltan las temáticas que giran alrededor de la administración de la información pública en general, los datos gubernamentales de acceso abierto, la protección de datos, la información legislativa y los archivos, entre otras. Últimamente se consideran comunes los debates en todos los niveles sobre las Tecnologías de la Información y la Comunicación, lo que trae consigo una transformación de los valores y de la forma de pensar en las condiciones tecnológicas, políticas y sistémicas que nos brindan los entornos nacional y regional.

Egbert John Sánchez Vanderkast 


\title{
Datos públicos eficientes: Web oficial, portal de reutilización y portal de transparencia"
}

\author{
LUIS FERNANDO RAMOS SIMÓN \\ Universidad Complutense de Madrid, España
}

\section{INTRODUCCIÓN}

T a implantación de la Administración electrónica o eGobierno ha supuesto el reconocimiento del derecho de los ciudadanos a relacionarse con las administraciones públicas por medios electrónicos. Este derecho, para que pueda ejercitarse, implica que las administraciones han de dotarse de medios telemáticos y electrónicos. Asimismo, conlleva la asunción del principio general de accesibilidad, por cuanto las tecnologías de la información pueden actuar como factor de exclusión, ya sea por problemas físicos o culturales, o bien, por origen de la llamada brecha digital, que afecta a grupos importantes: personas con discapacidad, rentas bajas, mayores, etcétera. De ahí la necesidad de

* Agradecimiento a la Dirección General de Asuntos del Personal Académico (DGAPA, UNAM), proyecto "Buenas prácticas en el acceso a la información gubernamental" (PAPIIT IN 403113). 
garantizar el principio general de accesibilidad ${ }^{1}$ que este autor considera que se asienta sobre cuatro pilares básicos:

- El derecho de acceso a la información y a los servicios, garantía clásica que se desprende directamente del principio de transparencia y publicidad, aspecto al que nos referimos más adelante.

- El principio de igualdad para garantizar la "igualdad de condiciones", con independencia de las circunstancias personales de los administrados, y sin relación con sus circunstancias económicas, técnicas o culturales.

- Diseño para todos, para asegurar que la usabilidad de las plataformas tecnológicas que utilice la administración no tengan barreras, para que los colectivos con dificultades puedan acceder sin problemas.

- Servicio universal, con el propósito de garantizar la accesibilidad universal a Internet de calidad que permita el acceso a los servicios públicos electrónicos.

Como hemos señalado, la transparencia y publicidad de la información y los servicios públicos se desgajan del principio general de accesibilidad al Gobierno electrónico. Transparencia se asimila a la "casa de cristal", metáfora que acuñó Turati hace más de un siglo: "Donde un interés superior público no imponga un secreto momentáneo la casa de la Administración debería ser de vidrio"; ${ }^{2}$ esto se debe plasmar en un principio general de actuación de los organismos públicos. Por su parte, la publicidad persigue la difusión de información, de modo que se facilite el acceso a las fuentes de información administrativas. Por otro lado, es evidente que la incorporación de los servicios públicos al canal de Internet potencia exponencialmente la difusión de la información pública. 


\section{LAS SEDES ELECTRÓNICAS Y LA DIFUSIÓN DE INFORMACIÓN PÚBLICA EN INTERNET}

En el ámbito de la Administración electrónica o e-Gobierno, la sede electrónica es la dirección electrónica (Web) disponible para los ciudadanos a través de Internet cuya titularidad, gestión y administración electrónica corresponden a un organismo público en el ejercicio de sus competencias. En general, se puede decir que las sedes electrónicas cumplen en la Web las mismas funciones que llevan a cabo las oficinas físicas.

En cualquier caso, la difusión de información pública en la sede Web "implica la responsabilidad de su titular con respecto a la calidad de la información difundida y, en particular, con respecto a la integridad, veracidad y actualización de esta información."3

Con carácter general, la legislación no suele establecer unos contenidos mínimos de información general que deban estar a disposición de los ciudadanos en sus sedes electrónicas o páginas web, aunque sí lo hacen leyes específicas, como las de reutilización o de transparencia. Desde la doctrina del Derecho Administrativo se propone que se debería disponer de un contenido mínimo de información administrativa, junto a la información normativa relacionada con el ejercicio de sus competencias. Además de la información que se proporciona a los ciudadanos en las sedes físicas, las páginas Web deberían disponer de información sobre procedimientos, trámites y servicios electrónicos ofrecidos. Todo ello, en una página Web bien estructurada, con herramientas de búsqueda y un mapa de navegación que ordene la información por materias o categorías ${ }^{4}$ (Cuadro 1). 
La información gubernamental y el acceso a la información...

Cuadro 1

Diez primeros países del "Open data Index

\begin{tabular}{|c|c|c|}
\hline $\begin{array}{l}\text { Sort } \\
0 \text { alphabetically } \\
\text { ○ by score }\end{array}$ & 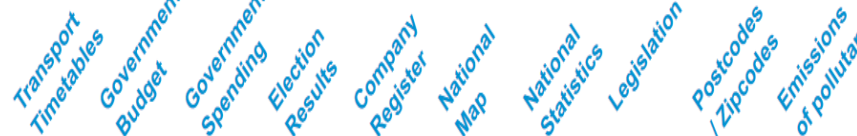 & \\
\hline United Kingdom & & 940 \\
\hline United States & & 855 \\
\hline Denmark & |||| & 835 \\
\hline Norway & |||| & 755 \\
\hline Netherlands & \|\| & 740 \\
\hline Finland & || |||||||| ||||||||| ||||| & 700 \\
\hline Sweden & ||||| & 670 \\
\hline New Zealand & ||||||| ||||||||| & 660 \\
\hline Australia & |||||||| & 660 \\
\hline Canada & ||||||| |||||||||| ||||||||| |||||||||| |||||||||| ||||||||| & 590 \\
\hline
\end{tabular}

Fuente: https://index.okfn.org/country

\section{TIPOLOGÍA DE PORTALES DE DATOS}

\section{ABIERTOS GUBERNAMENTALES}

Como indicábamos, la apuesta por la apertura masiva de datos en el sector público tiene su inicio con el primer mandato de Barack Obama, en enero de 2009. Más tarde, a finales de 2011, la Comisión Europea proclamó también la importancia de los datos abiertos para impulsar las transparencias en la gestión pública y su importancia para el crecimiento económico y el empleo, en todos los sectores, incluidas las 
bibliotecas, los archivos y los museos. La última de estas grandes proclamas en favor de los datos abiertos proviene de la cumbre del G8, en junio de 2013, en Irlanda. ${ }^{5}$

En algunas organizaciones se hace un seguimiento de los portales abiertos, aunque no se ve una clara consonancia de los datos entre las distintas fuentes. Una de las organizaciones más dinámicas en este ámbito es la fundación Open Knowledge Foundation (OKF), autora de un ranking de transparencia denominado "Open Data Index", con datos procedentes de 70 países. La calidad de los datos del análisis para realizar el ranking presenta serias deficiencias. En algunas variables que hemos podido comprobar, los datos aportados no proceden de organismos públicos, sino de operadores privados que ni siquiera cumplen los requisitos de transparencia fijados en la legislación europea, es decir, denominación social y domicilio y datos de inscripción registral. (Véase el proveedor de datos sobre transporte para España. ${ }^{6}$

Por otro lado, la página Web Open Government Data, promovida también por un grupo de expertos en datos abiertos de todo el mundo vinculados a la fundación OKF, publica un Datacatalog ${ }^{7}$ que incluye una lista de 377 catálogos de datos abiertos, si bien la presentación de los portales es heterogénea y no permite una categorización sencilla. Más sistemática es la referencia que figura en el portal de datos abiertos del gobierno de Estados Unidos, donde se cifra en 45 el número de gobiernos nacionales que disponen de portal de open data y en 163 los portales regionales en todo el mundo. ${ }^{8}$ Sin embargo, al igual que en los casos anteriores, una vez descargados los datos, su heterogeneidad y dispersión no permite realizar una estudio con un mínimo rigor (Cuadro 2). 
La información gubernamental y el acceso a la información...

Cuadro 2

Portales de datos públicos en el mundo

\begin{tabular}{|c||c|c|c|}
\hline U.S. States & $\begin{array}{c}\text { U.S. Cities and } \\
\text { Counties }\end{array}$ & $\begin{array}{c}\text { International } \\
\text { Countries }\end{array}$ & $\begin{array}{c}\text { International } \\
\text { Regions }\end{array}$ \\
\hline 39 & 46 & 45 & 163 \\
\hline
\end{tabular}

Fuente: https://www.data.gov/open-gov/

En este sentido, en 2012, ya nuestro grupo de investigación Publidoc-UCM analizó 10 portales gubernamentales de la Unión Europea. Si bien el dinamismo de este tipo de iniciativas puede ser discutible en su vigencia, las conclusiones del estudio pusieron en evidencia que:

[...] el portal de datos abiertos es una tarjeta de presentación para exhibir la transparencia pública, de coste bajo y relativamente fácil de construir. Pero detrás se encuentran datos poco estructurados y una oferta de información poco consistente en calidad y en cantidad, en relación con la oferta disponible de información pública. ${ }^{9}$

Asimismo, se ponía de relieve la dificultad de identificar unas características comunes y el diferente desarrollo en la creación de aplicaciones informáticas para explotar los datos de los portales.

Por su parte, la World Wide Web Foundation ${ }^{10}$ publicó a finales de 2013 un ranking de 81 Webs nacionales, aunque en sus análisis parece tener gran importancia la transparencia de los gobiernos indizados, ya que los resultados atienden a los siguientes cuatro criterios: acceso universal, contenidos relevantes, libertad y apertura, y empoderamiento. Por grupo de países, los primeros puestos son los que se muestran en el Cuadro 3. España y México ocupan posiciones similares en el cuadro general (28 y 30, respectivamente). En la clasificación general los cinco primeros de 
esta lista están dentro de los diez primeros del Open Data Index, mencionados más arriba.

Cuadro 3

2013 Web Index Report

\begin{tabular}{|c|c|c|c|c|c|}
\hline \multicolumn{2}{|c|}{ Developed Countries } & \multicolumn{2}{c|}{ Emerging Market Countries } & \multicolumn{2}{c|}{ Developed Countries } \\
\hline Country & Overall Rank & Country & Overall Rank & Country & Overall Rank \\
\hline Sweden & 1 & Mexico & 30 & Philippines & 38 \\
\hline Norway & 2 & Colombia & 32 & Indonesia & 48 \\
\hline United Kingdom & 3 & Brazil & 33 & Kenya & 53 \\
\hline United States & 4 & Costa Rica & 34 & Morocco & 54 \\
\hline New Zealand & 5 & South Africa & 35 & Ghana & 55 \\
\hline
\end{tabular}

Fuente: http://thewebindex.org/wp-content/uploads/2013/11/Web-Index-Annual-Report-2013-FINAL pdf.

Interesante es el esfuerzo realizado por la organización del G-8, el club de los países más poderosos del mundo. La Carta de los Datos Abiertos del G-8 (G8 Open Data Charter) se plantea como objetivo mejorar el flujo de información entre los países. Dicha Carta proclama cinco principios:

- Datos abiertos por defecto.

- Calidad y cantidad.

- Utilizables por todos.

- Publicar datos para mejorar el gobierno.

- Publicar datos para mejorar la innovación.

El propósito de la Carta excede la mera declaración de intenciones por cuanto se encomienda su aplicación para el año 2015, tanto de los principios como de los anexos técnicos. ${ }^{11}$ Estos últimos están divididos en dos apartados: buenas prácticas sobre los cinco principios, y planes de acción para aplicar la Carta en los países miembros. 
Es muy interesante la sistematización de las categorías de datos de alto valor que se propone (Cuadro 4 ), lo cual sin duda servirá para organizar los datos en los niveles nacionales y regionales. De hecho, el ranking de transparencia presentado en el Cuadro 1 presenta notable similitud con los criterios de la carta de datos abiertos del G8.

\section{Cuadro 4}

Áreas temáticas con alto valor de los datos

\begin{tabular}{|c|c|}
\hline Categoría de datos (orden alfabético) & Datasets de ejemplo \\
\hline Ciencia e investigación & $\begin{array}{l}\text { Datos sobre genoma, actividad educativa e investigación, resultados expe- } \\
\text { rimentales }\end{array}$ \\
\hline Compañías & Compañía/Registro Mercantil \\
\hline Contratos y finanzas públicas & $\begin{array}{l}\text { Costes de transacción, adjudicación de contratos, licitaciones, licitaciones } \\
\text { futuras, presupuesto local, presupuesto nacional (planeado y liquidado) }\end{array}$ \\
\hline Delitos, seguridad y justicia & Estadísticas sobre delitos y seguridad \\
\hline Democracia y responsabilidad de gobierno & $\begin{array}{l}\text { Puntos de información gubernamentales, resultados electorales, legislación } \\
\text { y estatutos, salarios (escalas salariales), atenciones/regalos }\end{array}$ \\
\hline Desarrollo global & Ayuda, seguridad alimentaria, sector extractivo, terrenos \\
\hline Educación & Listados de centros, rendimiento de las escuelas, habilidades digitales \\
\hline Energía y medio ambiente & Niveles de contaminación, consumo de energía \\
\hline Estadísticas & Estadísticas nacionales, Censo, infraestructuras, riqueza, formación \\
\hline Geoespacial & Topografía, códigos postales, mapas nacionales, mapas locales \\
\hline Movilidad social y bienestar & Vivienda, seguros de salud y subsidios por desempleo \\
\hline Observación terrestre & Meteorología/Tiempo, agricultura, caza, pesca y silvicultura \\
\hline Salud & Datos de prescripciones, datos de rendimiento \\
\hline Transporte e infraestructura & $\begin{array}{l}\text { Horarios de transporte público, puntos de acceso, penetración de la banda } \\
\text { ancha }\end{array}$ \\
\hline
\end{tabular}

Fuente: http://www.g8.utoronto.ca/summit/2013lougherne/lough-erne-open-data-annex.html

\section{BUENAS PRÁCTICAS EN LA GESTIÓN DE LOS PORTALES}

Las áreas clave para lograr una buena gestión de los portales se orientan en dos direcciones. Una se dirige a lo- 
grar una buena organización de los activos de información disponibles para su publicación dentro de los organismos públicos; la otra ha de procurar una buena difusión e integración de los datos para que puedan ser utilizados tanto por los ciudadanos como por las empresas. La mayoría de las declaraciones sobre apertura de datos son en sí mismas propuestas de buenas prácticas en el uso de la información pública. A partir de las distintas fuentes manejadas en el estudio de los datos públicos abiertos, entre otras ONU, ${ }^{12}$ OPSI, ${ }^{13}$ NISO $(2007)^{14}$ o usability.gov, ${ }^{15}$ proponemos una relación no exhaustiva de esas buenas prácticas:

- El origen de los datos que se pongan a disposición del público debe estar bien acreditado, y los usuarios de los datos deben hacer constar su origen y grado de actualización.

- Maximizar la información pública disponible, para lo que se deben utilizar procedimientos claros y sencillos.

- Deben facilitarse listados de datos y conjuntos de datos púbicos fácilmente accesibles, para que los ciudadanos conozcan el volumen de información disponible y sus características.

- Las licencias de uso de la información pública deben ser sencillas de entender y de aplicar, tanto por los organismos públicos como por los reutilizadores.

- Los formatos de presentación de la información deben ser abiertos en cuanto a su facilidad de uso y operables en el sentido de que puedan ser fácilmente intercambiables con otros conjuntos de datos.

- Promover la elaboración de herramientas informáticas (API) que permitan el acceso y la explotación de los datos públicos por el mayor número de usuarios. 
- Establecer un sistema de quejas y reclamaciones, de modo que los ciudadanos valoren los procedimientos aplicados en la difusión de información que sirva de foro y propongan mecanismos de mejora.

La mencionada guía de la $\mathrm{ONU}^{16}$ sobre datos abiertos gubernamentales recientemente publicada hace un conjunto de recomendaciones específicas, tendentes a conseguir que los portales públicos logren la colaboración de los ciudadanos en su gestión, por lo que propone algunas iniciativas:

- Establecer un procedimiento para permitir que el sector privado y otras instituciones de la comunidad añadan sus datos, pensar en él como en el catálogo del país, no del gobierno.

- Facilitar la mejora de los datos permitiendo que puedan ser catalogados otros datasets secundarios, facilitando, por ejemplo, añadir geolocalizaciones y compartir los resultados con todos.

- Permitir que los datos se distribuyan por todas partes, de modo que esos datos puedan ser utilizados por otros en distintos contextos.

- Evitar privilegios de acceso, impidiendo la creación de niveles privilegiados para algunas categorías de usuarios porque impide el compromiso de todos.

Lo principal es crear un espacio neutral. Una última conclusión y recomendación deseable es que, en cualquier caso, se deben impulsar buenas prácticas en el uso de la información pública en línea como las que apuntamos en la investigación 


\section{REFERENCIAS BIBLIOGRÁFICAS}

1. Rubén Martínez Gutiérrez (2009), Administración pública electrónica, Pamplona, Thomson-Reuters, p. 402.

2. Ibíd.

3. Agustí Cerrillo (2008), e-Administración, Barcelona, Editorial UOC, p. 83.

4. Rubén Martínez Gutiérrez (2009), Op. cit., p. 402.

5. G8 Open Data Charter [en línea], http://www.g8.utoronto.ca/ summit/2013lougherne/lough-erne-open-data.html

6. Acerca de RedTransporte [en línea], http://www.redtransporte. com/acerca-de.html

7. DataCatalogs.org [en línea], http://datacatalogs.org/about

8. Ibid.

9. Luis Fernando Ramos Simón; Rosario Arquero Avilés; Luliana Botezán; Silvia Cobo Serrano; Andrea Sala Jiménez; Rodrigo Sánchez Jiménez; Félix del Valle Gastaminza (2012), "De la reutilización de información del sector público a los portales de datos abiertos en Europa", en BID: textos universitaris de biblioteconomia i documentació, desembre, núm. 29 [en línea], http://bid.ub.edu/29/ramos2.htm

10. WEBINDEX [en línea], <http://thewebindex.org/>

11. G8 Open Data Charter: Annex [en línea], http://www. g8.utoronto.ca/summit/2013lougherne/lough-erne-open-dataannex.html

12. ONU (2013), Guidelines on Open Government Data for Citizen Engagement, Nueva York, UNO.

13. OPSI (2005), The Re-use of Public Sector Information: A Guide to the Regulations and Best Practice, Londres, Office of Public Sector Information (OPSI). 
La información gubernamental y el acceso a la información...

14. NISO (2007), A Framework of Guidance for Building Good Digital Collections. 3rd edition. A NISO Recommended Practice, Baltimore, National Information Standards Organization (NISO)

15. usability.gov [en línea], http://guidelines.usability.gov/

16. ONU (2013), Op. cit. 


\title{
Las publicaciones oficiales de la Administración Pública de Bogotá, Colombia
}

\author{
WiLSON E. COLMENARES MORENO \\ Fundación Conector, Colombia
}

\section{INTRODUCCIÓN}

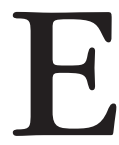

n Colombia se han realizado muy pocos análisis y estudios relacionados con las publicaciones oficiales. Para ser más exactos, únicamente se ha abordado el tema en un trabajo de grado, ${ }^{1}$ en un informe de investigación $^{2}$ y en un artículo de revista, ${ }^{3}$ producidos hace casi dos décadas; por lo tanto, es posible decir que en el país se han desarrollado pocas investigaciones relacionadas con las publicaciones oficiales. Ahora bien, ninguna institución gubernamental del país ha generado una definición y una caracterización de este tipo de obras. Sin embargo, leyes y decretos hacen referencia a las publicaciones oficiales de forma directa o indirecta, estableciendo obligaciones legales, sin definir sus características de forma o contenido.

El objetivo de este trabajo es generar información que permita analizar y explicar el estado de la producción, edición, publicación y control bibliográfico de las publicaciones oficiales producidas por las instituciones gubernamentales 
de Bogotá, desde 2008 hasta 2012. Además, busca fortalecer a la Administración Pública en:

- Racionalizar la inversión pública en la edición, difusión, organización, almacenamiento y acceso a las publicaciones oficiales.

- Fortalecer la transparencia y confianza en la gestión pública, a partir del acceso a los planes e informes de gestión materializados en publicaciones oficiales.

\section{LAS PUBLICACIONES OFICIALES SEGÚN EL MODELO DE ADMINISTRACIÓN PÚBLICA DE BOGOTÁ}

Las publicaciones oficiales son un instrumento importante para el funcionamiento del Estado como institución, dado que se convierten en guías y evidencia de la formulación, ejecución y evaluación de políticas, planes, programas y proyectos gubernamentales, además de ser el principal soporte de la legislación que regula la vida cotidiana y colectiva de las sociedades. Sin embargo, en la literatura convencional existe una cierta confusión terminológica al momento de referirse a las publicaciones oficiales como una tipología documental; por lo tanto, es posible encontrar diferentes denominaciones. Al respecto, se mencionan algunas en la Tabla 1.

Tabla 1

Diferentes denominaciones para referirse a las publicaciones oficiales

\begin{tabular}{|c|c|}
\hline Publicaciones oficiales & Documentos oficiales \\
\hline Publicaciones gubernamentales & Documentos gubernamentales \\
\hline Publicaciones estatales & Documentos estatales \\
\hline
\end{tabular}


La American Library Association (ALA), en 1939, había establecido tres aspectos para considerar los productos que debían ser reconocidos como publicaciones oficiales:

- Las obras producidas por la imprenta del gobierno (imprenta nacional) para uso de los organismos y agencias del gobierno.

- Si tienen el nombre impreso o grabado de una agencia gubernamental y éste es reconocido y usado por la agencia en sus operaciones, o las publicaciones se distribuyen, oficialmente, en el curso de asuntos de gobierno.

- Si la publicación está editada por un distribuidor oficial, organización o grupo individual perteneciente a los organismos del Estado.

La UNESCO, en la Conferencia General de París celebrada en 1988, definió que "[...] se podían considerar publicaciones oficiales las producidas por los gobiernos, los organismos y las instituciones gubernamentales en función de su capacidad ejecutiva, legislativa, administrativa, judicial, informativa, etcétera, y que se produzcan con fondos públicos.” 4

Años después, Mateo Maciá “[...] considera publicación oficial en sentido estricto aquellas editadas por una institución oficial y cuya publicación es preceptiva de acuerdo con las leyes y los reglamentos vigentes en el momento de la edición." Esta definición brinda a las publicaciones oficiales una importante característica, la cual radica en el mandato, orden, regla o instrucción que una institución gubernamental establece y materializa en una publicación oficial para el conocimiento y aplicación por parte de la administración pública y de los ciudadanos. 
En 2001 la IFLA definió las publicaciones oficiales como "[...] cualquier documento, impreso o producido en múltiples copias por cualquier método reprográfico, publicado por una organización que puede considerarse como oficial y distribuido a una audiencia más amplia que la propia institución productora". "Un aspecto importante al intentar definir este tipo de obras es la que expresa Marcelle Beaudiquez, ${ }^{7}$ en la cual afirma que el sector de las publicaciones oficiales es muy complejo puesto que hay importantes diferencias de criterios entre países y Estados. Además, las publicaciones oficiales se consideran como el "espejo" de los gobiernos y chocan con numerosas dificultades para poder definirlas con precisión.

Ahora bien, la siguiente legislación colombiana es la única que hace referencia a las publicaciones oficiales, de forma directa o indirecta; sin embargo, no se aborda una definición o alcance que describa sus caracterices de forma o contenido. Veamos:

- El Decreto 2937 de 1948, en su artículo 2 estableció que “[...] los Directores de Educación llevarán el detalle de las publicaciones oficiales que se hagan en los respectivos departamentos, y pasarán oportuno informe a la Dirección de la Biblioteca Nacional de Colombia." 8

- La Ley 23 de 1982, en su artículo 210 definió que "[...] los Directores de publicaciones oficiales, sean periódicos, revistas o de cualquier otra índole, tienen las mismas obligaciones de los demás editores, y deberán hacer los depósitos de obras." 9

- El Decreto 019 de 2012, en su artículo 213 instauró que

[...] las entidades oficiales que ordenen la edición de obras de cualquier carácter, lo mismo que los directores o encargados de empresas oficiales de índole publicitaria, tales como imprentas, 
establecimientos tipográficos, quedan obligados a enviar a la $\mathrm{Bi}$ blioteca Nacional de Colombia, en Bogotá, dentro de los treinta días siguientes a la publicación de libros, folletos, revistas, grabados, audiovisuales, DVD, CD y otros mecanismos electrónicos de publicación, sesenta (60) ejemplares, para canje con entidades nacionales o extranjeras vinculadas a la Biblioteca y para divulgación cultural entre bibliotecas públicas y otras instituciones nacionales o extranjeras relacionadas con el sector cultural. ${ }^{10}$

Según el anterior análisis, es posible decir que en Colombia y Bogotá no existe una disposición legal que defina las características de forma y contenido de las publicaciones oficiales, a diferencia de países como Estados Unidos y Polonia, en los cuales sí se cuenta con una legislación particular para este tipo de obras. ${ }^{11} \mathrm{Si}$ a nivel nacional es difícil que haya disposiciones legales que definan la razón de ser de las publicaciones oficiales, a nivel regional y local es mucho más complicado. Al respecto, Jasion decía que "[...] las publicaciones oficiales municipales o locales constituyen un sector de las publicaciones oficiales que rara vez se incluye expresamente en la legislación.” Para poder comprender qué es una publicación oficial, es importante analizar de forma general los conceptos de Información oficial, Documento oficial y Publicación oficial. Al respecto, en la Figura 1 se citan las definiciones de Cordón, López Lucas y Vaquero Pulido, ${ }^{12}$ teniendo en cuenta que hacen una contribución importante debido a que mencionan algunas diferencias entre los tres tipos de información. 
La información gubernamental y el acceso a la información...

Figura 1

Pirámide de la información oficial

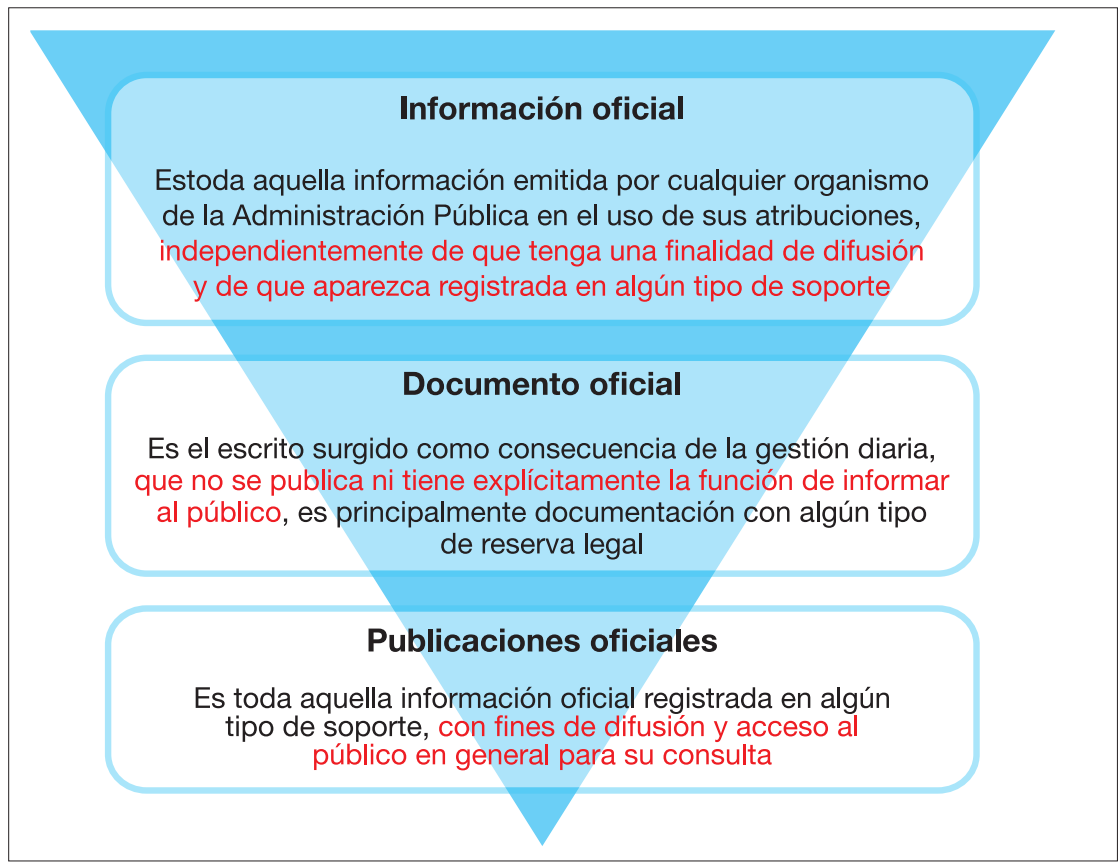

Fuente: Adaptación de Cordón, López Lucas y Vaquero Pulido. ${ }^{13}$

Duranti, desde la diplomática, realizó un análisis de las características de los documentos, encontrando que "[...] un documento es una evidencia escrita de un hecho [...] y que se redacta cumpliendo determinadas formas que sirven para dotarlo de plena fe y crédito." ${ }^{14}$ Así, un documento contiene información que refleja estructuras políticas, legales, administrativas y económicas, así como culturales, hábitos o mitos; en sí: ideas o hechos seleccionados por el autor para integrar el contenido del documento. Duranti hace especial énfasis en que un documento puede tener características formales e intelectuales. De modo que el documento tiene 
un aspecto externo (su forma física), una articulación interna (su forma intelectual) y un mensaje para transmitir (su contenido).

Si se analiza con mayor rigor una publicación oficial, es posible identificar que ésta es mucho más que un soporte, una forma o un contenido; una publicación oficial representa la existencia de un hecho y la voluntad de manifestarlo, como la voluntad de dar origen a un acto. También indica un propósito. En sí, la existencia de una publicación oficial, directa o indirectamente, determina consecuencias, es decir, puede crear, sustentar, modificar o concluir situaciones. ${ }^{15}$ En esencia, las publicaciones oficiales son la manifestación y representación de las acciones de un gobierno.

La "función" de la cual surge una publicación oficial es un rasgo importante, pero ¿qué se entiende por función? Durati $^{16}$ relaciona la función con los hechos y los actos. Un hecho es un acto originado por la voluntad de producir exactamente el efecto que produce. Si tal efecto tiene naturaleza jurídica, la voluntad ha generado un acto jurídico. Al respecto, se podría pensar que las publicaciones oficiales permiten comunicar y conocer los actos jurídicos (políticas, leyes y funciones) del Estado, permitiendo verificar las diferencias entre lo que planea una administración pública y lo que ha ejecutado; además, las publicaciones oficiales ayudan a contrastar la distancia que separa el aparato legal y administrativo del valor real de las reglas sociales.

Las administraciones públicas producen documentos y publicaciones oficiales que cumplen la función de apoyar los procesos internos de sus instituciones o informar de los mismos a la ciudadanía en general, lo cual hace diferente a los documentos oficiales de las publicaciones oficiales; por ejemplo, los documentos oficiales contienen información que ha sido producida día a día por la administración 
pública con el fin de apoyar principalmente sus procesos administrativos, sin requerir que la información contenida en ese tipo de documentos tenga que ser difundida a nivel general (bien sea porque la información está sin culminar, no ha sido aprobada, es de índole confidencial o sencillamente no es de interés general).

Ahora bien, las publicaciones oficiales contienen información administrativa, legal, técnica o académica, que ha sido aprobada o avalada por una institución gubernamental para que sea comunicada a la sociedad en general, luego de haber pasado por un proceso de normalización editorial y bibliográfica.

Las publicaciones oficiales, en la mayoría de los casos, no están en los medios de comercialización o consulta convencionales (editoriales, librerías, bibliotecas), y tienen una baja impresión de ejemplares o copias e ineficiente difusión, ya que en la mayoría de los casos los actores políticos de turno no ven la necesidad, no les interesa o no les conviene materializar sus acciones gubernamentales en un soporte documental que haga evidente sus acciones y comprobables.

La información que produce la administración pública es numerosa, variada y de diversa utilidad para la sociedad. Eso hace que cada vez se haga más necesario formular nuevas formas de acceder a la información oficial. Según las definiciones abordadas, es posible decir que, en general, no existe una definición unánime de publicación oficial, tanto a nivel mundial, nacional y local. Por tal motivo, en la Figura 2 y en la Figura 3 se proponen algunos aspectos y características, con el fin de establecer una definición propia de publicación oficial. 
Las publicaciones oficiales de la Administración Pública...

Figura 2

Aspectos de la publicación oficial

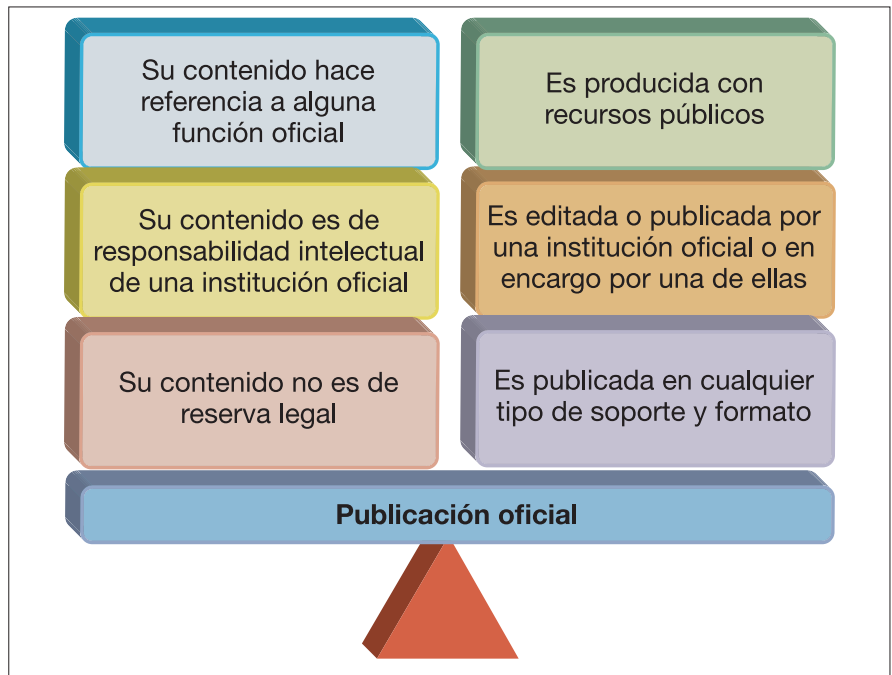

Figura 3

Características de la publicación oficial

\begin{tabular}{|c|c|}
\hline $\begin{array}{c}\text { Características } \\
\text { de contenido }\end{array}$ & $\begin{array}{c}\text { Características } \\
\text { de forma }\end{array}$ \\
\hline $\begin{array}{c}\text { Función } \\
\text { Planeación, ejecución, } \\
\text { seguiminiento, evaluación } \\
\text { y rendición de cuentas }\end{array}$ & $\begin{array}{c}\text { Tipo de fuente } \\
\text { Libro o publicación } \\
\text { periódica o seriada }\end{array}$ \\
\hline $\begin{array}{c}\text { No es de reserva } \\
\text { legal }\end{array}$ & $\begin{array}{c}\text { Soporte } \\
\text { Digital }\end{array}$ \\
\hline
\end{tabular}

a. Características de contenido. En diplomacia, el contenido es la representación escrita de hechos: 
Entre los hechos humanos en general, el tipo especial de hechos que resultan de una voluntad determinada de producirlos se llama una acción o acto. La operación de la voluntad distingue un acto, de cualquier otro hecho en general. Por eso todos los actos son también hechos, pero sólo aquellos hechos generados por una voluntad determinada son actos. ${ }^{17}$

Esto quiere decir que, para el caso de las publicaciones oficiales, su contenido representa diferentes tipos de hechos o situaciones, pero contiene acciones o actos únicamente cuando el contenido es producido o aprobado por la voluntad de una institución gubernamental, según sus funciones legales o técnicas. Teniendo en cuenta que el contenido es la representación escrita de hechos o actos, se describen las siguientes funciones de las instituciones gubernamentales de Bogotá. Dichas funciones son identificadas a partir de la Constitución Política de Colombia.

- Función. Partiendo de la idea de que una buena gestión pública se mide por el cumplimiento de la responsabilidad del Estado frente a la sociedad civil en términos de la consecución de objetivos que contribuyan a la creación de nuevas oportunidades de desarrollo social, económico, cultural, ambiental, etcétera, para la población. En este sentido, la función de los gobernantes y de las instituciones gubernamentales debe estar orientada al cumplimiento de las funciones de planificación, ejecución, seguimiento y evaluación de las políticas, programas y estrategias de desarrollo económico, social, cultural, tecnológico, ambiental, político e institucional de una administración, y la rendición de cuentas sobre la base de las metas acordadas de manera democrática.

Teniendo en cuenta los anteriores aspectos, las funciones de las instituciones gubernamentales se basan 
en el principio de planificación estratégica, entendida como: un proceso que busca vincular proactivamente a los diversos actores de un territorio en la formulación del plan de desarrollo, y con ello procura que en el transcurso se construya, conscientemente, una actitud y unas aptitudes de la sociedad en general, de responsabilidad y compromiso con su desarrollo, socializa resultados y crea una institucionalidad plural y sostenible para adelantar las transformaciones concertadas. ${ }^{18}$

- Reserva legal. No toda la información oficial puede ser accedida de forma universal debido a que el acceso a cierta información puede presentar algún tipo de daño a los intereses públicos, para lo cual el artículo 74 de la Constitución Política de Colombia, el artículo 12 de la Ley 57 de 1985, el artículo 27 de la Ley 594 de 2000, la Ley 1097 de 2006, el literal d) del numeral 4 del artículo $2^{\circ}$ de la Ley 1150 de 2007, la Ley 1219 de 2008, el artículo $2^{\circ}$ de la Ley 1266 de 2008 y el artículo 24 de la Ley 1437 de 2011 establecieron que es de reserva legal la información, documentos, bases de datos y contratos relacionados con defensa y seguridad nacional, orden público y relaciones internacionales. A esto se añade que la Ley 1581 de 2012 también considera información de reserva legal los datos personales y, finalmente, también se debe tener en cuenta lo establecido en la Ley 1712 de 2014, ley de transparencia y del derecho de acceso a la información púbica nacional.

Lo anterior quiere decir que la única información gubernamental que no se puede comunicar a través de una publicación oficial es aquella que esté relacionada con la defensa y seguridad nacional, el orden público, relaciones internacionales o que afecte la intimidad de una persona. Por lo 
tanto, es posible decir que la demás información gubernamental puede ser publicada, comunicada y consultada de forma universal sin ningún impedimento legal.

b. Características de forma. La forma de la publicación oficial está relacionada con el conjunto de características que pueden ser identificadas y separadas de los hechos; esto quiere decir de su contenido, personas, lugares o situaciones que trata. En consecuencia, los rasgos distintivos que se identifican como los más relevantes para el presente estudio son: el tipo de fuente, el soporte y formato.

- Tipo de fuente. El libro y la publicación periódica y seriada son los dos tipos de fuentes documentales seleccionados, según las características indicadas en la Figura 4.

Figura 4

Requisitos de tipo de fuente de las publicaciones oficiales

\begin{tabular}{|c|c|}
\hline Libro & $\begin{array}{c}\text { Publicación periódica } \\
\text { o seriada }\end{array}$ \\
\hline $\begin{array}{c}\text { Cuenta con normalización } \\
\text { editorial y bibliográfica: }\end{array}$ & $\begin{array}{c}\text { Cuenta con normalización } \\
\text { editorial y bibliográfica: }\end{array}$ \\
\hline $\begin{array}{c}\text { Título, autor, año e ISBN } \\
\text { Número Estándar Internacional } \\
\text { de Libros }\end{array}$ & $\begin{array}{c}\text { Título, editor, año, } \\
\text { volumen, número e ISSN } \\
\text { Número Internacional Normalizado } \\
\text { de Publicaciones Seriadas }\end{array}$ \\
\hline $\begin{array}{c}\text { Las páginas preliminares deben mencionar la participación } \\
\text { de una institución oficial }\end{array}$ \\
\hline El diseño editorial debe tener la imagen institucional \\
de un ente oficial
\end{tabular}


Se identificó el libro y la publicación periódica y seriada como los principales tipos de fuentes de publicaciones oficiales partiendo de los siguientes fundamentos:

1. Estos dos tipos de fuentes documentales son las más convencionales; por lo tanto, las más producidas;

2. lo cual indica que estas dos fuentes son las que más cumplen estándares de normalización editorial y bibliográfica,

3. principalmente teniendo en cuenta que según la legislación colombiana todos los libros y publicaciones periódicas y seriadas que se producen tanto en el sector privado como en el sector público tienen la obligación de tener ISBN o ISSN, como lo indica la Ley 98 de 1993.

- Soporte. El tipo de soporte definido es el digital, entendido como aquel medio que contiene información codificada en bits, y para acceder, visualizar o almacenar la información se requiere de un dispositivo que presente la información codificada en bits. Al representarse digitalmente, los datos son convertidos en dígitos $(0,1)$ perceptibles por una máquina.

- Formato. El formato PDF (Portable Document Format: Formato de Documento Portátil) es uno de los más utilizados a nivel mundial para el intercambio de documentos digitales, principalmente, por estar basado en un estándar abierto, lo que garantiza la integridad, longevidad y accesibilidad a la información almacenada. El presente estudio lo identificó como el formato más utilizado para el intercambio de publicaciones oficiales. 


\section{LOS SISTEMAS DE EDICIÓN DE PUBLICACIONES OFICIALES}

Las instituciones gubernamentales de los diferentes países y ciudades editan sus publicaciones a través de diversos sistemas de edición, entendidos como el procedimiento a través del cual se desarrollan las actividades editoriales que permiten materializar el contenido de una obra en una publicación. Es así como Boisard ${ }^{19}$ introduce los términos de sistemas centralizados y descentralizados de edición de publicaciones oficiales, y más adelante se comienza a hablar de sistemas de edición mixtos.

El Decreto 267 de 2007 define que la Imprenta Distrital de Bogotá tiene como función "[...] programar, dirigir, coordinar y controlar el proceso de diseño, diagramación, impresión y encuadernación de las artes gráficas y publicaciones requeridas por las diferentes entidades y organismos del Distrito Capital". ${ }^{20}$ Según lo anterior, es posible decir que el sistema de edición de publicaciones oficiales de Bogotá es centralizado. Dicho sistema presenta las ventajas y desventajas asentadas en la Tabla 2.

Tabla 2

Ventajas y desventajas del sistema editorial centralizado

\begin{tabular}{|l|l|}
\hline \multicolumn{1}{|c|}{ Ventajas } & \multicolumn{1}{c|}{ Desventajas } \\
\hline Facilita el control bibliográfico & $\begin{array}{l}\text { Lentitud en los procesos de publicación debido al volumen } \\
\text { editorial }\end{array}$ \\
\cline { 1 - 1 } Permite un mayor control de gasto público & $\begin{array}{l}\text { Graves problemas en el acceso a las bras publicadas ya } \\
\text { que, en la mayoría de los casos, la distribución y difusión } \\
\text { se hace por las instituciones públcas responsables del } \\
\text { conteo intelectual de la obra o por teceros controlados por } \\
\text { cada institución }\end{array}$ \\
\cline { 1 - 1 } $\begin{array}{l}\text { Facilita la creación de un catálogo bibliográfico con todas } \\
\text { la distribución de las obras editadas tiene un único punto } \\
\text { de partida }\end{array}$ & \\
\cline { 1 - 1 } $\begin{array}{l}\text { Permite identificar el total de publicaciones producidas por } \\
\text { todas las instituciones }\end{array}$ & \\
\cline { 1 - 1 } $\begin{array}{l}\text { Permite determinar con mayor facilidad las competencias } \\
\text { de cada institución en materia editorial }\end{array}$ & \\
\hline
\end{tabular}

Fuente: Adaptado de Sainero Carrizo ${ }^{21}$ 


\section{LOS SISTEMAS DE CONTROL BIBLIOGRÁFICO DE PUBLICACIONES OFICIALES}

Son mecanismos que permiten identificar la cantidad de publicaciones que produce anualmente una institución oficial o el gobierno de un país o ciudad. Además, facilitan el intercambio de información entre las diferentes entidades oficiales y los ciudadanos, y contribuyen al control bibliográfico mundial. Dentro de los mecanismos convencionales

que permiten hacer dicho control, para el presente estudio se menciona el Número Internacional Normalizado de Identificación de Obras, que es responsabilidad de la Cámara Colombiana del Libro. Esta institución basa sus funciones en que en Colombia todos los libros que se produzcan tanto en el sector privado como en el público tienen la obligación de tener el ISBN, como lo indica el artículo 11 de la Ley 98 de $1993 .^{22}$

\section{METODOLOGÍA}

El alcance de la investigación fue exploratorio; recopiló y produjo información que permitió analizar y explicar qué es una publicación oficial, su producción, edición, publicación y control bibliográfico durante la Administración Pública de Bogotá desde 2008 hasta 2012. Por una parte, la información se obtuvo del análisis de fuentes de información bibliográfica y documental a nivel internacional, nacional y local, con el fin de formular una definición de publicación oficial según el modelo de Administración Pública de Bogotá. Por otra parte, se solicitó a 35 instituciones gubernamentales de Bogotá, a una institución gubernamental del nivel nacional y a una agremiación sin ánimo de lucro, diligenciar un cues- 
tionario estructurado de 14 preguntas cerradas sobre el presupuesto invertido en la producción, edición, publicación y control bibliográfico de publicaciones oficiales, la generación de ISBN y el depósito legal. De las 37 instituciones, el cuestionario fue aplicado por las siguientes 13 instituciones:

1. Imprenta Distrital.

2. Departamento Administrativo del Servicio Civil.

3. Instituto Distrital de Recreación y Deporte.

4. Instituto Distrital de Turismo.

5. Secretaría de Educación.

6. Secretaría de Gobierno.

7. Secretaría de Movilidad.

8. Secretaría de Planeación.

9. Secretaría Distrital de Cultura, Recreación y Deporte. Fundación Gilberto Alzate Avendaño.

10. Secretaría General.

11. Veeduría Distrital.

12. Biblioteca Nacional de Colombia.

13. Cámara Colombiana del Libro.

El objetivo del cuestionario era identificar la diferencia entre el presupuesto invertido en la producción, edición e impresión con el control bibliográfico de las publicaciones oficiales de la Administración Pública de Bogotá, desde junio de 2008 hasta junio de 2012.

\section{RESULTADOS Y DISCUSIÓN}

Teniendo en cuenta el modelo de Administración Pública de Bogotá, las definiciones establecidas por las organizaciones 


\section{multilaterales consultadas y las características identificadas, se formuló la siguiente definición de publicación oficial:}

Una publicación oficial es una unidad o tipología documental que ha sido financiada, avalada y producida por una institución oficial o en encargo por ella. Su contenido tiene autenticidad. Es emanado de la autoridad del Estado según sus funciones. No debe ser de reserva legal. Puede ser publicada en cualquier tipo de soporte o formato garantizando su integridad y normalización editorial.

Lo ilustrado en la Figura 5 son los resultados encontrados entre el presupuesto invertido en la producción, edición e impresión de publicaciones oficiales de la Administración Pública de Bogotá, ${ }^{23}$ bajo el plan de desarrollo "Bogotá positiva: para vivir mejor”: desde 2008 hasta 2012.

Figura 5

Presupuesto invertido por ocho instituciones gubernamentales en la producción y publicación de investigaciones y estudios técnicos oficiales de Bogotá desde 2008 hasta 2012

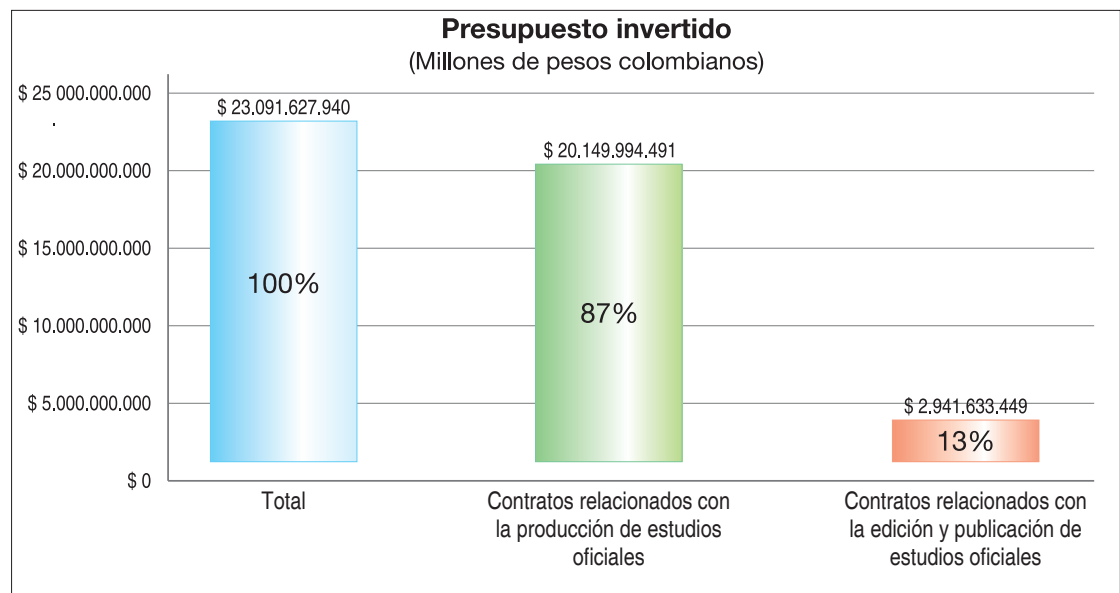

Fuente: Instituto Distrital de Recreación y Deporte, Instituto Distrital de Turismo, Secretaría de Educación, Secretaría de Gobierno, Secretaría de Movilidad, Secretaría Distrital de Cultura, Recreación y Deporte. (Fundación Gilberto Alzate Avendaño), Secretaría General y Veeduría Distrital. (2012) 
Según la información suministrada por la Imprenta Distrital de Bogotá, el total de publicaciones oficiales editadas y publicadas en soporte papel, desde enero de 2008 hasta junio de 2012, se muestra en la Tabla 3.

Tabla 3

Total de publicaciones oficiales impresas por la Imprenta Distrital desde enero de 2008 hasta junio de 2012

\begin{tabular}{|c|c|c|c|c|c|c|c|}
\hline Tipo de publicación & Soporte & $\begin{array}{c}\mathbf{2 0 0 8} \\
\text { Enero }\end{array}$ & $\mathbf{2 0 0 9}$ & $\mathbf{2 0 1 0}$ & $\mathbf{2 0 1 1}$ & $\begin{array}{c}\mathbf{2 0 1 2} \\
\text { Junio }\end{array}$ & $\begin{array}{c}\text { Total } \\
\text { Títulos }\end{array}$ \\
\hline Anexo Distrital & Papel & 21 & 23 & 23 & 10 & 24 & 101 \\
\hline Cartillas & Papel & 73 & 67 & 139 & 100 & 54 & 433 \\
\hline Folletos & Papel & 69 & 79 & 43 & 44 & 17 & 252 \\
\hline Lbros & Papel & 64 & 69 & 74 & 164 & 74 & 445 \\
\hline Periódicos & Papel & 74 & 84 & 58 & 42 & 13 & 271 \\
\hline Registro Distrital & Papel & 227 & 231 & 241 & 234 & 116 & 1049 \\
\hline Decretos, acuerdos, resoluciones & Papel & 14 & 3 & 5 & 27 & 12 & 61 \\
\hline Revistas & & 542 & 556 & 583 & 621 & 310 & $\mathbf{2 6 1 2}$ \\
\hline \multicolumn{2}{|c|}{ Total títulos } & & & & &
\end{tabular}

Fuente: Imprenta Distrital. Secretaría General. Alcaldía Mayor de Bogotá (2012).

\section{CONCLUSIONES}

La Administración Pública de Bogotá carece de una definición reglamentada que establezca las características de forma y contenido de las publicaciones oficiales. Dicha definición permitiría a las diferentes administraciones públicas basar sus procesos de planeación, ejecución, seguimiento, evaluación y rendición de cuentas en un soporte documental con adecuadas características de normalización editorial y bibliográfica que garanticen la autenticidad, integridad y validez del contenido. Así, por ejemplo, el material que más publica la Imprenta Distrital es principalmente publicitario y literatura infantil, muy pocos planes de desarrollo, 
informes de gestión y publicaciones relacionadas con las funciones de planificación estratégica de las instituciones gubernamentales de Bogotá.

El sistema de edición de publicaciones oficiales de Bogotá es centralizado, enfoca sus procesos editoriales a generar publicaciones principalmente en soporte papel, no cuenta con objetivos estratégicos orientados a la publicación en ambientes web y no se enmarca en una política de acceso abierto. Aquí cabe preguntarse, ¿para la Administración Pública de Bogotá es realmente importante que sus funcionarios y ciudadanos accedan de forma abierta a las publicaciones oficiales que producen? ¿Está a la vanguardia el sistema de edición de la Imprenta Distrital con las nuevas dinámicas tecnológicas del mundo y de acceso abierto a la información oficial que demandan las iniciativas de participación ciudadana?

La Figura 6 muestra que el total de publicaciones oficiales recibidas por depósito legal por la Biblioteca Nacional de Colombia desde enero de 2008 hasta diciembre de 2011 es supremamente alto, en relación con las otras dos variables. Esto hace pensar que el dato no es exacto o que la Biblioteca Nacional de Colombia realmente está haciendo un control bibliográfico efectivo a través del Depósito Legal. Si es así, ¿por qué no es representativa la cantidad de publicaciones oficiales procesadas por la Imprenta Distrital en relación con la cantidad de presupuesto invertido en la producción y publicación de investigaciones oficiales? Sobre todo, teniendo en cuenta que el sistema de edición de publicaciones oficiales de Bogotá es centralizado. 
Figura 6

Comparativo entre las publicaciones oficiales impresas, ISBN asignados

y publicaciones recibidas por depósito legal

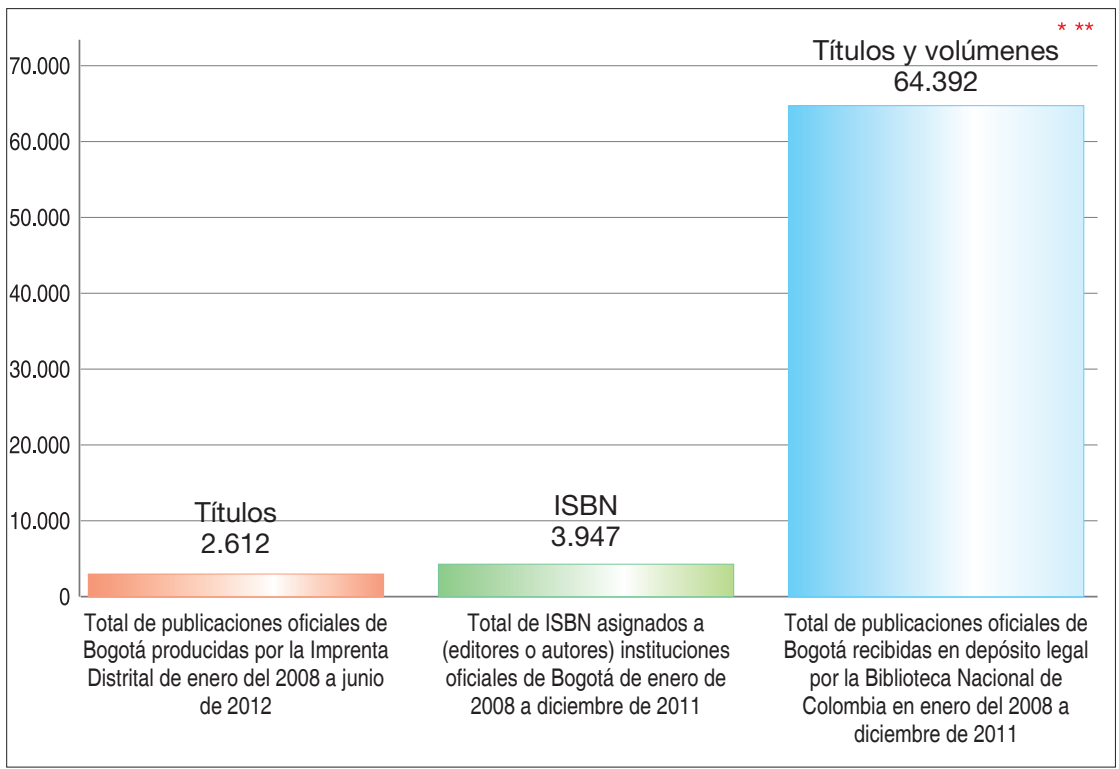

* Incluye libros y revistas en soporte papel y digital.

** El total no es exacto debido a que algunas publicaciones oficiales son producidas sin normalización editorial y la Biblioteca Nacional de Colombia no cuenta con procedimientos y herramientas que permitan recuperar de forma exacta las publicaciones oficiales de Bogotá.

Fuente: Imprenta Distrital de Bogotá, Cámara Colombiana del Libro y Biblioteca Nacional de Colombia. (2012)

La ciudadanía y la misma Administración Pública de Bogotá tiene problemas al momento de acceder de forma abierta a las publicaciones oficiales producidas por sus instituciones gubernamentales, principalmente para soportar los procesos de planeación, seguimiento y evaluación de las decisiones gubernamentales. Al respecto cabe preguntarse, ¿responde el costo invertido en los procesos de creación, edición e impresión de publicaciones oficiales en soporte 
papel (Figura 5) las necesidades reales de acceso y uso por parte de las Administración Pública y de los ciudadanos?

La austeridad o racionalización del gasto público en la Administración Pública de Bogotá es un objetivo importante, según lo estipulado por la Ley 617 de 2000 y la Directiva Distrital 001 de 2001, expedida por la Alcaldía Mayor de Bogotá, en la cual se establecen medidas para la utilización eficiente de los recursos distritales. En concordancia con estas medidas, sería importante que la Administración Pública de Bogotá tuviera en cuenta la cantidad del presupuesto invertido en la producción y publicación de estudios oficiales, según el costo reflejado en la Figura 5 y la materialización de ese costo según las cifras presentadas en la Figura 6. ¿No sería más económico, eficiente y eficaz para la Administración Pública de Bogotá y para la ciudadanía implementar una política pública distrital de acceso abierto desde la web a las publicaciones oficiales?

Finalmente, teniendo en cuenta la cantidad de preguntas que surgieron con el desarrollo del presente estudio, es posible pensar que todavía hay un camino largo por recorrer, máxime con los fenómenos y relaciones que se pueden crear entre las publicaciones oficiales, la web y el acceso abierto.

\section{REFERENCIAS BIBLIOGRÁFICAS}

1. M. Pedraza Robayo, P. R. Echeverry, V. E. Torres y V. Durán (1988), Informe final de la investigación sobre disponibilidad y uso de las publicaciones oficiales en Colombia, Universidad Javeriana, Bogotá.

2. Ibíd. 
3. J. Ordoñez Arias (2007), "Las publicaciones oficiales en Colombia: situación actual y necesidades del control bibliográfico", en Bibl. Tecnol. Inf., vol. 4, núm. 1, pp. 34-44.

4. G. C. Sainero Carrizo (2010), Las publicaciones oficiales: sistemas editoriales e información, Universidad de Alcalá, Alcalá de Henares, p. 64.

5. M. Maciá (1998), Manual de documentación jurídica. Síntesis, p. 24.

6. J. A. Cordón García, J. López Lucas y J. R. Vaquero Pulido (2001), Manual de investigación bibliográfica y documental. Teoría y práctica, Madrid, Pirámide, p. 1.

7. G. C. Sainero Carrizo (1998), Las publicaciones oficiales: estudio y fuentes, pp. 305-320.

8. Decreto 2937 de 1948 [en línea], http://laboral.fedepalma. org:8082/labpalma/docs/decreto_2937_1948.htm

9. Ley 23 de 1982 [en línea], http://www.alcaldiabogota.gov.co/ sisjur/normas/Norma1.jsp?i=3431

10. Decreto 019 de 2012 [en línea], http://www.alcaldiabogota. gov.co/sisjur/normas/Norma1.jsp?i=45322

11. Organización de las Naciones Unidas para la Educación, la Ciencia y la Cultura, UNESCO (2000), Legislación sobre depósito legal: directrices.

12. J. A. Cordón García, J. López Lucas y J. R. Vaquero Pulido (2001), Op. cit., p. 1.

13. Ídem.

14. L. Duranti (1996), Diplomática: usos nuevos para la antigua ciencia, Carmona, Sevilla, S\&C Ediciones, p. 28.

15. Ídem.

16. Ídem. 
17. Ídem.

18. Colombia. Departamento Nacional de Planeación, DNP (2011), Lineamientos para la rendición de cuentas a la ciudadanía por las administraciones territoriales. Guía para autoridades territoriales y ciudadanía.

19. P. Boisard (1988), "La production éditoriel des publications officielles”, en Marquet, Marie-Claude; Pelou, Pierre (coord.), La gestion des publications officielles.

20. Decreto 267 de 2007, Artículo 25 literal a.

21. G. C Sainero Carrizo (2010), Op. cit., p. 64.

22. Colombia. Congreso de Colombia, Ley 98 de 1993, por medio de la cual se dictan normas sobre democratización y fomento del libro colombiano.

23. Alcaldía Mayor de Bogotá, Decreto 054 de 2008, por el cual se reglamenta la elaboración de impresos y publicaciones de las entidades y organismos de la Administración Distrital. 


\title{
Los portales latinoamericanos de datos abiertos: nuevas herramientas para el acceso y la reutilización de la información gubernamental
}

\author{
SILVIA COBO SERRANO \\ Universidad Complutense de Madrid, España
}

\section{INTRODUCCIÓN}

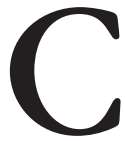

ada vez más, las instituciones gubernamentales son conscientes de la importancia social de la apertura de datos y de la disposición de éstos en formatos accesibles, de tal manera que se garantice la transparencia y el derecho de acceso de los ciudadanos a la información gubernamental. En consecuencia, esta apertura, con independencia de la estructura administrativa de cada país, permite la reutilización de los conjuntos de datos públicos, también denominados datasets; es decir, facilita "[...] el uso de documentos que obran en poder de organismos del sector público por personas físicas o jurídicas con fines comerciales o no comerciales distintos del propósito inicial que tenían esos documentos en la misión de servicio público para la que se produjeron." ${ }^{1} \mathrm{El}$ alcance de esta reutilización fue extendido a bibliotecas (incluidas las universitarias), archivos
\end{abstract}


y museos europeos, lo que permite crear nuevos servicios a partir de datos públicos con valor añadido en todos los sectores sociales. ${ }^{2}$ Ejemplos de esta reutilización son las numerosas aplicaciones desarrolladas recientemente, tales como conocer en qué se invierte el dinero público, contratación pública, tráfico de los medios de transporte terrestre en tiempo real, horario de los metros, búsqueda de farmacias, alertas sísmicas o incluso la evolución de los nombres de las personas en las últimas décadas.

Por otro lado, la puesta a disposición de los datos gubernamentales en formatos abiertos y por medios electrónicos no ha sido suficiente para satisfacer las necesidades informativas de la ciudadanía, ya que la dispersión de estos conjuntos de datos en los websites institucionales seguía siendo una problemática constante cuya resolución requería de nuevos esfuerzos gubernamentales. En pocos años, este problema se ha resuelto mediante la creación de portales nacionales de datos abiertos; iniciativas públicas de los gobiernos, tanto de los Estados Miembros de la Unión Europea como de América Latina, que permiten la centralización de los activos de información o conjuntos de datos en un único portal. En este sentido, son destacables y paradigmáticos los portales de Reino Unido, Estados Unidos, Australia o Nueva Zelanda así como los estudios comparativos de carácter cualitativo de estos portales de datos abiertos en Europa.

En este sentido, uno de los trabajos más significativos sobre los portales europeos de datos abiertos es la publicación de Ramos Simón et al., en diciembre de 2012, cuyo objetivo fundamental era "[...] identificar los portales open data puestos en marcha por los gobiernos de los países miembros de la Unión Europea, describir las licencias de acceso y uso de la información pública y analizar las ca- 
racterísticas de los recursos de información desde el punto de vista técnico."

En el ámbito latinoamericano, son destacables las iniciativas Open Data Latinoamérica ${ }^{4}$ y Open Data for Development in Latin America and the Caribbean..$^{5}$ La primera de ellas es un catálogo de datos que permite el acceso a los datasets mediante la utilización del propio catálogo, el servicio de búsquedas y el uso de las colecciones destacadas para, posteriormente, poder reutilizarlos a partir de la explotación de los mismos. Respecto al proyecto OD4D -encabezado por el w3C Brasil y la Comisión Económica para América Latina y el Caribe (CEPAL), y apoyado económicamente por el Centro Internacional de Investigación y Desarrollo de Canadá (IDRC)-, la iniciativa pretende la sensibilización social sobre los beneficios e importancia de los datos abiertos, así como apoyar la "[...] apertura de datos sustentables y durables." Finalmente, es destacable la celebración, en junio de 2013, de la Conferencia Regional de Datos Abiertos para América Latina y el Caribe, en la que se abordaron cuestiones fundamentales como el valor social y económico de los datos públicos, los desafíos gubernamentales, aspectos técnicos, periodismo de datos y la apertura de datos en el ámbito educativo, sanitario y medioambiental, entre otros.

A tenor de lo anteriormente mencionado, el objetivo del presente trabajo es analizar los portales nacionales de datos abiertos más significativos o representativos en América Latina de forma genérica, de tal manera que se pueda determinar el estado o situación actual de los mismos a partir de una serie de parámetros de estudio. 


\section{METODOLOGÍA}

Dada la extensión geográfica de América Latina y en esta primera aproximación a la temática, en primer lugar se procedió a la identificación de los países con portales de datos abiertos (es decir, nuevas herramientas al servicio de la sociedad para favorecer la transparencia gubernamental y el acceso a datos útiles para la actividad profesional, así como para el desarrollo de nuevas aplicaciones) a partir de la búsqueda de estos nuevos instrumentos en 22 países de Latinoamérica: Argentina, Bolivia, Brasil, Chile, Colombia, Costa Rica, Cuba, Ecuador, El Salvador, Guatemala, Haití, Honduras, Jamaica, México, Nicaragua, Panamá, Paraguay, Perú, Puerto Rico, República Dominicana, Uruguay y, finalmente, Venezuela.

Los resultados de esta búsqueda inicial permitieron conocer la existencia de numerosos portales de datos abiertos tanto a nivel nacional como estatal o provincial (administración pública de nivel inferior); es decir, muchos de los gobiernos de los distintos niveles de las administraciones públicas publican sus datos de forma uniforme y centralizada mediante la inclusión de los conjuntos de datos en estos portales públicos. De todos ellos, se han seleccionado aquellos que, por un lado, responden a los criterios o parámetros de análisis contemplados en este trabajo (volumen de datasets, accesibilidad, descripción y formatos) y, por otro lado, son representativos para cada país y pioneros con versiones beta en estos momentos. En total, se presentan 10 portales latinoamericanos de datos públicos, tal y como se puede observar en el Cuadro 1; de esos portales, únicamente los de México y Perú están relacionados con una estructura administrativa federal y metropolitana, respectivamente. 
Los portales latinoamericanos de datos abiertos...

Cuadro 1

Presentación de los portales y catálogos de datos abiertos

seleccionados en América Latina

\begin{tabular}{|c|c|}
\hline PAís & PORTALES DE DATOS ABIERTOS \\
\hline Argentina & Portal de Datos Público $^{6}$ \\
\hline Brasil & Portal Brasileiro de Dados Abertos $^{7}$ \\
\hline Chile & Portal de datos públicos datos.gob.cl $^{8}$ \\
\hline Colombia & Catálogo de Datos Abiertos \\
\hline Costa Rica & Portal de Datos Abiertos $^{10}$ \\
\hline Ecuador & datosabiertos.ec ${ }^{11}$ \\
\hline El Salvador & Datos Abiertos El Salvador ${ }^{12}$ \\
\hline México & Datos Abiertos DF ${ }^{13}$ \\
\hline Perú & Datos Abiertos de Lima Metropolitana ${ }^{14}$ \\
\hline Uruguay & Catálogo de Datos Abiertos \\
\hline
\end{tabular}

A continuación, se procedió a la identificación de los parámetros de estudio de los portales ya mencionados (volumen de datasets, accesibilidad, descripción y formatos) para, seguidamente, presentar los resultados obtenidos.

\section{VOLUMEN DE DATASETS}

El grado de desarrollo de los catálogos de datos abiertos suele estar directamente relacionado con el número de datasets incluidos y campos descriptivos de los mismos. En términos generales, se puede indicar que los catálogos son de reciente creación y su objetivo común es fomentar la transparencia gubernamental, la participación ciudadana y la creación de nuevos servicios tecnológicos a partir de datos públicos. Por ello, son numerosos los países latinoamericanos que forman parte de la Alianza para el Gobierno Abierto (Open Government Partnership) desde 2011, iniciativa en la que participan actualmente 63 países del mundo. ${ }^{16}$ 
Respecto al número de datasets incluidos en los catálogos de los portales seleccionados para el presente estudio, éstos se pueden dividir en tres grandes grupos (véase la Figura 1). En primer lugar, destaca el conjunto de datos del catálogo chileno, que representa casi el 50\% de la muestra al disponer de más de 1.100 datasets. Con bastante diferencia cuantitativa, se identifica un segundo grupo formado por Colombia (aproximadamente 500 datasets), Brasil y Costa Rica (con 240 y 254 conjuntos de datos, respectivamente), que se sitúan entre el $10 \%$ y el $20 \%$ de la muestra analizada para, finalmente, poder clasificar el tercer grupo de portales cuyos conjuntos de datos se encuentran entre el $1 \%$ y el $4 \%$ y agrupan a los seis países restantes. En este sentido, se puede decir que son portales cuyos catálogos disponen de escasos datasets, ya que éstos suelen oscilar entre los 20 y los 95, y la suma de todos ellos (seis catálogos) no supera los 350 conjuntos de datos.

Figura 1

Estimación porcentual de los datasets existentes en los catálogos de los portales abiertos de América Latina.

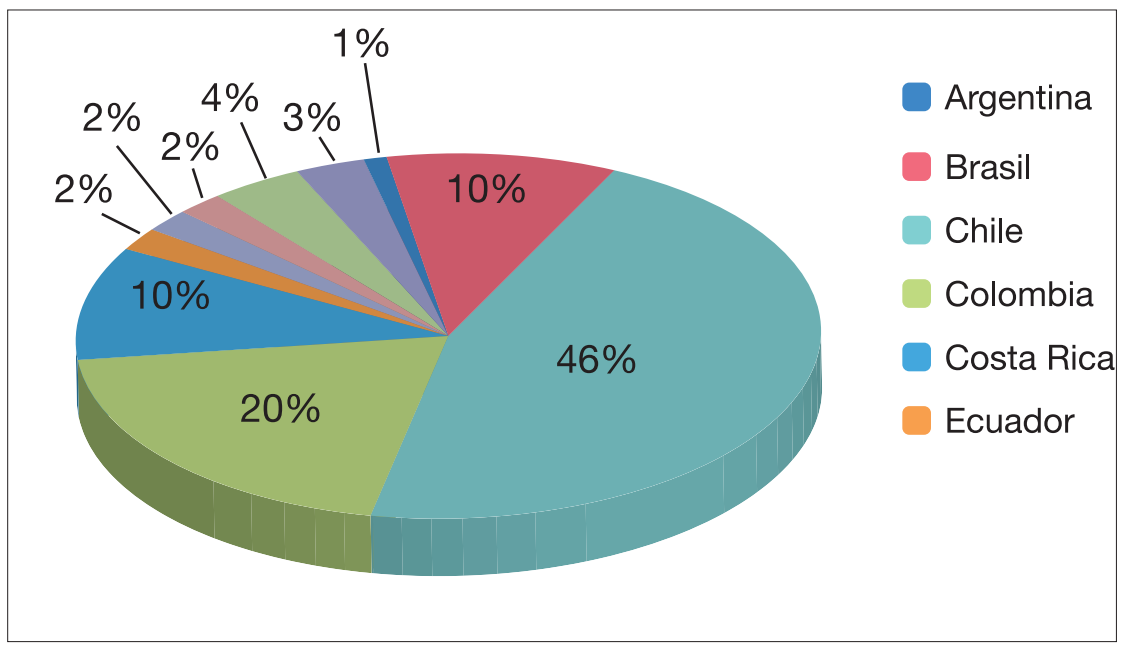




\section{ACCESO Y DESCRIPCIÓN DE LOS DATASETS}

Respecto al acceso a la información, en todos los catálogos se utilizan sistemas de búsqueda simple (introducción de términos en lenguaje natural) que pueden ser combinados con la selección de otros filtros de búsqueda, como por ejemplo formatos u organismos. Aunque no todos los filtros que se relacionan a continuación aparecen en todos los portales, se puede indicar que los catálogos de datos abiertos de los portales gubernamentales de América Latina seleccionados para el presente estudio permiten filtrar la búsqueda por: entidad (hace referencia al organismo productor del conjunto de datos; otros términos utilizados para referirse a este filtro son Autor u Organizaciones), categorías temáticas, etiquetas, formatos, grupos de conjuntos, licencias y recursos (Figura 2).

Figura 2

Ejemplo de filtros de búsqueda en el Portal de Datos Abiertos de Costa Rica

\begin{tabular}{|l|l|l|l|l|}
\hline Seleccione... Titulo \\
Filtrar recursos
\end{tabular}

Fuente: http://datosabiertos.gob.go.cr 
En lo que a campos descriptivos de los registros se refiere, existe cierta variación entre los mismos, si bien es cierto que los portales de Argentina, Ecuador y Uruguay presentan grandes similitudes en la estructura y, por tanto, en los campos de descripción, ya que utilizan la misma plataforma tecnológica para la creación de sus portales de datos abiertos. Esta similitud, aunque con otra plataforma tecnológica, también se presenta en los catálogos de Costa Rica y Perú.

Con independencia de esta circunstancia y siendo conscientes de la variación numérica de los campos descriptivos de los catálogos, se puede indicar que los campos con mayor frecuencia de aparición en los registros de los catálogos son:

- Título.

- Descripción.

- Autor / Entidad / Institución.

- Mantenedor (normalmente, suele ser el autor).

- Etiqueta.

- Categoría.

- Datos y recursos para descargar.

- Url.

- Fecha de publicación.

- Fecha de última actualización.

- Alcance geográfico / Cobertura espacial.

- Alcance temporal / Cobertura temporal.

- Licencia.

Con menor frecuencia de aparición, otros campos identificados son:

- Documentación asociada.

- Formato fuente (indicación del tipo de archivo desde el que se han recolectado los datos).

- Visitas al datasets. 


\section{FORMATOS}

Otro de los parámetros de análisis fue el formato de los archivos. En este sentido, el estudio pretende la identificación de los formatos disponibles en los diez portales latinoamericanos de datos abiertos, ya que un análisis de la adecuación de los mismos para la descarga y posterior reutilización de los conjuntos de datos requeriría un estudio de mayor profundidad, el cual no es objeto de este trabajo introductorio a la materia.

En consecuencia, se han identificado (aproximadamente) 25 formatos durante el análisis de los diez catálogos de datos abiertos, entre los que destacan los formatos de carácter ofimático, web y de compresión. Sin lugar a dudas, el formato CSV está presente en los diez catálogos latinoamericanos y es seguido de cerca por el formato de documentos ofimáticos XLS / XLSX; esto es un 70\% del total de la muestra analizada. En posiciones inferiores se encuentran los formatos HTML, PDF, ZIP, otros textuales como DOC o TXT, y también formatos para archivos de datos y lenguajes de marcado. En el Cuadro 2, se presenta el ranking de los cinco formatos más frecuentes en los catálogos de datos analizados.

Cuadro 2

Top 5 de los formatos más frecuentes en los catálogos de datos

\begin{tabular}{|c|c|c|}
\hline Posición & Formatos & \% de aparición en los portales \\
\hline 1 & CSV & $100 \%$ \\
\hline 2 & XLS (XLSX) & $70 \%$ \\
\hline 3 & HTML / XML / PDF & $40 \%$ \\
\hline 4 & ZIP & $30 \%$ \\
\hline 5 & DOC (DOC) / TXT / SAV / KML / RAR / JSON / DBF & $20 \%$ \\
\hline
\end{tabular}




\section{DISCUSIÓN}

En primer lugar, se observa el compromiso de los gobiernos latinoamericanos para fomentar la transparencia y la apertura de datos mediante la creación de portales y la participación en la Alianza del Gobierno Abierto, iniciativa de la que forman parte países latinoamericanos tales como México, Brasil, Colombia, Perú, Chile, Argentina y Uruguay, entre otros.

Asimismo, sería recomendable reducir el volumen desigual de los datasets en los catálogos de los portales con la intención de garantizar el equilibrio entre estas herramientas latinoamericanas de acceso a la información pública.

En general, las búsquedas simples pueden generar ruido y poca precisión en los resultados obtenidos, aunque ciertamente la utilización de varios filtros puede resolver esta problemática, ya que funcionan como una búsqueda avanzada. En consecuencia, se ha de señalar esta circunstancia como una fortaleza que requiere de la actualización permanente de dichos filtros.

Finalmente, se potencia el periodismo de datos a partir de fuentes gubernamentales a un clic del ratón y la creación de nuevas aplicaciones tecnológicas que inciden en el bienestar social.

\section{AGRADECIMIENTOS}

Al proyecto "Buenas prácticas en el acceso a la información gubernamental”, PAPIIT IN 403113, apoyado por la Dirección General de Asuntos del Personal Académico de la UNAM; al proyecto de investigación "Organización del acceso, uso y reutilización de la información del sector público en España. Hacia la consolidación de una industria de la infor- 
mación”, financiado por Plan Nacional de I+D en España (Ref.: CSO2010-17451); al Ministerio de Educación, Cultura y Deporte (España) en apoyo al programa "Formación del Profesorado Universitario".

\section{REFERENCIAS BIBLIOGRÁFICAS}

1. Directiva 2003/98/CE del Parlamento Europeo y del Consejo, de 17 de noviembre de 2003, relativa a la reutilización de la información del sector público (Diario Oficial de la Unión Europea 31.12.2003). [s.p.] [en línea], http://eurex.europa.eu/ LexUriServ/LexUriServ.do?uri=OJ:L:2003:345:0090:0096:ES:P DF

2. Directiva 2013/37/UE del Parlamento Europeo y del Consejo, de 26 de junio de 2013 por la que se modifica la Directiva 2003/98/CE, relativa a la reutilización de la información del sector público (Diario Oficial de la Unión Europea 27.6.2013) [en línea], http://eurlex.europa.eu/LexUriServ/LexUriServ.do? uri=OJ:L:2013:175:0001:0008:ES:PDF

3. L. F. Ramos Simón, R. Arquero Avilés, I Botezan, S. Cobo Serrano, A. Sala Jiménez, R. Sánchez Jiménez, F. del Valle Gastaminza (2012), "De la reutilización de información del sector público a los portales de datos abiertos en Europa", en BID: textos universitaris de biblioteconomia i documentació, núm. 29. [s.p.] [en línea], http://www.ub.edu/bid/29/ramos2.htm

4. Open Data Latinoamérica [en línea], http://www.opendatalatinoamerica.org/

5. Open Data for Development in Latin America and the Caribbean [en línea], http://www.od4d.org

6. Argentina. Portal de Datos Públicos [en línea], http://datospublicos.gob.ar 
7. Brasil. Portal Brasileiro de Dados Abertos [en línea], http:// dados.gov.br

8. Chile. Portal de Datos Públicos "datos.gob.cl" [en línea], http:// datos.gob.cl

9. Colombia. Catálogo de Datos Abiertos [en línea],www.datos. gov.co

10. Costa Rica. Portal de Datos Abiertos [en línea], http://datosabiertos.gob.go.cr

11. Ecuador. datosabiertos.ec [en línea], http://datosabiertos.ec

12. El Salvador. Gobierno Abierto [en línea], http://www.gobiernoabierto.gob.sv/

13. México. Datos Abiertos D.F. [en línea], http://datosabiertos. df.gob.mx

14. Perú. Datos Abiertos de Lima Metropolitana [en línea], http:// lima.datosabiertos.pe

15. Uruguay. Catálogo de Datos Abiertos [en línea], https://catalogodatos.gub.uy

16. Open Government Partnership [en línea], http://www.opengovpartnership.org 


\title{
El portal de datos abiertos de la Unión Europea en el contexto del Open Data Government
}

\author{
ROSARIO ARQUERO AVILÉS* \\ GONZALO MARCO CUENCA \\ Universidad Complutense de Madrid, España
}

\section{INTRODUCCIÓN}

os movimientos alrededor de los datos abiertos en el
sector público, que se producen desde el año 2009 en
Europa, han fomentado la creación de múltiples portales en el territorio de la Unión Europea. ${ }^{1}$ El portal de datos abiertos de la Unión Europea constituye un punto de acceso único para una gran diversidad de datos que han sido producidos por instituciones y otros organismos de la Unión Europea. Los datos abiertos representan una excelente solución para la difusión de la información y su reutilización posterior, facilitando el acceso al público en general y a los investigadores.

El portal promueve el uso de los datos como un medio para fomentar el desarrollo de nuevos proyectos innovado-

* Agradecimiento a la Dirección General de Asuntos del Personal Académico (DGAPA, UNAM), proyecto "Buenas prácticas en el acceso a la información gubernamental” (PAPIIT IN 403113) 
res aprovechando toda la información semántica que contienen. Tal y como indican en el propio portal web, los "[...] datos se pueden utilizar, reutilizar, enlazar y redistribuir gratuitamente con fines comerciales o no comerciales."

En este contexto, el portal de datos abiertos de la Unión Europea se enlaza con la Directiva 2013/37/UE, del Parlamento Europeo y del Consejo, relativa a la reutilización de la información en el sector público. ${ }^{3}$ La Directiva, que modifica y actualiza una norma anterior, pretende establecer políticas de apertura a la información que propicien la disponibilidad y la reutilización generalizadas de la información en el sector público con fines privados o comerciales, con restricciones mínimas o nulas de carácter jurídico, técnico y económico, y que deben favorecer la circulación de la información no sólo para los agentes económicos, sino también entre el público en general. La nueva Directiva se relaciona también con la Agenda Digital Europea, iniciativa emprendida por la Comisión Europea (2010) que, a su vez, promueve la comunicación de la Comisión Europea sobre datos abiertos como motor para la innovación, el crecimiento y la gobernanza transparente. ${ }^{4}$ La Directiva 2013/37/UE también supone un esfuerzo importante para conseguir una armonización mínima de las normas y prácticas nacionales en materia de reutilización, y proporciona una considerable mejora para la reutilización transfronteriza de los datos.

Hay que tener en cuenta que autorizar la reutilización de los datos de los organismos públicos confiere a los mismos un valor añadido para los reutilizadores, para los usuarios finales y para la sociedad en general; además, contribuye a la generación y desarrollo de nuevos conocimientos. De igual modo, supone para los organismos públicos una mejora asociada a la propia transparencia del organismo e implica un 
aumento de la responsabilidad sobre los datos que favorece la mejora de la calidad de la información que se difunde.

\section{CONTENIDOS DEL PORTAL}

El portal de datos de la Unión Europea es un importante activo de información para el conjunto de estados miembros de la Unión Europea y, por consiguiente, es un importante vehículo de propagación de la información que la Unión Europea genera y pone a disposición pública de la sociedad en general y de los investigadores. Con este recurso de acceso fácil y gratuito a los datos, la Comisión Europea pretende fomentar el uso público de los datos y su reutilización en beneficio de nuevos proyectos innovadores y transfronterizos.

Los datos que se facilitan a través del portal pueden utilizarse y reutilizarse con fines comerciales o no comerciales, con lo cual se busca impulsar su potencial económico. Su reutilización, de forma gratuita, conlleva únicamente la citación de la fuente (véase Figura 1). Toda la información que se ofrece está sujeta a una cláusula de exención de responsabilidad, a un aviso de derechos de autor y a las normas aplicables de protección de datos personales. 
La información gubernamental y el acceso a la información...

Figura 1

Captura de la página de inicio del portal de datos abiertos de la Unión Europea

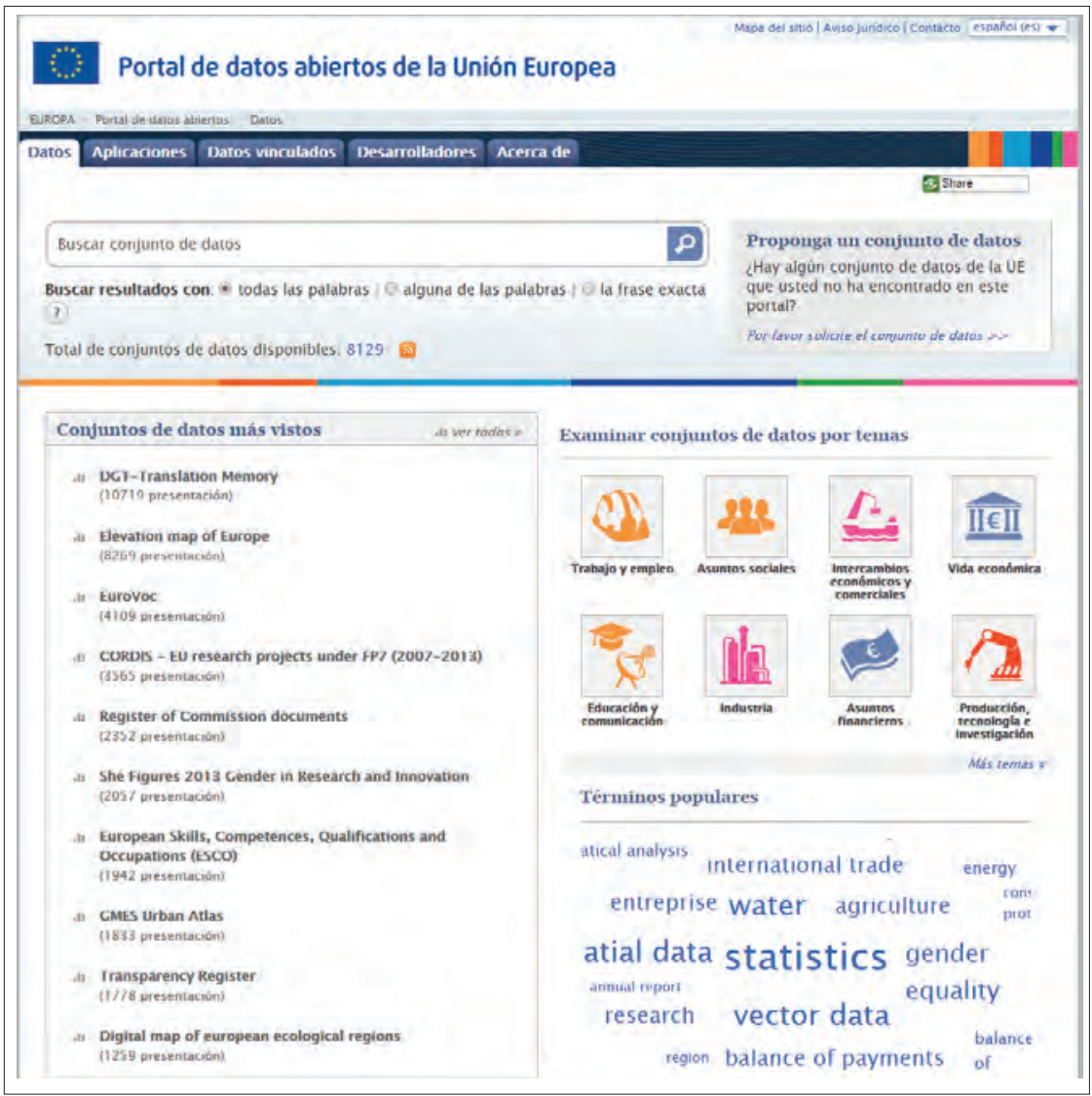

De forma general, como ya se ha comentado, los datos se pueden reutilizar de manera gratuita y solamente un pequeño conjunto de excepciones incluyen determinadas condiciones para su reutilización, la mayoría relacionadas con la propiedad intelectual de terceras partes.

El portal, disponible en 22 idiomas, constituye también una fuente de importante valor para la comparación de datos entre los diversos organismos productores y fomenta el 
establecimiento de relaciones entre éstos y la comunidad de usuarios. Además, como herramienta, dispone de un área exclusiva para proveedores de datos.

En cuanto a los datos, el portal presenta un catálogo de metadatos que facilita su acceso. Los metadatos son vinculados y normalizados basándose en estándares que facilitan su recuperación y reutilización posterior. Estos conjuntos de datos se encuentran disponibles en formatos que permiten su interpretación humana, y son también legibles por un ordenador para facilitar su inmediata reutilización.

El total de recursos o conjuntos de datos disponibles es de 6.565 .5 En cuanto a los formatos de distribución de estos recursos, se encuentran en su gran mayoría en más de un formato. El formato comprimido .zip es el más habitual, seguido del formato .html y otros, tal y como se muestra en la Figura 2.

Figura 2

Formatos de distribución de los recursos del portal de datos abiertos Europeo

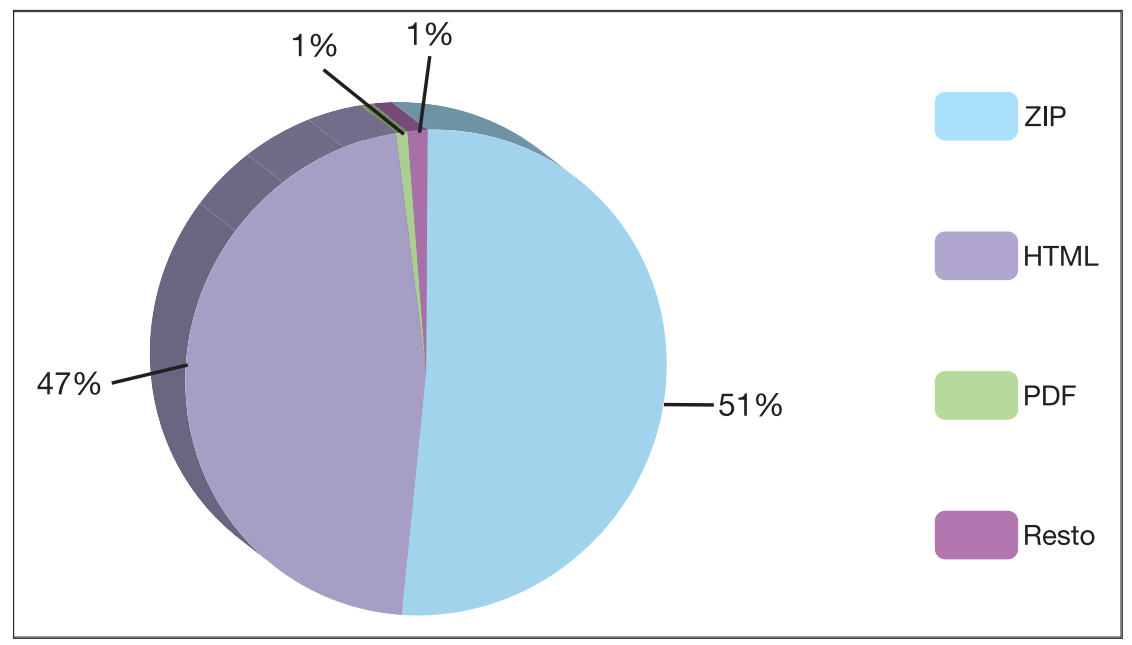

Fuente: Elaboración propia, a partir del portal de datos abiertos de la Unión Europea 
Partiendo de esta panorámica inicial, hemos de señalar que los datos que ofrece el propio portal, en el apartado de formato de recursos, no reflejan con precisión la presencia de formatos que favorecen la reutilización. ${ }^{6}$

En este sentido, un análisis inicial de estos datos muestra un alto porcentaje (48\%) de documentos en formatos .html y .pdf (formatos de distribución que no son los más adecuados para la reutilización), lo cual contrasta, a priori, con el bajo porcentaje mostrado de recursos en formatos estructurados o delimitados: xml, rdf, xls, csv, txt (1\% de los recursos).

Además, si se tiene en cuenta que los archivos comprimidos .zip (que representan el $51 \%$ de los datos de distribución en el apartado de formato de recursos mencionado) pueden considerarse un contenedor de otros formatos o ficheros, se confirma que la información preliminar de formatos de recursos que ofrece el propio portal no reflejan la representación real de los formatos en el portal.

Un desglose de los formatos integrados en los archivos comprimidos .zip desvela una presencia superior de formatos estructurados y delimitados que los proporcionados $a$ priori en el apartado mencionado.

De este modo, para conocer el formato del contenido de estos .zip es preciso explorar cada recurso para comprobar su formato específico, lo que resulta poco ágil cuando tenemos que utilizar diferentes recursos. Con esta operación, y teniendo en cuenta que la mayoría de los datos proviene de la Oficina de Estadística de la Unión Europea (Eurostat), podemos observar que se da una presencia mucho más alta de formatos estructurados y delimitados que la que se muestra en la información previa. En consecuencia, pensamos que el detalle en el desglose de los formatos resulta realmente importante en un contexto en el que se busca 
el fomento de la reutilización. En esta línea, resulta crucial concienciar a los proveedores para que faciliten los metadatos lo más completos posibles y, en especial, a aquellos relacionados con los formatos.

En cuanto a los editores de los datos, Eurostat es la principal editora de conjuntos de datos, con un 95\% de los éstos. Al respecto, destaca también la aportación de la Agencia Europea de Medio Ambiente (ver Figura 3). En total, participan más de 40 editores diferentes que presentan conjuntos especializados de todo tipo.

Figura 3

Editores de conjuntos de datos del portal de datos abiertos Europeo

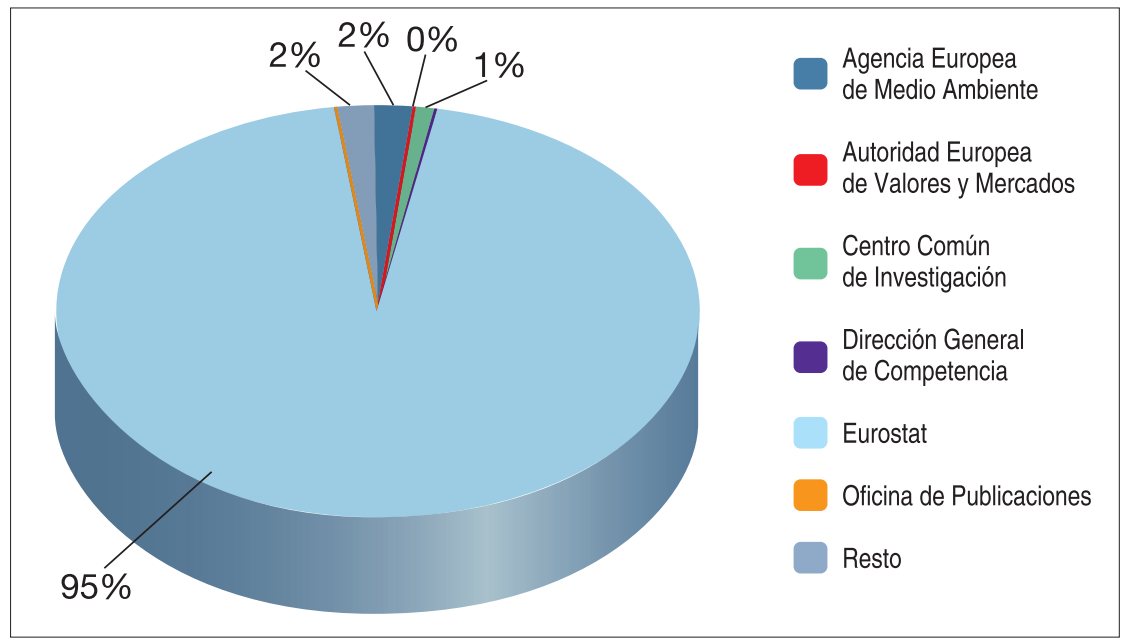

Fuente: Elaboración propia, a partir del portal de datos abiertos de la Unión Europea

La información que se puede encontrar para describir cada conjunto de datos, los cuales conforman el catálogo de metadatos anteriormente mencionado, está constituida por los siguientes elementos: editor, descripción del recurso, recursos (con enlaces para la descarga e información sobre el formato en el que se pueden encontrar los datos, también 
se incluye una etiqueta que representa el formato del fichero que los contiene, que suele ser un fichero comprimido .zip o una página .html), su Uniform Resource Identifier (URI), su estado, un identificador, un tipo de conjunto de datos, la fecha de modificación, la cobertura temporal del recurso, los datos de contacto del editor, información sobre la licencia, palabras clave, e información sobre su registro en el catálogo.

\section{DATOS VINCULADOS: ESTÁNDARES}

Este portal se presenta también como un entorno de datos vinculados donde se toman como base los principios de Linked data y otras técnicas de la Web Semántica. Los datos vinculados son un método normalizado de representar gran variedad de temas, lo cual facilita su relación y su uso. Resultan también útiles para el desarrollo de nuevas aplicaciones que permiten combinar datos de origen heterogéneo.

Además, el portal se apoya en diferentes estándares que permiten su adecuada descripción y una eficaz recuperación, como por ejemplo el lenguaje de consulta SPARQL para RDF. SPARQL es una recomendación de la W3C que define la forma de expresar consultas a través de diversas fuentes de datos, si los datos se almacenan de forma nativa en formato RDF. ${ }^{7}$ Por otro lado, también se apoya en el Data Catalog Vocabulary (DCAT), otra recomendación de la w3C, que conforma un vocabulario en formato RDF diseñado para facilitar la interoperabilidad entre los diferentes catálogos de datos publicados en la Web. ${ }^{8}$

Tomando como base DCAT se ha creado un vocabulario de metadatos que puede consultarse por medio de una hoja de datos o por medio de una ontología en formato OWL. 
Este vocabulario se ha generado con el objetivo de que sea compatible con Asset Description Metadata Schema (ADMS). $A D M S$ es un perfil de DCAT usado para describir activos semánticos. Estos activos semánticos o, simplemente "activos", facilitan aquellos componentes altamente reutilizables para este tipo de proyectos u otros basados en metadatos (como, por ejemplo, esquemas XML, modelos de datos genéricos, etcétera) y también para recuperar los datos de referencia (como, por ejemplo, listas de códigos, taxonomías, diccionarios, vocabularios, etcétera) utilizados para el desarrollo y la descripción de los valores en los sistemas de e-government o Gobierno abierto.?

\section{APLICACIONES DE VISUALIZACIÓN}

Existen conjuntos de datos sin procesar que utilizan aplicaciones que han sido elaboradas en torno a los datos, para que puedan ser consultados y reutilizados. Estas aplicaciones han sido creadas por diversos proveedores de datos y conforman una serie de herramientas excepcionales para explorar, interpretar y reutilizar de forma eficiente la información suministrada. Las aplicaciones se muestran en una galería e incluyen 10 herramientas. ${ }^{10}$

Cabe destacar, entre otras aplicaciones, el Marcador de la Agenda Digital (DG Connect), capaz de crear gráficos de forma interactiva a partir de la consulta de datos, el Visor de Mapas del Centro Europeo de Información Forestal (EFDAC), una aplicación web cartográfica personalizada que permite al usuario visualizar, navegar y consultar mapas y otros conjuntos de datos geográficos, el EuroStat LänderProfile, que incluye perfiles de los países a partir de un amplio grupo de indicadores de interés sobre cada país: población, 
educación, seguridad, condiciones de vida, economía, medio ambiente, etcétera, ofreciendo además tablas, gráficos y mapas interactivos (ver Figura 4) o la aplicación CubeViz, un navegador facetado para datos estadísticos que emplea el vocabulario $R D F$ Data Cube, el más avanzado para representar datos estadísticos en RDF.

Figura 4

Captura de una consulta en la aplicación EuroStat LänderProfile disponible en el portal de datos abiertos de la Unión Europea

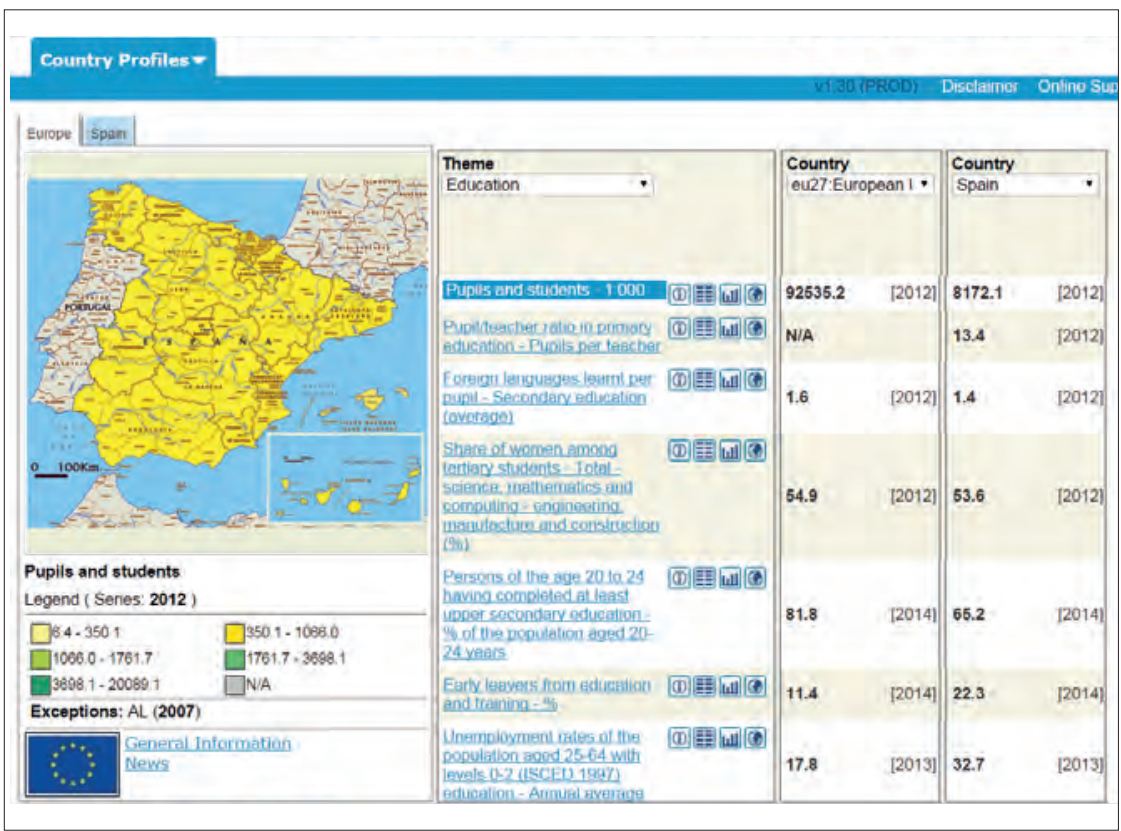

CONCLUSIONES Y RECOMENDACIONES.

El Portal de datos abiertos analizado constituye en su concepción, sin lugar a dudas, un recurso muy valioso como punto de acceso único a datos elaborados por instituciones 
y organismos de la Unión Europea. Como tal, se configura como una iniciativa que propicia la disponibilidad de información del sector público y su reutilización, con fines comerciales o no comerciales, en el contexto del movimiento de datos públicos abiertos.

En consecuencia, dado que la finalidad primordial a la que responde es el fomento del uso público de los datos y su reutilización, se perfila como una plataforma para el surgimiento de nuevos proyectos de carácter innovador y transfronterizo.

En línea con el análisis realizado como usuarios de dicho activo de información y teniendo en cuenta, tal y como se ha señalado, que dicho portal se encuentra en fase de desarrollo, pensamos que sería recomendable mejorar o definir de forma más precisa algunas de sus características para contribuir a reforzar mejor su finalidad en el incentivo a la reutilización. En este sentido, pensamos que sería muy positivo mejorar el desglose en la presentación de formatos de recursos disponibles, dado que la presencia real de formatos reutilizables es superior a la mostrada en el apartado de formato de recursos del propio portal.

También consideramos que resultaría muy positiva la incorporación de ayudas sobre cómo usar el buscador o información complementaria sobre las características idiomáticas del portal. En esta línea hemos de señalar que, aunque el formulario de consulta es multilingüe, no es posible formular consultas con palabras clave en español.

En línea con esa mejora de las características, sería muy útil en la navegación del portal disponer de una organización de los contenidos por grandes áreas temáticas.

Finalmente, como activo de información vivo, aún en fase de desarrollo y en constante transformación, confiamos en que, progresivamente, se irá produciendo un aumento de la 
participación de nuevos proveedores de datos que, sin lugar a dudas, redundará en un incremento cuantitativo del número de conjuntos de datos y aplicaciones y en una mayor diversificación de editores y contenidos.

\section{REFERENCIAS BIBLIOGRÁFICAS}

1. L. F. Ramón Simón et al. (2012), "De la reutilización de información del sector público a los portales de datos abiertos en Europa", en bid: textos universitaris de biblioteconomia i documentació, 29 [en línea], http://bid.ub.edu/29/ramos2.htm. DSGS

2. Unión Europea (2013), Portal de datos abiertos de la Unión Europea [apartado: “¿De qué trata este Portal de datos?”], [en línea], https://open-data.europa.eu

3. Parlamento Europeo (2013), "Directiva 2013/37/UE del Parlamento Europeo y del Consejo, de 26 de junio de 2013 por la que se modifica la Directiva 2003/98/CE, relativa a la reutilización de la información del sector público," en Diario Oficial de la Unión Europea (27/06/2013) [en línea], http://eurlex.europa.eu/LexUriServ/LexUriServ.do?uri=OJ:L:2013:175:0001:0008: ES:PDF

4. Comisión Europea (2011), "Comunicación de la comisión al parlamento europeo, al consejo, al comité económico y social europeo y al comité de las regiones. Datos abiertos: un motor para la innovación, el crecimiento y la gobernanza transparente" $\operatorname{COM}(2011) 882$ final [en línea], http://eur-lex.europa.eu/ LexUriServ/LexUriServ.do?uri=COM:2011:0882:FIN:ES:PDF

5. Unión Europea (2013), Op. cit.

6. Ibíd.

7. W3C Recommendation. SPARQL Query Language for RDF [en 
línea], http://www.w3.org/TR/rdf-sparql-query/

8. w3C Recommendation. Data Catalog Vocabulary (DCAT) [en línea], http://www.w3.org/TR/vocab-dcat/

9. w3C Working Group Note. Asset Description Metadata Schema (ADMS) [en línea], http://www.w3.org/TR/vocab-adms/

10. Unión Europea (2013), Op. cit. 
Hacia una transparencia activa focalizada en el ámbito universitario chileno

JORGE PÉREZ

Universidad de Chile

CARACTERÍSTICAS GENERALES DEL MODELO

DE TRANSPARENCIA Y ACCESO A LA INFORMACIÓN

PÚBLICA EN CHILE

n Chile, desde 2009 rige la Ley $N^{\circ} 20.285$ sobre Acceso $\checkmark$ a la Información Pública, ${ }^{1}$ la cual regula el modo en L el que la ciudadanía puede acceder a la información que obra en poder de los órganos de la administración del Estado (entre los cuales se encuentran las universidades públicas) y la forma en que éstos transparentan su gestión. Para tales efectos, existen dos vías principales: una remite al derecho para solicitar información que obre en poder de los organismos del Estado, declarada pública salvo excepciones que indique la ley; la otra, obedece a la obligación legal que tienen dichas instituciones públicas de transparentar su gestión publicando información a través de sus respectivos sitios web.

El derecho de acceso a la información pública, el cual ejercen voluntariamente las personas, se hace efectivo a tra- 
vés de una solicitud presentada ante un organismo del Estado, bajo las condiciones que esta ley determina. Por otra parte, la ley chilena dispone de un mecanismo de rendición de cuentas, permanente y actualizado, por medio de la publicación de información sobre la gestión institucional, a través de los sitios web de los distintos organismos afectos. Este modelo es conocido como transparencia activa, dado que la acción de apertura se inicia desde el propio Estado, sin esperar requerimiento o solicitud alguna de la población. No significa esto que sea prerrogativa de la administración, o una acción voluntaria. Como señala Schedler: "[...] la rendición de cuentas no es un derecho de petición", ${ }^{2}$ sino una obligación definida por el principio de transparencia de los actos de la misma y el derecho de acceso a la información; obligación que también es regulada y fiscalizada, y cuyas contravenciones son sancionadas por un órgano autónomo del Estado, facultado para tales efectos: el Consejo para la Transparencia.

En el diseño del modelo chileno se conjugan lo que Schedler señala como "[...] los tres pilares de la rendición de cuentas [...] información, justificación y castigo"; 3 se reconoce el derecho de requerir y recibir información; se determina la obligación de la administración del Estado de rendir cuentas, y se establecen sanciones. En este último punto, podemos señalar que también cumple con lo que O’Donnell define como rendición de cuentas horizontal:

[...] la existencia de organismos estatales que están legalmente habilitados y autorizados, y de hecho dispuestos y capacitados, para emprender acciones que abarcan desde la fiscalización rutinaria hasta sanciones penales o destitución, en relación con actos $\mathrm{u}$ omisiones de otras instituciones del Estado, que puedan calificarse, en principio o presuntamente, como ilícitos. ${ }^{4}$ 
Cabe señalar que la acción sancionadora sobre asuntos que riñen con el principio de transparencia y el derecho de acceso a la información no se agota en el organismo especial antes señalado, sino que ésta incorpora, como también lo señala O'Donnell, “[...] redes de instituciones que incluyen en su cúspide a los tribunales -incluyendo los más altos- dedicados a esa rendición de cuentas." 5

\section{TRANSPARENCIA ACTIVA FOCALIZADA:}

DESAFÍO PARA EL ÁMBITO UNIVERSITARIO CHILENO

Las universidades chilenas que pertenecen al Estado (16 de un total 60, en un sistema de altos componentes de mercado) están afectas a las normas de la Ley $\mathrm{N}^{\circ}$ 20.285, así consideradas como órganos descentralizados de la administración del Estado, reconocidas como servicios públicos por la Ley Orgánica Constitucional de Bases Generales de la Administración del Estado.

En esa lógica, las normas sobre transparencia activa (que incluye las Instrucciones Generales del Consejo para la Transparencia, en este ámbito) ${ }^{6}$ aplicables a las universidades estatales son las mismas que rigen para el resto de los servicios públicos, como puede ser una Municipalidad, el Servicio de Impuestos Internos, el Ministerio de Defensa o cualquier otro organismo, sin distinguir sobre la especificidad de la función pública que se cumple.

Bajo este punto, subyace una discusión ya agotada respecto a la aplicabilidad de las normas contenidas en la Ley $\mathrm{N}^{\mathrm{o}}$ 20.285, en contraposición al argumento de la autonomía universitaria que estas entidades detentan. Al respecto, coincidimos con lo señalado por Gil Antón, en virtud de lo cual: 
[...] su posición como entidades autónomas para garantizar el gobierno adecuado a sus fines de manera independiente, y la autodeterminación académica y administrativa, resulta un valor profundo a preservar como condición para una gestión adecuada y responsable; de ella derivan la libertad de cátedra, investigación y la generación de expresiones críticas, a través de la difusión del saber, no constreñidas por ningún poder constituido o fáctico. ${ }^{7}$

Y es por el resguardo, desarrollo y fortalecimiento de la autonomía referida que, en el caso particular de estas entidades, se hace necesario contar con mecanismos de transparencia que eviten o al menos alerten sobre el intento de captura sobre ellas, ya sea por parte de poderes fácticos, grupos políticos o económicos, que intenten lucrar o intervenir de manera desmedida en el devenir institucional. Lo anterior se refiere a la defensa del interés superior de la sociedad que ha depositado en estas instituciones poderes únicos, exclusivos y excluyentes, tanto en las universidades estatales como en las privadas, y esa delegación especialísima de poderes merece y debe tener un contrapeso a través de mecanismos de transparencia y acceso a la información.

Existe un amplio consenso (y en la práctica así rige), en tanto entender que la autonomía universitaria no puede transformarse en pretexto para crear en sí un universo propio, inconexo y por sobre las normas y la sociedad a la cual se deben. Sin embargo, hay una cuestión pendiente y aún, creo, muy poco abordada en los espacios de discusión universitarios y en los entes reguladores chilenos. Esto es, el tipo de información que las universidades deben poner a disposición de la ciudadanía. Como bien señala Gil Antón, "[...] las situaciones que ocurren en el nivel de la sociedad en general no son idénticas a las correspondientes a la actividad universitaria." 8 
Al igualar las universidades con la generalidad de los servicios públicos que son parte de la administración del Estado, en lo concerniente a transparencia activa, paradójicamente se oculta de la visión ciudadana el principal rol que éstas cumplen en la sociedad y aquello que los movimientos sociales han logrado instalar en los últimos dos años en Chile: educación de calidad, igualitaria y sin lucro. La calidad, para el caso de las universidades, estará dada por el mejor y más amplio cumplimiento de sus tareas clásicas de docencia, investigación y extensión, cuestiones que no son medibles sólo por el cumplimiento de los protocolos de compras públicas a través del portal web estatal, o por la mera mención de aquellas normas que les son aplicables. La especificidad de la labor universitaria exige que el modelo de transparencia sea adecuado a ella, de manera que la información que se deba mantener pública a la ciudadanía sirva, efectivamente, como medio de control social del cumplimiento de las prerrogativas exclusivas que la sociedad ha depositado en los planteles de educación superior, cuestión fundamental de la necesidad de transparencia. Aquí resulta imperativo reconocer que cada ámbito de la vida social y pública tiene particularidades, "[...] vulnerabilidades y dinámicas de funcionamiento propias, las cuales determinan los contenidos y formas de intervención para promover el acceso a la información."” En el estado de situación actual, no encontramos en la información que se obliga publicar aquella que, como señala Plasencia, nos dé la "[...] posibilidad de utilizarla en beneficio concreto e individual de los usuarios". ${ }^{10}$

En este contexto surge el concepto de "Transparencia Focalizada", ${ }^{11}$ que remite a la necesidad de publicitar información efectivamente útil para el público objetivo, y en general, que permita a la ciudadanía observar con menor opacidad la gestión de los servicios en su particular ámbito 
de competencias. Al respecto, Trinidad Zaldívar y Cruz concuerdan en "[...] que la información deje de ser una simple acumulación de datos -difícilmente descifrables- y que se le transforme en conocimiento [...] para que ella pueda ser un instrumento realmente útil y de interés para un público amplio." ${ }^{2}$ De tal modo, la transparencia activa, vista como la disposición de información pública a modo de mero cúmulo de datos, no cumple la función de vehículo de rendición de cuentas (en su dimensión informativa, argumentativa y punitiva, como señala Schedler) de los actos de la administración, ni como herramienta eficaz de fiscalización, o para la toma de decisiones de la ciudadanía (usuarios de los servicios públicos), si esta información no genera en sí misma conocimiento que responda a las expectativas de la población. Hoy, podríamos encontrarnos ante una puesta en escena representativa, una alegoría de la transparencia que transmuta en opacidad, en la que políticos, funcionarios, instituciones y la propia legislación usaría (y en ocasiones abusaría) de conceptos de transparencia y apertura, como un mero ropaje frente a la ciudadanía, con declaraciones rimbombantes y escasa efectividad a la hora del ejercicio efectivo del derecho de acceso a la información, donde, cómo señala García Canclini, "[...] en vez de la transparencia de las decisiones prometidas por el aumento de la información, hallamos el vaciamiento de la comunicación pública o su saturación con anécdotas y datos insignificantes."13

INCORPORACIÓN DE LAS UNIVERSIDADES PRIVADAS A LAS OBLIGACIONES DE TRANSPARENCIA

Respecto al anterior punto, no bastaría con hacer más específica, accesible o comprensible la información objeto a 
transparentar por parte de las universidades, si este esfuerzo no incluye también a las de carácter privado. Cabe detenernos un momento sobre el efecto marginal que tiene la aplicación de la Ley $\mathrm{N}^{\mathrm{o}} 20.285$ en el contexto universitario chileno, siendo que las instituciones de propiedad estatal no representan más del $27 \%$ del total, con una participación en la matrícula que cayó entre 2008 y 2012, de 32,03\% a 25,06\% (Tabla 1).

Tabla 1

Evolución de la matrícula en universidades chilenas 2008-2012

\begin{tabular}{|c|c|c|c|}
\hline & $\mathbf{2 0 0 8}$ & $\mathbf{2 0 1 0}$ & $\mathbf{2 0 1 2}$ \\
\hline Total Matrícula Nacional & 509.552 & 587.117 & 631.256 \\
\hline Matrícula Universidades Privadas & 346.351 & 424.833 & 473.064 \\
\hline \% Respecto a la Matricula Nacional & 67,97 & 72,36 & 74,94 \\
\hline Matrícula Universidades Estatales & 163.201 & 162.284 & 158.192 \\
\hline \% Respecto a la Matrícula Nacional & 32,03 & 27,64 & 25,06 \\
\hline
\end{tabular}

Fuente: Ministerio de Educación de Chile (elaboración propia)

En concordancia con este punto se encuentra la opinión de Muruyama, quien señala que:

[...] la transparencia y la rendición de cuentas en las universidades van mucho más allá de las instituciones de carácter público; atañe también a las instituciones privadas, puesto que la educación es un bien público, un servicio público, aunque se llegue a proveer de forma privada [...] La obligación para quien brinda servicios educativos en el ámbito privado no puede estar al margen de una serie de obligaciones que superan las que tuviera cualquier otra empresa. ${ }^{14}$

Esta conclusión también encuentra sustento desde la perspectiva de la ampliación del espacio público, producto del traspaso de la provisión de servicios públicos a las empresas, ya sea por la privatización total o por la asociación entre el Estado y el sector privado. Así, la acción pública 
ya no está circunscrita a los actos de los organismos de la administración pública, sino también a los agentes privados que proveen de servicios públicos.

Es también razón de análisis que, en las entidades universitarias del Estado -si bien comparten con otros organismos públicos que la ley les dé esa categoría y que las personas que en esos lugares trabajan son nombradas en sus cargos como funcionarios públicos-, subsiste una gran diferencia en su financiamiento, pues aunque no ha menguado la convicción de la comunidad universitaria por denominarse "del Estado de Chile" y "pública”, sí al menos merece un cuestionamiento moral. En tanto, nadie podría aceptar que el Ministerio de Defensa no tuviese un presupuesto anual 100\% a cargo de las arcas fiscales (al menos no hasta ahora), por más de 30 años las universidades públicas reciben en promedio sólo el 15\% de financiamiento estatal para su funcionamiento anual, lo cual no es razón de asombro al constatar que, según informes de la Contraloría General de la República, el financiamiento fiscal a la educación superior en Chile está orientado hacia los estudiantes, llevándose éstos más del doble de los recursos que reciben las instituciones, y siendo estas últimas en su mayoría privadas, los problemas se agudizan para la educación pública. Así, se hace evidente el hecho de que en Chile no es el origen público del financiamiento lo que obliga a las instituciones a rendir cuentas, a transparentar su gestión, aunque sean éstas orientadas a proporcionar servicios públicos, como la educación (Tabla 2).

Tabla 2

Distribución del financiamiento fiscal a estudiantes por tipo de universidad

\begin{tabular}{|c|c|c|}
\hline & $\mathbf{2 0 1 1}$ & $\mathbf{2 0 1 2}$ \\
\hline Universidades privadas & $66,63 \%$ & $66,45 \%$ \\
\hline Universidades estatales & $33,37 \%$ & $33,55 \%$ \\
\hline
\end{tabular}

Fuente: Contraloría General de la República de Chile (elaboración propia) 
En conclusión, se requiere la implementación de un modelo de transparencia activa focalizada en el ámbito universitario chileno que distinga la especificidad de la función pública que se cumple, que responda a las necesidades de un usuario específico, que se adecúe a los códigos particulares de la realidad que pretende transparentar, y así, cumplir efectivamente con su objetivo de generar las condiciones para el pleno ejercicio del derecho de acceso a la información, como medio para la consecución y el ejercicio de otros derechos. Se hace necesario avanzar hacia un modelo de transparencia activa basado en la realidad universitaria, tanto estatal como privada, que incluya la obligatoriedad de publicar información que dé cuenta, en primer lugar, de su compromiso real con la calidad de la educación, en su dimensión de docencia, investigación y extensión.

Que este nuevo marco de transparencia focalizada sea efectivo, dependerá de su aplicación general sobre el ámbito universitario, en razón de la redefinición de lo público, el interés social por la educación, el origen del financiamiento y en el bien superior de la sociedad, que descansa en la confianza depositada en sus instituciones, sean éstas de origen estatal o privado.

\section{REFERENCIAS BIBLIOGRÁFICAS}

1. Ley $\mathrm{N}^{\circ}$ 20.285, Sobre Acceso a la Información Pública, Chile [en línea], http://bcn.cl/msg

2. Andreas Schedler (2008), “QQué es la rendición de cuentas?”, en Cuadernos de Transparencia, núm. 3, p. 15

3. Ibid., p. 13.

4. Guillermo O’Donnell (1997), "Rendición de cuentas horizontal 
y nuevas poliarquías", en Nueva Sociedad, núm. 152, p. 13.

5. Ibid., p. 15.

6. Instrucciones Generales del Consejo para la Transparencia, Chile [en línea], http://www.consejotransparencia.cl/instrucciones-generales/consejo/2012-12-19/205010.html

7. Manuel Gil Antón (2008), "Transparencia y vida universitaria, en Cuadernos de Transparencia, núm. 13, p. 15.

8. Ibíd., p. 13.

9. Paloma Baena Olabe y Juan Cruz Vieyra (2011), Acceso a la información y políticas de transparencia focalizada. Notas Técnicas, Washington, D.C., Banco Interamericano de Desarrollo, p. 13 [en línea], http://idbdocs.iadb.org/wsdocs/getdocument. aspx?docnum $=36547352$

10. Adriana Plasencia Díaz (2011), "La transparencia focalizada en el sector educativo: otra tarea pendiente”, en Ángel Trinidad Zaldívar y Juan Cristóbal Cruz Revueltas (coord.), Transparencia focalizada: ejercicio del derecho a la información pública en México, México, IFAI-COMAIP, p. 160.

11. Archon Fung, Mary Graham, David Weil (2007), Full Disclosure. The Perils and Promise of Transparency, Nueva York, Cambridge University Press.

12. Ángel Trinidad Zaldívar y Juan Cristóbal Cruz Revueltas, "Introducción” (2011), en Ángel Trinidad Zaldívar y Juan Cristóbal Cruz Revueltas (coord.), Transparencia focalizada: ejercicio del derecho a la información pública en México, México, IFAICOMAIP, p. 8.

13. Néstor García Canclini (2011), "De la sociedad de la información a la sociedad del desconocimiento", en Versión (Nueva época), núm. 27, sep., p. 8. [en línea], http://148.206.107.15/ biblioteca_digital/articulos/7-563-7998bxk.pdf

14. Ciro Muruyama Rendón (2007), “Obligaciones de transparen- 
Hacia una transparencia activa focalizada...

cia en las universidades", en Revista de Investigación Educati$v a$, vol. 4, ene.-jun. [en línea], http://www.uv.mx/cpue/num4/ critica/murayama_obligaciones_transparencia.html 


\title{
Medios para el acceso a la información pública en Venezuela
}

\author{
DIONNYS PEÑA OCANDO \\ NELLY PRIMERA MENDOZA \\ Universidad del Zulia, Venezuela
}

\section{INTRODUCCIÓN}

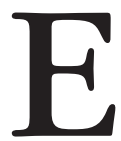

n el ámbito de las instituciones públicas, la información representa una fuente particular de contenidos de vital importancia para el funcionamiento de la dinámica gubernamental; asimismo, resulta un elemento esencial para facilitar innumerables actividades propias de tal gestión. Para reorientar este recurso hacia fines más trascendentes de servicio a los ciudadanos, se plantea el establecimiento de "políticas" como iniciativas que partan del Estado y sus entes ejecutores en forma de normativas o directrices vinculadas a las necesidades fundamentales de la comunidad y de los sectores productivos, pero, aunque conceptualmente se planteen principios ideales, no siempre existen buenas intenciones ni criterios profesionales y éticos respecto a los hechos que involucren información y que puedan expresarse en directrices claras para su implementación a través de los medios adecuados. 
En la realidad de muchos países latinoamericanos, las organizaciones públicas presentan inconvenientes en el cumplimiento de este tipo de políticas relacionadas con información, puesto que, aun cuando su misión básica sea el servicio social desinteresado y objetivo, prevalecen criterios que apuestan por el control sobre los datos y recursos asociados, a fin de mantener un régimen o ideología social y cultural determinada. De tal manera que las políticas que se formulan en el contexto gubernamental tienen un fuerte compromiso ante quienes esperan que se haga justicia frente a los vicios de control desmedido de la información.

Además de lo anteriormente planteado, es necesario destacar que el acceso a la información figura como un derecho y servicio universal, ${ }^{1}$ y se convierte en un principio que guía muchas de las acciones de los gobiernos en el contexto latinoamericano, y particularmente en países como Venezuela, donde se plantea una apertura a la participación y al control social. Es por ello que este trabajo tiene como objetivo explorar los medios de acceso a la información pública que se han establecido en ese país desde el año 1999 hasta finales de la primera década del siglo XXI, como una manera de hacer un balance de los avances alcanzados en esta materia, tanto en el contexto municipal como en el nacional.

Para el logro del objetivo expuesto, se acudió a una metodología documental basada en la revisión de aspectos conceptuales relacionados con la importancia de las políticas de información y referentes empíricos sobre las iniciativas para el desarrollo de los medios que faciliten el acceso a los insumos de información, lo cual sirvió como un referente para el análisis de la información procedente de las intenciones del gobierno venezolano a través de un marco jurídico que acoge con particular importancia los temas de información, además de la revisión de las acciones y medios 
emergentes para propiciar el acceso a este recurso en el ámbito público.

\section{ASPECTOS TEÓRICOS}

La consolidación de medios para el acceso a la información pública no es un hecho aislado, sino que parte de un basamento teórico-referencial que viabiliza este hecho y lo orienta hacia fines esenciales; por tanto, para efectos de este trabajo se han asumido las políticas como el mecanismo que genera tales condiciones de acceso, en el marco de los planteamientos de autores que abogan por la responsabilidad gubernamental de generar controles y respuestas para la superación de los conflictos sociales, el desarrollo y la democratización de las sociedades latinoamericanas. ${ }^{2}$

Las concepciones vinculadas al terreno de lo público plantean que, en esencia, las políticas de información parten del derecho de que todos los ciudadanos tienen a la información y el deber que tiene el estado de facilitarla; ${ }^{3}$ por lo tanto, su concepción puede sintetizarse como directrices, leyes, estrategias, o planes de acción, que precisen los aspectos puntuales de actuación en materia de generación, transferencia, disponibilidad, acceso y recuperación de la información dentro de cada área (redes, recursos de información, tecnología, gestión, formación y aspectos legales) para una mayor eficacia en la dirección, gestión y gobierno. ${ }^{4}$

Ahora bien, las políticas actúan como habilitadoras-estimulantes, pero no son suficientes para garantizar el acceso a la información pública, el cual se construye sobre la base de otros mecanismos, vías o medios que parten del ámbito gubernamental para responder a las necesidades informativas de sus habitantes y den apertura a la participación, 
entre ellos: publicaciones oficiales, oficinas de información y servicios dispuestos para tales fines. Tales mecanismos se consolidan mediante una infraestructura y una infoestructu$\mathrm{ra}^{5}$ que comprende la generación, contenidos, tratamiento y transferencia de información apoyado en tecnología útil para facilitar los procesos anteriores.

Las opciones que se plantean en el ámbito gubernamental para facilitar el acceso de la información se debaten entre modelos tradicionales e innovadores. Dentro de los modelos tradicionales se encuentran los archivos, bibliotecas, oficinas de información presenciales, prensa, radio y televisión. Para efectos de este trabajo abordaremos opciones innovadoras, como las unidades de información, las redes sociales, el gobierno electrónico, los sistemas de información comunitaria y la capacitación en materia de información. A continuación una breve descripción de los mismos:

a) Unidades o servicios de información; considerados como los componentes físicos y tecnológicos que permiten ejecutar los procesos para acceder a los contenidos ofrecidos por los entes gubernamentales. Se conforman por modernos centros de documentación o redes de unidades, mesas técnicas, oficinas de cómputo, infocentros y demás variantes consideradas como cerebros de las instituciones, ${ }^{6}$ cuya responsabilidad es convertir los datos en información, mediante funciones de recogida, clasificación, análisis, integración y empaquetado, para ser remitida a los ciudadanos y funcionarios que la ameriten. ${ }^{7}$

b) Gobierno electrónico; conocido a su vez como e-gobierno o e-government, se traduce en: proveer más y mejores prestaciones a los ciudadanos y a la propia gestión pública, en el sentido de brindar pun- 
tos de acceso unificados y sencillos para satisfacer múltiples necesidades informativas y de servicios; adicionar productividad, calidad a los ya existentes; proveer atención "a la medida" de los requerimientos de cada usuario; resolver trámites, consultas, reclamos y sugerencia "en línea", aumentar la calidad y reducir el costo (en dinero, tiempo, molestia y carga anímica) de las transacciones dentro del Estado. ${ }^{8}$ De tal modo, se plantea como un excelente medio para facilitar el acceso a la información esencial según demandas específicas.

c) Redes sociales; constituyen otras iniciativas importantes para la materialización del acceso a la información, debido a que se caracterizan por permitir la interacción de actores e impulsar liderazgos que conllevan al desarrollo de las potencialidades aprovechando la sinergia que produce compartir y socializar, dejando atrás el aislamiento. Algunos autores las definen como un espacio de diálogo y coordinación en el cual se encuentran ciudadanos independientes, organizaciones sociales e instituciones públicas y privadas en función de objetivos e intereses comunes, bajo una actuación coordinada en su intervención o solución de problemas de interés común. ${ }^{9}$ Otros hablan de redes "sociotecnicas", porque envuelven la constitución de una organización entre agentes sociales estimulada y mediada por instrumentos tecnológicos y lenguaje codificado, representados por el Internet y la tramas de hiperenlaces en la web, en casos específicos como Twitter, MySpace, Tuenti, Hi5, Facebook, LinkedIn, entre otras. ${ }^{10}$

d) Sistemas o servicios de información comunitaria (SIC); se conciben como el conjunto de componentes 
La información gubernamental y el acceso a la información...

(personas, hardware, software y datos) que interactúan entre sí para apoyar a la gestión comunal con información cualitativa que permita la toma de decisiones acertadas, la evaluación de la gestión y la transparencia en las acciones de beneficio común. Los SIC podrían instalarse en organismos públicos, privados u ONG insertas en las comunidades donde sus funciones radiquen en el aprovechamiento de las TIC para mantener informados a sus usuarios sobre lo que ocurre en su comunidad específica en cuanto a: planes y proyectos, censo social y demográfico, solución de problemas, aprovechamiento de oportunidades, identificación de amenazas, diseño de políticas, estrategias y normativas.

e) Capacitación para el acceso; para lograr el pleno acceso a la información, no se puede obviar un componente fundamental y quizá el más importante: la capacitación. La necesidad de garantizar un mayor y mejor acceso a los recursos de información por parte de la población tiene como aliada a la educación, entendiendo esta figura como "[...] el proceso continuo que busca desarrollar en el ser humano capacidades, aptitudes y actitudes, de forma que éste se prepare para ser motor fundamental en las actividades sociales, económicas y políticas de la sociedad." ${ }^{11}$ Mientras más instrumentos maneje cada individuo con sentido y significado para sus vidas, mayores posibilidades de desarrollo individual tendrá, y por ende su país.

Las referidas opciones constituyen algunos mecanismos enmarcados en el aprovechamiento de las Tecnologías de Información y Comunicación, de modo que se plantean como nuevas tendencias teóricas que ameritan ser valida- 
das en la realidad de cada contexto particular, las cuales no pueden pasar por alto las brechas de toda índole que obligan al retorno de medios tradicionales.

\section{INICIATIVAS DE ACCESO A LA INFORMACIÓN EN VENEZUELA}

Tal como se sugirió en la revisión teórica, los medios para facilitar el acceso a la información se plantearán en dos vertientes: en primer lugar, las políticas formuladas en el marco jurídico venezolano; en segundo lugar, en las iniciativas tangibles que se desprenden desde los diferentes entes gubernamentales, las cuales permiten evidenciar la concreción de las políticas en este sentido.

\section{El marco jurídico en materia de información}

La revisión documental realizada demuestra que no existe ningún instrumento político específico (llámese ley, decreto, reglamento, programa, proyecto) que regule el acceso a la información como tema central, ya que es considerado transversalmente como aspecto dentro de diversas leyes e instrumentos políticos. La Constitución de la República ${ }^{12}$ plantea los principios macros de acceso universal y el derecho de los ciudadanos a la información que son operacionalizados mediante otros instrumentos.

El marco legal queda conformado por la Ley orgánica de la administración pública, Ley orgánica de planificación, Ley Orgánica de Administración Central, Ley orgánica del poder ciudadano, Ley orgánica de telecomunicaciones, Decreto 825 sobre uso del Internet, Decreto $\mathrm{N}^{\circ} 3390$ sobre el Uso del Software Libre en la Administración Pública, Ley de Simplificación de Trámites Administrativos, Plan Nacional 
de Tecnologías de Información (2002-2013); Plan Nacional de Telecomunicaciones, informática y servicios postales (PNTIySP) 2007-2013, Proyecto Nacional Simón Bolivar 20072013, Plan Nacional de Ciencia y Tecnología (2005-2030), Ley de Mensajes de Datos y Firmas Electrónicas; Decreto sobre Acceso e Intercambio Electrónico de Datos, Información y Documentos entre los órganos y Entes del Estado, Ley de Infogobierno, entre otras que pueden consultarse en el Portal del Centro Nacional de Tecnologías de información (CNTI). ${ }^{13}$ Tales instrumentos marcan lineamientos concretos en materia de:

- El derecho de los ciudadanos a ser informados sobre asuntos públicos y acceso a los archivos y registros públicos.

- Derecho a disponer de información de calidad.

- Respuesta a solicitudes y requerimientos de información.

- Uso eficaz de las nuevas tecnologías por los órganos públicos.

- Obligación de los órganos y entes de la administración pública de informar públicamente sobre sus gestiones y actividades.

- Atención a las demandas de los ciudadanos y satisfacción de las mismas.

- Acceso al patrimonio cultural por la población y derecho a la documentación.

- Diseño de programas pedagógicos e informativos para el conocimiento de valores, virtudes y derechos ciudadanos, además de prever su inclusión en medios.

- Explotación de redes, interconexión y prestación de servicios. 
- Promoción de redes y servicios de carácter público y social.

- Uso de plataforma informática de acceso gratuito en todos los organismos públicos.

- Racionalización y optimización de las tramitaciones que realizan las personas ante la administración pública.

- Uso y aplicación de las TIC como herramientas habilitadoras del desarrollo.

- Desarrollo de un modelo comunicacional inclusivo, mediante una red eficiente de vías de información y educación no formal hacia el pueblo.

- Universalizar el acceso a los diferentes medios de comunicación.

- Creación de plataformas tecnológicas que viabilicen el acceso inmediato del ciudadano común a la información que facilita su calidad de vida (trámites administrativos e información para la contraloría social).

Como se puede observar, todas las normativas promulgadas conforman, en su conjunto, un marco legal en materia de información y nuevas tecnologías con carácter nacional que supone una responsabilidad por parte de los entes competentes de la administración para asegurar el "acceso a la información" a la mayoría de la población; para ello, se emplean todos los recursos y medios que ofrecen las nuevas tecnologías de la información y la comunicación, de manera tal que se cumplan los derechos fundamentales que están expresados en la constitución.

\section{Acciones y medios desarrollados}

Acudiendo a las opciones teóricas planteadas, el escenario para Venezuela no es muy favorecedor, dado que han existi- 
do muy pocas iniciativas en materia de servicios y unidades de información que partan de los organismos públicos. Actualmente sólo existe en el país una plataforma tradicional conformada por la Red Nacional de Bibliotecas Públicas y algunas iniciativas particulares de centros de procesamiento de información en los entes descentralizados, pero estas opciones no siempre han resultado efectivas para facilitar el acceso a los recursos de información dados los problemas de índole organizativo y funcional que presentan, así como la poca prioridad recibida en la inversión de recursos por parte del gobierno, lo cual contradice las políticas establecidas.

También, dentro de este rubro, se enmarcan los Infocentros, los cuales fueron diseminados por todo el territorio nacional venezolano desde el año 2000 y se concibieron como salas equipadas tecnológicamente para brindar acceso a Internet y contribuir al desarrollo de potencialidades de la ciudadanía y la organización de las comunidades. ${ }^{14}$ Sin embargo, no se les ha dado el seguimiento ni mantenimiento necesario para su consolidación y expansión, lo cual ha ocasionado la desaparición paulatina de la gran mayoría. Así lo demuestra la evaluación de su impacto realizada por el Centro Nacional de Tecnologías de Información, ${ }^{15}$ donde se consideró que estos centros tuvieron una buena aceptación, pues fomentaban la integración de las comunidades y el desarrollo, pero requerían de una gestión intermedia que permitiera aumentar el apoyo y la vigilancia del proyecto para su sustentabilidad en el tiempo.

En cuanto a los portales de gobierno electrónico, hay desarrollos significativos; entre ellos, se pueden mencionar el portal de gobierno en línea (www.gob.ve), alcaldías digitales (www.alcaldias.gob.ve), y otros portales de carácter informativo, como aquellos vinculados a los ministerios de poder popular. Las experiencias de su revisión revelan que 
estos medios intentan ofrecer los vínculos para acceder a información que pueda ser considerada fundamental por la mayor parte de la población, tal como noticias, arte, cultura, legislación, proyectos y programas en curso, estadísticas, indicadores, eventos, documentos, forma de hacer los trámites y servicios públicos, solicitudes, consultas, entre otras precisiones, lo cual es un gran paso para el acceso a la información pública. Dentro del rubro informativo $y$ transaccional se encuentran los portales de recaudación de impuestos (SENIAT), de la Oficina de Nacional de Identificación y Extranjería (ONIDEX), del Instituto Venezolano del Seguro Social (IVSS), para el control de divisas (CADIVI) y para la inscripción de proyectos en el Fondo Nacional de Ciencia y Tecnología (FONACIT), además de los portales ofrecidos para la obtención de beneficios sociales, como la Misión Vivienda, Venezuela Móvil, entre otros.

En lo que concierne a las redes sociales puede observarse que, en los últimos años, ha emergido una serie de grupos estimulados por las políticas gubernamentales, tales como cooperativas y asociaciones culturales y civiles, que atienden a diferentes sectores o servicios, llámense de educación, vivienda, salud y alimentación, con miras a constituirse en importantes redes sociales; no obstante, se han mantenido sin ningún tipo de coordinación formal y técnica, demostrando un bajo sentido de pertenencia y falta de liderazgo para su integración. Esta situación ocasiona duplicidad de esfuerzos y de recursos, además de la ineficiencia en el logro de metas comunes en lo económico, social, político y ético, entre otros aspectos vinculantes con el desarrollo social.

Paralelamente, existe un grupo de la población con las competencias en información y con mayor acceso a los recursos tecnológicos que se han apropiado de las redes sociales para extender datos, plantear criterios, exponer sus 
demandas y desarrollar movimientos que buscan generar cambios importantes fundamentalmente en materia política y económica.

En relación con los sistemas de información comunitaria, se asumen como de vital relevancia las iniciativas que emergen a partir del decreto de los consejos locales de planificación pública y los consejos comunales establecidos en la constitución y los requerimientos de información que estas figuras de participación imponen dentro de las comunidades organizadas, tales como llevar un mapa de información sobre las comunidades y el desarrollo de bases de datos sobre aspectos clave de las mismas que sirvan para gestionar recursos y acciones en su seno.

Pese a la necesidad imperante en materia de este tipo de sistemas dentro de las comunidades, aún no existen experiencias significativas por mencionar en Venezuela. El rastreo realizado por Internet arroja que se han desarrollado propuestas conceptuales de software y algunos comentarios o noticias aisladas en la materia, pero se requiere la asesoría metodológica especializada para entender la magnitud del proyecto.

Finalmente, en lo que respecta a los programas de formación como medio para facilitar el acceso, la tarea aún sigue pendiente y permanece en el plano de las políticas ante la necesidad de diseñar programas de alfabetización en materia de información orientados a las comunidades de menores recursos, que son por lo general quienes se encuentran más limitados y excluidos. Los avances gubernamentales apuntan hacia la formación en materia tecnológica mediante iniciativas como el Programa de Cisco e IBM, Academia de Software Libre y el otorgamiento de becas para estudios en la materia. ${ }^{16}$ 


\section{CONCLUSIONES}

La revisión anterior muestra el estado del arte de la situación del acceso a la información en Venezuela a partir de las políticas y medios que emplea el gobierno nacional para el cumplimiento de este derecho fundamental, de lo cual se puede destacar lo siguiente:

- Las políticas establecidas reflejan muchos de los aspectos teóricos sobre la importancia de la información pública para la participación y el desarrollo integral de los ciudadanos, así como también prevé los medios u opciones para facilitar su acceso en condiciones de igualdad; no obstante, una concepción favorable en cuanto a las políticas de información no siempre asegura su concreción en lineamientos claros, como puede verse en el caso del contexto municipal venezolano.

- En el plano de la instrumentación de las políticas, se observa la presencia de algunas iniciativas para garantizar el acceso a la información de los ciudadanos, sobre todo en materia de portales gubernamentales que intentan penetrar en el desarrollo del gobierno electrónico. No obstante, muchos de estos se han orientado a funciones transaccionales e informativas generales, con pocas posibilidades de obtener información que sirva para el control de la gestión gubernamental desde la perspectiva ciudadana.

- De igual manera, el emprendimiento de posibilidades de acceso que involucren un fuerte componente tecnológico, tales como redes sociales, sistemas de información comunitarios y otras fases transaccionales del gobierno electrónico, necesariamente requiere de potenciar las opciones de acceso tradicionales que también son de 
interés para el ciudadano común y que adolece de la experticia tecnológica, tales como las bibliotecas, museos, archivos, salas de consulta y otros espacios de acercamiento a los documentos oficiales. De igual modo, la capacitación en información se plantea como bandera, de manera que proyectos más ambiciosos se conviertan en una realidad sustentable en el tiempo.

A pesar de los pasos adelantados, puede considerarse que el acceso a la información en Venezuela es todavía una meta no alcanzada hasta tanto no sean superadas las barreras organizativas, funcionales, política, técnicas y presupuestarias que impiden la consolidación de los proyectos anteriores. En líneas generales se concluye que, aun existiendo las políticas de información como ejes centrales para garantizar el acceso y contando con las condiciones en el país para consolidar otros medios operativosmediante el aprovechamiento de los recursos de información, se requiere un estudio profundo de aquellos elementos que aportan las mayores facilidades y adecuación a las características deun contexto como el venezolano.

\section{REFERENCIAS BIBLIOGRÁFICAS}

1 S. Rodotá (2000), Tecnopolítica. La democracia y las nuevas tecnologías de la comunicación, Buenos Aires, Losada.

2. I. Páez (1999), Información para el progreso de América Latina, Caracas, Universidad Simón Bolívar-Congreso de la República; J. Esteinou (2002), "Los medios de comunicación como instrumentos del desarrollo", en Razón y Palabra, núm. 29 [en línea], http://www.razonypalabra.org.mx/anteriores/n29/ jesteinou.html 
3. J. Ros y J. López (1994), Políticas de información y documentación, Madrid, Edit. Síntesis; E. Morales (1999), "El derecho a la información y las políticas de información en América Latina", en 65th Conferencia General de la IFLA. Bangkok-Tailandia [en línea], http//www.ifla.org/IV/ifla65/papers/056-1375.htm

4. Ibíd. y M. Almada (2006), "Consideraciones para el análisis y diseño de políticas de información para la inclusión digital y el desarrollo social en América Latina”, en VIII Coloquio Internacional sobre Tecnologías aplicadas a los servicios de información, Maracaibo.

5. C. Viniegra (2010), "Infoestructura. La información como bien público”, en Política Digital, núm. 57, pp. 42-43.

6. F. Canales (2003), Manual de Instrumentación del Consejo Local de Planificación Pública, Caracas, Asamblea Nacional. Comisión Permanente de Participación Ciudadana, Descentralización y Desarrollo Regional.

7. F. Timmerman (2000), Cómo ganar el desafío de la información, Barcelona, Ediciones Deusto.

8. J. Tesoro, A. Arambarri, y C. Rodrigo (2002), Gobierno Electrónico: factores asociados a su desempeño. Hallazgos emergentes de un análisis exploratorio de experiencias nacionales, Buenos Aires, Instituto Nacional de la Administración Pública (INAP) [en línea], http://www.sgp.gov.ar/inap/publicaciones/ docs/sociedad/gobel.pdf

9. D. Eglander y C. Salazar (2005), "Creando redes", en Cartilla educativa (Boletín núm. 26), jun.

10. S. Kauchakje, M. Penna, K. Frey y F. Duarte (2006), "Redes socio-técnicas y participación ciudadana: propuestas conceptuales y analíticas para el uso de las TiCs", en Redes (Revista hispana para el análisis de redes sociales), vol. 11, núm. 3, pp. 1-26; J. Flores (2009), "Nuevos modelos de comunicación, perfiles y tendencias en las redes sociales", en Comunicar, núm. 33, pp. 73-81. 
11. Programa de Naciones Unidas para el Desarrollo (PNUD) (2002), Informe sobre Desarrollo Humano en Venezuela, Venezuela, Intenso Offset, p. 97.

12. Asamblea Nacional: Constitución Bolivariana de Venezuela (2000), Gaceta Oficial Extraordinaria, núm. 5.453, Caracas, Gráficas 2021, C.A.

13. CNTI: Portal del Ministerio del Poder Popular para la Ciencia, Tecnología e innovación [en línea], http://www.cnti.gob.ve/.

14. J. Berrizbeitia (2003), Tecnologías de Información y el desarrollo de las Comunidades, Presidente del Centro Nacional de Tecnologías (CNTI), Venezuela.

15. Centro Nacional de Tecnologías de la Información (2003), "Evaluación de impacto de los Infocentros en Venezuela", en Comunication Iniciative Network [en línea], http://www.comminit.com/en/node/68480/36

16. B. Mendoza (s/f), Un portal para el gobierno electrónico. Directorio de gobierno electrónico Venezuela [en línea], http:// www.gobiernoenlinea.ve/directorioestado/experiencias.html 


\section{El ciudadano bien informado \\ y la mediación bibliotecaria}

VERÓNICA ARAIZA DÍAZ

Universidad Nacional Autónoma de México

\section{INTRODUCCIÓN}

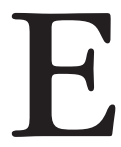

ste ensayo pretende reflexionar sobre la relación entre ciudadanía y acceso a la información pública en la era de la información, y sobre el papel del bibliotecario al respecto. Por un lado, el acceso a la información es un tema de la bibliotecología; por otro, en los últimos años, ha habido un gran énfasis en el derecho a la información en términos generales y, de manera más puntual, en el derecho de acceso a la información (científica, gubernamental, etcétera) que va de la mano del auge del discurso de la transparencia y de la resignificación del concepto de ciudadanía; todo lo cual plantea un nuevo reto para la labor bibliotecaria, porque se hace evidente el vínculo de dicho tema con lo jurídico y porque el papel social del profesional de la información se vuelve fundamental para el ejercicio ciudadano, con lo que adquiere un matiz francamente político.

El derecho a la información está consagrado en la Declaración Universal de los Derechos Humanos (1948), en 
el artículo 19; éste, de manera simple, se refiere a "[...] la garantía fundamental que toda persona posee a atraerse información, a informar y a ser informada." Ahora bien, de acuerdo con García Murillo, "[...] la información que comprende el derecho a la información es toda aquella que, incorporada a un mensaje, tenga un carácter público y sea de interés general, y que además pueda ser sujeto de cualquier proceso de difusión, investigación o almacenamiento que genere una multiplicación de los mensajes." A partir de ello, se puede identificar la justificación jurídica, toda vez que se hace referencia al interés público; asimismo, se manifiesta la materialidad de dicha información (documentos), lo que permite su tratamiento para fines de acopio, diseminación, indagación y producción de nueva información, con lo que se ve claramente el lazo entre la ciencia del derecho y la disciplina bibliotecológica.

Se advierte que dentro de este derecho se encuentra la facultad de producir información y, por ende, la libertad de expresión. Por ello, es necesario precisar o centrarse en el derecho de acceso a la información, que tiene que ver con los otros elementos contenidos en el artículo 19 de la DUDH y que se traduce en la obtención de documentos para finalmente estar informados y -con ello- cumplir el mandato jurídico. El derecho de acceso a la información se asocia principalmente con la información pública, pues ésta se concibe como la primordial fuente de interés común. Villanueva sostiene que "[...] el derecho de acceso a la información pública es la prerrogativa de la persona para acceder a datos, registros y todo tipo de informaciones en poder de entidades públicas y empresas privadas que ejercen gasto público y/o funciones de autoridad."3 


\section{CIUDADANÍA DIGITAL}

Puede afirmarse, entonces, que el derecho a la información es fundamental para la praxis ciudadana. Es conveniente explicar el concepto de ciudadanía, que es tan antiguo como el de democracia; si nos centramos en su concepción moderna (liberal), la ciudadanía tiene que ver con la obtención (reconocimiento por parte del Estado) de varios tipos de derechos: civiles (siglo XVIII), políticos (siglo XIX) y sociales y económicos (siglo $\mathrm{XX})^{4}$ que se han incorporado a lo largo de más de dos siglos, al tiempo que se han incluido más sujetos poseedores de esos derechos.

En el contexto actual, se observa una modificación de la noción de ciudadanía, en gran medida gracias a las transformaciones ocurridas hacia finales del siglo $\mathrm{XX}$, entre las que se destacan, según Castells: ${ }^{5}$ el desarrollo acelerado de las Tecnologías de Información y Comunicación (TIC), la explosión informativa, el desmantelamiento del Estado benefactor y la globalización (económica, política y cultural). Con ello, los ciudadanos han adquirido una nueva identidad (más activa), en virtud de que el Estado mínimo se ha distanciado de sus funciones sociales, a la vez que existe una mayor oferta y facilidad de acceso a diversas fuentes de información. Al mismo tiempo, la globalización ha cristalizado una idea de ciudadanía cosmopolita que "[...] consiste en defender un sistema global de derechos y deberes de alcance universal que vaya más allá de aspectos como el lugar de nacimiento o de residencia de cada individuo."

El uso de las TIC, en particular el de corte político, ha cobrado tal magnitud que hoy se habla de ciudadanía digital (o ciudadanía 2.0), que implica el ejercicio total o parcial de los derechos políticos o sociales a través de Internet de forma independiente, o por medio de la pertenencia a una 
comunidad virtual. ${ }^{7}$ Una parte crucial de dicho ejercicio es la relación directa con las entidades públicas, para obtener información o para realizar trámites. Así que, actualmente, el acceso a la información pública gubernamental no se puede pensar sin los medios electrónicos pues la ciudadanía presiona para que el Estado se comprometa a extender las posibilidades para acceder a los medios digitales y éste -a su vez- está consciente de la importancia de las TIC para su labor, toda vez que ellas facilitan, agilizan y amplían el acceso, al mismo tiempo que reducen costos; o sea, son un instrumento considerable que propicia una mayor eficacia en la gestión pública.

En síntesis, el concepto de ciudadanía es histórico y polisémico. La conducta ciudadana corresponde a la idea de democracia que se tenga (liberal, republicana, comunitaria, multicultural, cosmopolita). En este ensayo, se está a favor de una idea de ciudadanía (digital) cosmopolita, sostenida en una noción de democracia participativa e incluso directa; se piensa en una democracia que trabaje, como expresa Melucci, para "[...] prevenir el monopolio del lenguaje y para salvaguardar el 'derecho a la palabra' del que nuestro tiempo tiene urgente necesidad: aquella libertad de los individuos y de los grupos para establecer el sentido de lo que son y de lo que quieren ser." ciudadanía no sólo tiene que ver con derechos y responsabilidades de los individuos sino con la integración social, la participación política, la reivindicación de la identidad y el respeto a la diferencia. 


\section{TRANSPARENCIA Y MEDIACIÓN}

Una noción íntimamente ligada a la democracia y la ciudadanía es la de transparencia, que de acuerdo con Aguilar Rivera ${ }^{9}$ es un concepto que aparece, aunque no de manera tan visible pero sí muy significativa, en la filosofía política moderna, a la que Bentham (siglos XVIII-XIX) denominó publicidad y cuya función era hacer contrapeso al poder, aumentar la confianza del pueblo en el mismo, proporcionar a los ciudadanos la posibilidad de elegir de manera consciente, e incluso tener la oportunidad de aprovechar las ideas de éstos para contribuir al buen gobierno y, por lo tanto, garantizar su legitimidad.

En tal contexto, la prensa y después otros medios de comunicación masiva se adjudicaron el papel de interpelar al Estado, de tal suerte que éstos devinieron en la principal mediación" para ejercer la ciudadanía. Al respecto, Guerrero dice que, "[...] proveer de información, abrirse a las posturas y vigilar al poder, son las tareas históricas que las concepciones liberales del siglo XIX asignaron a los medios de comunicación, tres tareas que en su crecimiento han necesitado abrevar del acceso a la información gubernamental." ${ }^{10}$

De acuerdo con lo anterior, un ciudadano bien informado era aquel que accedía a dichos medios. A partir de ahí, la idea de transparencia se conformó de distinta manera y ritmo en varios países y se llegó al siglo XXI con la postura de que ella es la condición sine qua non de la democracia. Los medios, por su parte, no sólo se volvieron masivos sino que conformaron una industria altamente poderosa, y hoy incluso se puede poner en duda su contribución a la democracia.

\footnotetext{
* La mediación se entiende, de manera sencilla, como intervención o canalización entre dos partes, o sea, como aquello que está en medio de ellas, que podría llamarse también mediatez.
} 
Asimismo el siglo XX, de alguna manera, produjo una considerable democratización de la información en sentido amplio (mayor acceso a la educación y la cultura), lo que se acentuó hacia finales del mismo, producto de la incorporación de las TIC en distintos ámbitos de la vida cotidiana, lo que -dicho de manera simple- ha dado más autonomía y capacidad de participación a las personas. De tal suerte que hoy día, un ciudadano bien informado es quien trasciende la intermediación tradicional de los mass media y acude a diversas fuentes, incluidas las gubernamentales, con lo que se establece una comunicación directa entre el ciudadano y el Estado.

Efectivamente, las TIC han dotado a los individuos de herramientas que les permiten intervenir o ser más proactivos, pero eso no significa que gocen de total autosuficiencia, puesto que el mundo social se constituye por un entramado de relaciones interdependientes. A partir de ello, consideramos que, en materia de acceso a la información pública, cierta mediación es indispensable, pero ésta ya no debe ser concebida desde la óptica de los medios de comunicación masiva.

Esta perspectiva, aún hoy, en lo que respecta a democracia y transparencia no parece corresponder con la realidad actual. Es decir, no se observa un replanteamiento de la función de dichos medios, no obstante el reconocimiento del rol más activo de la ciudadanía. Guerrero sostiene que ellos son:

[...] ventanas para mirar fragmentos de lo que sucede en otros lugares; espejos que reflejan conductas sociales; filtros que privilegian determinados aspectos de la vida social y determinados discursos sobre otros; intérpretes de lo que sucede en el espacio público; legitimadores de valores, creencias y actitudes; espacios para difundir la innovación y el cambio; y auxiliares en la construcción y en la interpretación de la realidad social. ${ }^{11}$ 
Esta concepción de mediatez es demasiado intrusiva; incluso puede caer en lo que se denomina mediatización, que significa que los medios construyen realidades, lo que resulta altamente pernicioso para la democracia. Por el contrario, se requiere una mediación menos invasiva que no se proponga analizar, dirigir o sintetizar la información.

\section{MEDIACIÓN BIBLIOTECARIA}

Se trata de la mediación bibliotecaria, o lo que Almeida denomina mediación de la información, y define como "[...] todo acto de interferencia -realizado por el profesional de la información- directa o indirecta, consciente o inconsciente, singular o plural, individual o colectiva, que promueve la apropiación de la información que cumpla, total o parcialmente, una necesidad de información." ${ }^{12}$

En principio, el autor hace evidente que se trata de una intervención -agregaríamos estructurada- del profesional que él llama interferencia, pues se opone al planteamiento de la objetividad, y sostiene que la información de suyo no es neutral; al contrario, por lo mismo, hay que hacer consciente y evidente dicha interferencia para justamente lidiar de la mejor manera con los problemas que puedan surgir debido a ella. Otra cuestión importante es reconocer la parcialidad de la mediación, dada por el hecho de que el acceso total al universo informacional es irrealizable y de que los mecanismos de búsqueda son limitados. ${ }^{13}$

A su vez, Almeida ${ }^{14}$ expresa que la mediación suele asociarse con los servicios de información, ya que éstos son la cara más visible del quehacer bibliotecario, pero éste supone la selección, adquisición, almacenamiento, organización y diseminación de información, pues todo el proceso 
tiene la finalidad última de hacer llegar la información a los usuarios que la demandan. Por ello, el autor distingue entre mediación implícita y explícita; ${ }^{15}$ la primera se refiere a la que se da en los espacios, cuyas acciones ocurren sin la presencia física e inmediata del usuario (selección, almacenamiento y procesamiento de información); la segunda es la que se da ante la presencia inevitable del usuario, física o virtual (recuperación de información).

Por tal razón, Almeida ${ }^{16}$ afirma que el objeto de estudio de la bibliotecología es la mediación, la cual abarcaría todos los procesos bibliotecológicos. En otro sentido, podemos decir que esta mediación implica cierto tipo de filtro, toda vez que la selección de información conlleva una discriminación y quizás ahí puede haber un sesgo, pues el bibliotecario no es infalible. Sin embargo, la filtración no se entiende de la misma manera que desde la visión de los medios de comunicación masiva pues ellos, al interpretar, editorializan, y eso produce una alteración de la información.

Cabe resaltar que si se piensa en la información en el ambiente electrónico y, por lo tanto en el uso de las TIC, ellas mismas constituyen también una mediación, pero ésta no se da de manera estructurada; en otras palabras, tales tecnologías no establecen una interferencia subjetiva basada en determinados principios, sino que fungen como un medio muy potente para conseguir una mayor eficacia en materia de acceso.

Un elemento fundamental de la definición de mediación de Almeida ${ }^{17}$ es el de apropiación de la información, que va más allá de la obtención o el acceso. Ello envuelve una visión diferente del usuario; ya no se trata de un receptor pasivo, sino de un sujeto proactivo que lee e interpreta, que mejora su estado de conocimiento y, a partir de ello, hace determinados usos de dicha información y, así, se vuelve 
un agente en su realidad individual y colectiva. O como lo expresa Ríos, "[...] la información y el conocimiento son parte sustantiva del desarrollo humano y la autonomía de los individuos. En consecuencia, el conocimiento es fuente de poder porque crea un potencial y una capacidad de acción."18

Por lo tanto, la idea de apropiación es concebida en su dimensión social; es decir, tiene que ver precisamente con democratizar el acceso a la información y su posterior aprovechamiento y no simplemente con el acto de tomar para sí o acaparar, sino con la intención de impactar en el mejoramiento de la vida de los ciudadanos y sus comunidades. Ahora bien, esta suerte de conquista de información asociada a la ciudadanía digital implica que al mismo tiempo se produce una apropiación de la tecnología, en este caso de las TIC. Se pone pues de manifiesto la importancia de la información (digital) en sentido amplio, lo cual tiene que ver con el concepto de capital informacional, que:

[...] comprende la capacidad financiera para pagar la utilización de redes electrónicas y servicios de información, la habilidad técnica para manejar las infraestructuras de estas redes, la capacidad intelectual para filtrar y evaluar la información, como también la motivación activa para buscar información y la habilidad para aplicar la información a situaciones sociales. Ello presupone diferentes condiciones de organización: de la información a la deliberación, de los procesos de consulta y dinamización cultural a la elección y decisión vinculante. ${ }^{19}$

Así pues, se considera que en el contexto actual, de grandes y acelerados flujos de información, la gestión de ésta no sólo es indispensable, sino más compleja, y el tratamiento documental constituye la mediación que se requiere para garantizar el derecho de acceso a la información. De tal forma que quien puede y debe asumir ese papel (mediador) es 
naturalmente el bibliotecario, pues posee un sentido muy distinto al de los medios de comunicación masiva, cuyo propósito es formar opinión; mientras que el interés del profesional de la información está precisamente orientado a hacer llegar ésta a los usuarios y no a interpretarla con fines ulteriores. Y este cometido no se cumple conforme a "[...] la postura enfáticamente defendida, de que ese profesional es pasivo, superveniente, destituido de una aptitud proactiva, sin iniciativa, que sólo contribuye, auxilia y apoya"; ${ }^{20}$ al contrario, los profesionales de la información son "[...] sujetos en la sociedad y participan efectivamente en la construcción del destino de la humanidad. Incluso más que eso: es con la conciencia de que interfiere, de que se realiza como profesional en la relación con el usuario, que la democracia de la información podrá concretizarse." 21

A partir de todo lo anterior, se propone el término mediación bibliotecaria para la ciudadanía, y se refiere al trabajo de gestión de información de interés público, particularmente la documentación gubernamental. En la actualidad, para que un ciudadano esté bien informado -y así pueda ejercer sus derechos y ser parte de una sociedad democrática-, se requiere de la mediación bibliotecaria para hacer efectiva la ordenanza en materia de acceso a la información, ya que no puede haber obtención/apropiación sin sistematización previa.

Al igual que Ríos, ${ }^{22}$ se hace énfasis en la importancia del acceso abierto a la información. Es decir, ya no sólo se trata de la concepción del acceso a la misma como un derecho humano, sino que éste debe estar acompañado de la noción de acceso abierto, que como se sabe surge en el contexto de la sociedad de la información/conocimiento, entendida ésta en su concepción social más que económica y en donde se piensa a la información y al conocimiento como bienes 
públicos o bienes comunes, sobre todo cuando han sido financiados con fondos públicos y constituyen una fuente vital del desarrollo humano.

La cuestión del acceso abierto es de suma importancia pues refleja un cambio de paradigma que se da en la era de la información, pero no el que se refiere a ésta como motor de la economía, sino aquel que da vida a lo que se denomina cultura libre, para la cual la información y el conocimiento, como recursos sociales, deben fluir bajo un modelo horizontal y descentralizado.

Ahora bien, la idea de mediación antes descrita se relaciona con la propuesta de Ríos sobre la formación ciudadana. ${ }^{23}$ Dicho autor centra su análisis en la biblioteca, como instancia social y pública, cuyas funciones son: educación, desarrollo humano, disfrute de la cultura e interacción con el gobierno. Podemos decir que la biblioteca permite la obtención de información en sentido amplio, no sólo por lo que contienen sus colecciones sino porque proporciona acceso a Internet y con ello a un gran universo informativo, dentro del cual se encuentra -por supuesto- aquello que es de interés público, e incluso por medio de la red se puede hacer contacto con las instituciones públicas, con lo cual se hablaría de participación ciudadana.

No obstante, en la noción de mediación, más que pensar en la biblioteca como el espacio donde ésta ocurre, se prefiere resaltar el papel del bibliotecario como mediador pues éste no sólo realiza esta actividad en los espacios concebidos para ello, sino que su vocación se manifiesta en todo momento y lugar. En suma, el profesional de la información tiene una responsabilidad social y política que no puede ni debe eludir dentro y fuera de su espacio laboral, pues la demanda de información en general -y la de interés público en particular- pueden surgir en cualquier instante. Cumplir con 
tal papel, en este sentido, es lo que da la visibilidad, el valor social y la importancia que merece la labor bibliotecaria. Cabe resaltar que, en el contexto actual de expansión de la información, ella también se ha visto trastocada en términos de una mayor demanda de profesionales, altamente especializados, capacitados para gestionar información en todo tipo de organizaciones tanto públicas como privadas, institucionales o alternativas, quienes tendrían que adquirir competencias no sólo en función de la parte del proceso que realizan sino por el tipo de información que manejan (científica, gubernamental, educativa, cultural, artística, etcétera).

Por otro lado, Ríos parte de la idea de que la ciudadanía requiere educación política, la cual "[...] lleva tiempo concretar y requiere del acceso a las fuentes, la información de calidad, la interacción acertada con los flujos de información, así como el escrutinio y la toma de decisiones." ${ }^{24}$ Dicha educación no depende -por supuesto- del bibliotecario; sin embargo, su función sí es coadyuvar a la formación de ciudadanos reflexivos, que desarrollen su capacidad de agencia. Y eso se logra, precisamente, a través de lo que se ha definido como mediación bibliotecaria, dentro de la cual se debe incluir la instrucción para el discernimiento en la búsqueda de información, lo que se conoce como Desarrollo de Habilidades Informativas, que implica que los usuarios tengan clara su necesidad específica de información, accedan de manera eficaz a ella, que sean capaces de evaluarla de manera crítica, para utilizarla de manera creativa. ${ }^{25}$

En suma, la ciudadanía del mundo de hoy tiene un papel más activo, de mayor presión al Estado y sus instituciones; es decir que la exigencia democrática se expande, profundiza y complejiza, al tiempo que la mediación para ella también se transforma, incluso por el uso de las TIC. Por todo ello: 
Si se quiere un sistema democrático no esclerotizado, es necesario que haya debates abiertos a la participación de todos los individuos, sin exclusiones, donde se contrasten distintas visiones e ideales antes de definir lo compartido. Más y mejor democracia se demanda hoy en las calles de diversos lugares del mundo. Los mediadores que trabajen para el poder establecido y los que surjan de la resistencia deben tomar en cuenta esa demanda y los cambios que se están produciendo en paralelo a la expansión de las TIC. Internet y sus redes sociales no sólo han abierto millones de foros de discusión, sino que han aumentado enormemente las expectativas de participación directa. No sólo está cambiando la comunicación de masas, sino también los modos de mediar entre la Administración y los ciudadanos, así como las características de los mediadores que pueden cumplir eficazmente esa función. ${ }^{26}$

\section{CONCLUSIONES}

Todas las sociedades son sociedades de la información, no se puede pensar el proceso civilizatorio sin información. Sin embargo, en los estudios sociales, las explicaciones sobre los fenómenos culturales, económicos, políticos, etcétera, esto se pierde de vista, justamente porque se da por sentado que toda experiencia humana (individual y colectiva) implica uso de información en sentido amplio, pero de manera estricta o formal, la información contenida en un soporte es gestionada para poder fluir. Dicho flujo depende obviamente de circunstancias económicas, políticas, tecnológicas, culturales, etcétera, pero siempre implica un tratamiento profesional de la información.

De eso se trata la labor bibliotecaria, la cual es importante para la sociedad, pero lo es más cuando se trata de información gubernamental, pues su acceso es crucial para el ejercicio ciudadano; por lo tanto, la mediación en relación con este tipo de información requiere no sólo de un alto ni- 
vel de profesionalización, sino de una gran responsabilidad ética y política por parte del bibliotecario.

Por último, es importante resaltar la cuestión de que si bien las TIC han aumentado las posibilidades de acceso a la información y son instrumentos que permiten a los usuarios actuar de manera más autónoma, esto no significa que ellos puedan prescindir de todos los profesionales (bibliotecólogos, profesores, comunicólogos, consultores, informáticos). Al contrario, en una sociedad altamente compleja, como en la que vivimos, se requiere un alto nivel de especialización de todo trabajo vinculado al manejo de información, el cual está por supuesto orientado a mejorar la vida de las personas y éstas adquieren por su parte un rol más activo, lo que implica también un mayor vínculo con tales profesionales, quienes son precisamente los mediadores entre la información y los usuarios. Sin embargo, estos expertos son "[...] portadores de una responsabilidad ética y política para producir y distribuir recursos cognitivos, pero no tienen el derecho de orientar los destinos de la sociedad como 'consejeros del príncipe' o como 'ideólogos de la protesta'”. ${ }^{27}$

En suma, se insiste en la importancia de la mediación bibliotecaria para la construcción de ciudadanía, lo que requiere de la visibilidad y reconocimiento de los profesionales de la información por parte de las instituciones del Estado y por la sociedad. A su vez, dichos profesionales deben estar preparados para asumir una responsabilidad tan grande como lo es edificar el puente de acceso a la información pública.

\section{REFERENCIAS BIBLIOGRÁFICAS}

1. E. Villanueva (coord.) (2009), Diccionario de Derecho de la Información, México, Cámara de Diputados / UNAM / Miguel Ángel Porrúa, p. 331. 
2. J. G. García Murillo (2004), Derecho a la información. Consideraciones jurídicas para reglamentarlo en México, Guadalajara, Universidad de Guadalajara, p. 95.

3. E. Villanueva (2009), Op. cit., p. 331.

4. J. A. Horrach Miralles (2009), "Sobre el concepto de ciudadanía: historia y modelos", en Factótum (Revista de filosofía), núm. 6, pp. 376-377.

5. M. Castells (2008), La era de la información. Economía, sociedad y cultura. Vol. I: la Sociedad red, México, Siglo XXI Editores.

6. J. A. Horrach Miralles (2009), Op. cit.

7. J. M. Robles (2009), Ciudadanía digital. Una introducción a un nuevo concepto ciudadano, Barcelona, Edit. UOC, p. 19.

8. A. Melucci (2001), "Hacerse personas: nuevas fronteras para la identidad y la ciudadanía en una sociedad planetaria”, en Vivencia y convivencia. Teoría social para una era de la información, Madrid, Trotta, p. 57.

9. J. A. Aguilar Rivera (2008), Transparencia y democracia: claves para un concierto, México, Instituto Federal de Acceso a la Información y Protección de Datos.

10. M. A. Guerrero (2006), Medios de comunicación y función de transparencia, México, Instituto Federal de Acceso a la Información y Protección de Datos, p. 6.

11. Ibid., p. 17.

12. O. F. Almeida (2009), "La mediación de la información y la lectura de la información", en Ibersid: revista de sistemas de información y documentación, vol. 3, p. 24.

13. O. F. Almeida (2007), "Mediación e información", en Ibersid: revista de sistemas de información y documentación, vol. 1, pp. 27-35. 
14. O. F. Almeida (2009), Op. cit. p. 24.

15. Ídem.

16. Ídem.

17. Ídem.

18. J. Ríos Ortega (2013), "El acceso abierto a la información y la formación ciudadana”, en E. Morales Campos (coord.), Regulaciones que impactan la infodiversidad y el acceso abierto a la información en la sociedad global y multicultural, México, UNAM-IIBI, p. 140.

19. V. M. Marí Sáez y F. Sierra Caballero (2008), "Capital informacional y apropiación social de las nuevas tecnologías. Las redes críticas de empoderamiento local en la Sociedad Europea de la Información", en Telos. Cuadernos de Comunicación Innovación, núm. 74, ene.-mar., p. 131.

20. O. F. Almeida (2007), Op. cit., p. 31.

21. Ídem.

22. J. Ríos Ortega (2013), Op. cit., p. 140.

23. Ídem.

24. Íbid., p. 142

25 J. Lau (2007), Directrices sobre Desarrollo de habilidades informativas para el aprendizaje permanente, Veracruz, IFLA, p. 31.

26. F. Bernete García (2013), "Identidades y mediadores de la ciudadanía digital”, en F. Sierra Caballero (coord.), Ciudadanía, tecnología y cultura. Nodos conceptuales para pensar la nueva mediación digital, Barcelona, Gedisa, p. 142.

27 J. A. Horrach Miralles (2009), Op. cit., pp. 376-377. 
Aportes del proyecto "Costa Rica hacia la Sociedad de la Información: de todos para todos" para

la construcción de una política nacional de información en Costa Rica

\author{
MARCELA GIL CALDERÓN \\ MAGDA SANDI SANDI \\ Universidad de Costa Rica
}

\title{
INTRODUCCIÓN
}

\section{Conceptualización de políticas de información}

7 s importante enumerar algunas definiciones para en$\checkmark$ tender el concepto de políticas de información. En $\mathcal{L}$ una primera instancia se va a definir qué se entiende por política; luego, políticas públicas, y por último, políticas de información.

Existe una diversidad de autores de diferentes latitudes que conceptualizan el término política. Ésta es definida como la primera disciplina dentro de las ciencias sociales que se planteó la capacidad directiva de los gobiernos, cuyo objetivo es incrementar la capacidad de decisión. ${ }^{1}$ Se menciona esta definición, porque lo que se buscaba era la eficiencia del Estado en utilizar y distribuir, de una manera 
organizada e inteligente, los recursos públicos. Una alternativa fue la creación del término políticas públicas; al respecto, uno de los grandes exponentes fue Harold Lasswell, quien las definió como el "[...] conjunto de disciplinas que se ocupan de explicar los procesos de elaboración y ejecución de las políticas, y se encargan de localizar datos y elaborar interpretaciones relevantes para los problemas de políticas de un período determinado." 2 Lo anterior evidencia la necesidad de que los gobiernos dispongan de una estrategia clara para planificar, a corto, mediano y largo plazos, las metas y objetivos contenidos en los planes y programas de gobierno que faciliten la toma de decisiones para solventar los problemas públicos. Esto, con la participación de cada uno de los actores sociales y políticos que legitimen la validez y pertinencia de las acciones gubernamentales.

Es decir, las políticas públicas son una de las tantas herramientas que utiliza el gobierno para perpetuar su mandato político. Debe quedar claro que no todos los problemas de un país se resuelven con la creación o puesta en marcha de una política pública, pero lo que sí es evidente es que una política pública orienta y define la vía o la acción a seguir para solventar un problema de índole público. Lo que hacen los actores o agentes involucrados es que, mediante un ejercicio democrático de toma de decisiones, enmarcan el alcance y la dimensión del problema para su abordaje y análisis.

En América Latina, el tema de las políticas públicas se halla en la institucionalidad del Estado; no obstante, la responsabilidad de diseñar y ejecutar las políticas públicas siempre recae en el gobierno. Por ello, se debe hacer un inventario a nivel nacional y público sobre los recursos institucionales y la capacidad instalada de dichas instituciones para el diseño de las herramientas, para la toma de decisiones a nivel gubernamental y para la solución de los problemas de ín- 
dole público. El tema es complejo, porque entran en juego diversidad de factores, agentes y actores sociales, civiles y políticos, que buscan el bien común.

La clave del éxito de una política pública es lograr conciliar todos y cada uno de los intereses de los actores sociales y, además, dar respuesta a un problema específico de índole público. Cada país, región o sector podrá valorar la eficacia y eficiencia de la política en términos de cumplimiento de las acciones mediante los mecanismos de participación ciudadana establecidos por el Estado. Es importante en este apartado hacer una diferenciación entre los términos.

- Política de Estado: son acciones plasmadas en la Constitución política de un país, con preceptos claros que trascienden periodos de gestión de un determinado gobierno o intereses partidistas.

- Política de gobierno: son acciones de gobierno planteadas en la estrategia de un gobernante o de un partido político en el poder.

- Políticas públicas: son acciones de gobierno con objetivos de interés público que surgen del proceso de diagnosticar un problema en el cual la ciudadanía participa para dar soluciones.

De lo anterior, se desprende que las políticas públicas deben estar claramente enunciadas, planificadas y presupuestadas (dotadas de recursos) dentro de los planes de gobierno, con objetivos estratégicos bien definidos, con responsables y actores que van a desarrollar y ejecutar las acciones, tareas, actividades y procesos necesarios para el diseño, ejecución e implementación de la política. No se olvide que una política pública trae implícito un fuerte interés político-partidista que, en ocasiones, puede dar al 
traste con la buena acción o intención gubernamental de atacar un problema.

Por tanto, deben ser enunciados simples, con principios y directrices viables y alcanzables; además, deben ser verdaderos instrumentos y herramientas para la toma de decisiones que solucionen los problemas que han sido identificados por los propios afectados o involucrados en la solución del problema. Es pues responsabilidad de todos (gobierno, institucionalidad y sociedad civil) encontrar las mejores soluciones y que éstas emanen de diferentes sectores, espacios y organismos con niveles de gestión pertinentes y con un gran compromiso que los diversos actores tienen acceso real y definitorio en el proceso de toma de decisiones.

Una política pública es un proceso que presupone que todos los involucrados están debidamente informados del problema a solventar; son diferentes niveles y categorías que se deben definir para dimensionar el alcance del problema a resolver. La política pública no es simplemente un enunciado o una voluntad política expresa; es más que eso: constituye un compromiso claro, un proceso racional, veraz y realizable, equilibrado, para distribuir de manera adecuada los recursos públicos con el objetivo de solucionar dicho problema. En ello, la institucionalidad será puesta a prueba en la selección de las normas, reglamentos y procedimientos de los cuales dispone el Estado para proteger y salvaguardar el bien común. En consecuencia, es importante retomar el concepto de planeación estratégica, por cuanto es un proceso racional que debe prever los posibles escenarios, favorables o no, para anticipar las acciones estratégicas necesarias con el fin de minimizar las consecuencias de una eventual implementación de una política pública en entornos cambiantes, dinámicos o volátiles, como los que se viven en la actualidad. 
Es necesario situarse en un entorno de cambio, y es importante conceptualizar el término de políticas de información como lo hace Sánchez: "[...] las políticas de información son el estudio de las orientaciones y directrices que rigen la actuación de los diferentes sectores o grupos de la sociedad en la transferencia de información, su disponibilidad, su acceso y recuperación como medio para la comunicación de información entre personas generadoras y usuarios de información."

Es decir, son guías de los procedimientos y las actividades que deben planificarse y presupuestarse a nivel de gobierno, para lograr el libre acceso de los recursos informativos por parte de la ciudadanía. Ello presupone que, para implementar una política pública de información, deben tomarse en cuenta todos aquellos agentes y actores de una sociedad que producen, gestionan, distribuyen y utilizan los recursos informacionales. Entre ellos, se pueden citar los archivos y los documentos, tanto impresos como digitales, las bases de datos, los repositorios de información, los sistemas de información, las bibliotecas y los centros de información especializados, los procedimientos, las herramientas, los manuales la normativa vigente y los reglamentos; todos los cuales se derivan del uso de las tecnologías de la información y la comunicación y, más aún, de aquellos recursos y servicios que hoy en día están disponibles y hospedados en la "nube" del conocimiento.

El tema sobre políticas de información en la región latinoamericana no es nuevo: tiene su antecedente $\mathrm{u}$ origen en las décadas de los setenta y ochenta del siglo pasado cuando, por iniciativa de UNESCO, se empezó a gestar un movimiento a nivel mundial para la implementación del Programa General de Información (PGI), el cual se estableció en los Consejos Nacionales de Ciencia y Tecnología de los 
países de la región. Una de las acciones prioritarias de ese programa fue definir los lineamientos generales para la creación de políticas nacionales de información y así lograr un uso eficiente de los recursos informacionales de los países.

Los esfuerzos y los resultados obtenidos en esos años fueron muchos y efectivos, pero el factor "financiero" y "político" incidió para que muchos otros países de la región, entre ellos Costa Rica, no pudieran continuar sosteniendo iniciativas como las que habían impulsado los Consejos Científicos en materia de políticas de información.

\section{Antecedentes sobre políticas de información en Costa Rica}

En Costa Rica, el término políticas públicas se acuñó dentro de la administración pública; éstas fueron incluidas en la agenda pública de los gobiernos en turno, pero también están claramente identificadas en los planes de gobierno y en las estrategias nacionales de desarrollo. Esas iniciativas están sustentadas en mandatos que tienen que ver con las políticas enunciadas a nivel macro que legitiman la intervención del Estado en la resolución de los problemas nacionales. También, están íntimamente relacionadas con lo que enuncia la Constitución política sobre el accionar de los poderes del Estado y la función pública que debe ejercer.

En el caso particular del acceso a la información pública, la Constitución política de Costa Rica, en su artículo 30, "[...] garantiza el libre acceso a los departamentos administrativos con propósitos de información sobre asuntos de interés público. Quedan a salvo los secretos de Estado". ${ }^{4}$ Éste es quizá el antecedente de normativa del cual puede derivarse la necesidad de plantear la construcción de una 
política nacional de información, desde el enfoque de "política pública".

Es un hecho fehaciente que Costa Rica carece de una política nacional de información. No fue sino hasta la década de los noventa cuando se promulgó la Ley de Promoción del Desarrollo Científico y Tecnológico del 13 de junio de 1990. Gracias a esta ley, el Estado le confiere al Ministerio de Ciencia y Tecnología definir, establecer e implementar las políticas nacionales del sector de la ciencia y la tecnología costarricense. Por otra parte, es responsabilidad del Ministerio de Planificación Nacional y Política Económica establecer las prioridades de desarrollo según el sector de desarrollo nacional, pues es claro que en el Plan de Desarrollo 2011-2014 se establece una serie de lineamientos para impulsar el desarrollo de políticas públicas en materia de desarrollo informático y de acceso a la información pública. No se menciona nada en particular, y todo parece indicar que el tema subyace en políticas de otros sectores u otras ramas del sector público.

\section{Iniciativas nacionales y públicas que han aportado insumos para la formulación de una política de información en Costa Rica: normativa}

Si bien es cierto que en Costa Rica se han gestado iniciativas que han aportado insumos para la formulación de una política de información, aún no se dispone de políticas, planes y programas nacionales públicos/privados articulados de generación, organización y uso de información con perspectiva de desarrollo nacional. ${ }^{5}$ Se carece de un esfuerzo articulado para construir una sociedad de información nacional que sustente su desarrollo social, institucional, político, económico y medioambiental, en el uso intensivo de información por toda la población. ${ }^{6}$ 
Para ejemplificar y mostrar las más recientes leyes, decretos o normas que tienen o han tenido injerencia en la la promulgación o redacción de una política pública que tenga relación con el tema de la "información", a continuación se presenta un extracto de la recopilación realizada por Rosales y Ruiz en su tesis de Licenciatura en Bibliotecología y Ciencias de la Información: ${ }^{7}$

- 2000, SINABI. Constituye una red que integra a la Biblioteca Nacional y a las bibliotecas públicas que se ubican a lo largo del territorio nacional.

- 2000, Artículo 2do. Ámbito de protección de la ley de Información no divulgada. Ley No. 7975 (se busca asegurar aquella información que se clasifique como secreto comercial o industrial).

- 2001, Ley de Derecho a Internet. Esta ley defiende el acceso libre e irrestricto por parte de la población, sin distingo de edad, credo, nivel de escolaridad o condición social.

- 2002-2006, Programa Gobierno Digital. Esta iniciativa se implementó con la finalidad de facilitar las herramientas, procedimientos y tecnologías para el funcionamiento de las dependencias y entidades del sector público, en relación con la gestión y flujo de la información para una mayor eficiencia del Estado.

- 2004, SIBESE-CR. Es un sistema que reúne a las bibliotecas de las universidades públicas estatales para el intercambio de información y servicios para los usuarios de estas universidades.

- 2006-2010, Centros Comunales Inteligentes (CECI). Espacios dotados de la infraestructura telemática con el propósito de poner al servicio de la ciudadanía todos 
aquellos recursos de información para suplir las necesidades de la población a la cual sirven.

- 2012, Política Nacional de Cultura. Constituye un instrumento que dará permanencia, articulación y condiciones básicas de sostenibilidad a una visión de desarrollo nacional que incorpore de forma estratégica a la cultura, en su condición de derecho humano, y de motor y vector de desarrollo.

Existen muchas otras iniciativas que no se citan en este aparatado, la cuales también tienen relación con el tema información. Por ejemplo: está en la corriente legislativa un anteproyecto de Ley de Acceso a la Información Pública, documento que ha sido impulsado por la Secretaría del Gobierno Digital y el programa de Gobierno Abierto, la Escuela de Bibliotecología y Ciencias de la Información de la Universidad de Costa Rica ha estado participando activamente en las consultas públicas de este anteproyecto como en el documento sobre Política Nacional de Cultura.

En el siguiente apartado se desarrollará con mayor detalle lo relacionado al proyecto de investigación que se llevó a cabo en la Escuela de Bibliotecología y Ciencias de la Información de la Universidad de Costa Rica, para impulsar la creación de una política nacional de información.

PROYECTO "COSTA RICA HACIA LA SOCIEDAD DE LA INFORMACIÓN: DE TODOS PARA TODOS”

En su Estatuto Orgánico, artículo 3, "La Universidad de Costa Rica [establece que] debe contribuir con las transformaciones que la sociedad necesita para el logro del bien común, mediante una política dirigida a la consecución de una justi- 
cia social, de equidad, del desarrollo integral, de la libertad plena y de la total independencia de nuestro pueblo."

Inspirado en ese principio, un grupo de docentes de la Escuela de Bibliotecología y Ciencias de la Información de la Universidad de Costa Rica, inscribimos el proyecto de investigación No. 246-B0-235, titulado Costa Rica hacia la Sociedad de la Información: de todos para todos, cuya vigencia fue de agosto de 2010 a julio de 2013. El objetivo general fue visibilizar, desde la perspectiva del usuario de la información, la situación del componente información a nivel nacional, tomando en consideración la oferta y organización de la misma, así como la cobertura temática y geográfica, el uso de los recursos tecnológicos que realizan los usuarios y la institucionalidad que cobija el componente información: legislación, entidades, programas, recursos, entre otros. Todo esto, con el fin de contribuir a la construcción participativa de una consistente sociedad de la información costarricense, con una clara cultura de información, de manera que el desarrollo del país se apuntale en sólidos pilares en cuanto al recurso información. Para alcanzar este objetivo general, se plantearon los siguientes objetivos específicos:

- Objetivo específico 1. Iniciar una construcción participativa de una visión de Costa Rica 2020, operando como una sociedad de la información.

- Objetivo específico 2. Construir los componentes básicos de una política de Estado y de un plan maestro que viabilicen la construcción de Costa Rica 2020 como sociedad de la información.

- Objetivo específico 3. Elaborar una propuesta básica de los términos de referencia de un modelo de organización y operación público/privada de iniciativas de in- 


\section{Aportes del proyecto "Costa Rica hacia la Sociedad...}

formación del país, para construir una política nacional de información que articule el trabajo de entidades y programas conforme a la visión construida.

\section{Metodología de trabajo}

Para alcanzar los objetivos propuestos en el proyecto de investigación, los participantes, docentes de la Escuela de Bibliotecología y Ciencias de la Información de la Universidad de Costa Rica, aprovechamos los espacios que la academia ofrece y el posicionamiento que tiene la Unidad Académica tanto en lo interno de la Universidad como a nivel nacional.

El grupo de investigadores que se formó es de corte interdisciplinario, con un total de nueve integrantes (Marcela Gil Calderón, Magda Cecilia Sandí Sandí, Jorge Sariego MacGinty, Ramón Masís Rojas, María Lourdes Flores de la Fuente, Walther González Barrantes, Esteban González Pérez, Ricardo Chinchilla Arley, Max Cerdas López), de los cuales seis son bibliotecólogos que, además, cuentan con especialidades en el ámbito de la administración y la computación; otros dos son politólogos, con especialidades en administración y relaciones internacionales; y uno es investigador, con estudios en el área de sociología y con una especialidad en comunicación social.

Para iniciar con el análisis y discusión de la situación en cuanto a las políticas de información en el país, se organizó el I Congreso Nacional de Información para el Desarrollo Costa Rica "Hacia la Sociedad de la Información: de todos y para todos", celebrado los días 29 y 30 de setiembre y 1 de octubre de 2010. En dicho evento, se organizaron cuatro mesas de trabajo bajo la modalidad de taller, a cargo de coordinadores académicos; cada uno de ellos respondía a una temática específica; a saber: Institucionalidad, políticas 
públicas y avances para una visión de Costa Rica 2020 (mesa de trabajo número 1); Desarrollo de una cultura nacional de entendimiento y uso de la información (mesa de trabajo número 2); Conectividad, equipos y centros de información para el desarrollo local (mesa de trabajo número 3), y Rol de la empresa privada, de las organizaciones sociales y de los medios de comunicación (mesa de trabajo número 4).?

Asimismo, para continuar con la construcción participativa y posterior al congreso, se organizaron actividades colectivas que fueron abordadas durante los tres años de vigencia del proyecto. Se realizaron un total de cinco talleres, con la participación de actores de la administración pública, empresa privada y sociedad civil, entre otros. En dichos talleres, se abordaron los mismos temas de las mesas de trabajo del Congreso, y se trató además el tema de la Política Nacional de Información.

Paralelamente, los docentes investigadores -desde los cursos que imparten, a nivel avanzado del bachillerato en bibliotecología con énfasis en ciencias de la información, y a nivel de licenciatura en bibliotecología y ciencias de la información- abordaron esta temática y otras afines; entre ellas, se pueden mencionar: alfabetización informacional, cultura de información, conectividad, software libre y normativa vigente relacionada con el tema. Esto permitió la participación activa de los estudiantes, futuros profesionales en los que desde ya se promueve la generación de conciencia sobre estos tópicos.

Aunado a esta metodología, la Unidad Académica eligió el tema de políticas de información como eje central de las actividades a realizar durante 2013. Para ello, se estableció una coordinación con la Comisión de Acción Social de la Escuela y se organizó la lección inaugural titulada "Necesidad de la exigencia de una política nacional de informa- 
ción", a cargo del doctor Emir Suaiden, director del Instituto Brasileño en Ciencia y Tecnología quien, además, dictó un taller sobre el mismo tema. También, se desarrollaron las v Jornadas de Investigación: "Políticas de información y su vinculación con la investigación".

Se impartieron además cinco charlas abiertas cuya temática contempló la alfabetización informacional y la preservación impresa y digital de la memoria histórica nacional. Esto se hizo en coordinación con el Sub-Comité de Herencia Digital del Comité Nacional de Memoria del Mundo de la UNESCO, del cual es parte la Escuela de Bibliotecología.

Para fortalecer el marco teórico del proyecto, se realizó un trabajo final de graduación, bajo la modalidad de tesis, realizado por las estudiantes Rebeca Rosales Reyes y Adriana Ruiz Gómez, Aproximación a los aportes bibliotecológicos a una política pública de información en Costa Rica, ${ }^{10}$ el cual sistematiza los antecedentes históricos de una política pública de información, en el contexto nacional costarricense, durante el periodo comprendido entre 1985 y 2012. Asimismo, propone el ciclo de la política pública de información y aporta importantes recomendaciones relacionadas con las acciones a desarrollar desde la política pública, la gestión de la información, la infraestructura informacional, la infraestructura TIC y la cultura de información.

Las redes sociales no podían faltar en la metodología utilizada en el proyecto. Por eso, la profesora María Lourdes Flores, investigadora asociada, desarrolló y coordina el grupo "Políticas de información", utilizando Facebook. Actualmente, la comunidad está integrada por 522 miembros de diversos países, particularmente de Costa Rica, España, Argentina, Colombia, México, Venezuela, Brasil, Chile, Ecuador y Bolivia. Los temas abordados en este grupo son: cultura de información, contenidos y accesibilidad, software, 
La información gubernamental y el acceso a la información...

hardware y conectividad, alfabetización informacional, normativa (legislación vigente). ${ }^{11}$

\section{Resultados principales}

A continuación se realiza un recuento de los principales resultados del proyecto:

a) Identificación de los requerimientos para una política nacional de información.

b) Identificación de esfuerzos e iniciativas a nivel de país, tales como: políticas sectoriales, legislación y otros documentos que expresan con claridad la necesidad de establecer una política de información.

c) Establecimiento de alianzas con los diferentes actores, a nivel de país, que están trabajando el tema de políticas, tales como: Ministerio de Cultura, Ministerio de Planificación Nacional y Política Económica-(MIDEPLAN), Ministerio de Ciencia y Tecnología (MICIT) en la representación de la Secretaría Técnica del Gobierno Digital, la Dirección Nacional de Documentos Electrónicos y Firma Digital, el Consejo Nacional para Investigaciones Científicas y Tecnológicas (CONICIT), el Ministerio de Agricultura y Ganadería (MAG), la Sección de Archivística-Escuela de Historia de la Universidad de Costa Rica, la Unidad de Gestión y Transferencia del Conocimiento para la Innovación (PROINNOVA) de la Universidad de Costa Rica, el Programa Sociedad de la Información y el Conocimiento (PROSIC), el Centro de Informática de la Universidad de Costa Rica y el Sub-Comité de Herencia Digital del Comité Nacional de Memoria del Mundo de la UNESCO. 
d) Elaboración de documentos técnicos, base para el inicio de la discusión sobre el tema de políticas de información.

e) Propuesta básica de los términos de referencia de un modelo de organización y operación de iniciativas, a nivel público y privado, para construir una política nacional de información.

f) El proyecto ha tenido gran impacto entre los actores que han participado de las diferentes actividades que se han organizado en torno a la temática, por lo cual se convocó a alrededor de 120 personas, profesionales del campo de la bibliotecología en su mayoría y de otras disciplinas afines, tanto del sector público como del privado. La concurrencia a estas actividades ha sido exitosa debido a la capacidad de convocatoria que ha demostrado tener la Escuela de Bibliotecología y Ciencias de la Información a lo largo de los tres años de existencia del proyecto.

g) Visibilidad, proyección, presencia y reconocimiento de la Escuela de Bibliotecología y Ciencias de la Información en las discusiones, a nivel nacional, sobre la temática y la articulación con iniciativas similares a nivel de gobierno central, pues el grupo investigador de este proyecto fuimos convocados en diferentes sesiones de validación por parte del equipo de trabajo del Ministerio de Cultura y Juventud para la validación de la Política Nacional de Cultura. Asimismo, algunos investigadores del proyecto participaron en la validación del proyecto de Ley "Acceso Público a la información". Esta aportación le ha permitido a la Escuela de Bibliotecología y Ciencias de la Información abrir espacios de coordinación con la Secretaría del Gobierno Digital. 
h) Lograr la participación de múltiples actores, deseosos de continuar con la construcción de una política de información, para beneficio de la sociedad costarricense.

\section{CONSIDERACIONES FINALES}

Si bien es cierto se ha iniciado la construcción interactiva de una política nacional de información, el proceso requiere de la participación e involucramiento de muchos sectores, tanto públicos como privados. El proyecto permitió la elaboración de documentos base, la identificación de actores clave del proceso y la alianza entre pares.

Como resultado de la interacción de la Escuela de Bibliotecología y Ciencias de la Información con entidades gubernamentales, o bien con iniciativas públicas en materia de información, se pueden sugerir algunas temáticas que deriven en nuevos proyectos de investigación, en trabajos finales de graduación a nivel de grado, o bien, en otras iniciativas dentro de los cursos de bachillerato o de licenciatura. En las actividades de participación colectiva, se identificaron otros temas que deben ser abordados, como por ejemplo: acceso público a la información, datos abiertos, gobierno abierto, preservación del patrimonio digital y memoria histórica de los pueblos, y minería de datos.

Será entonces un esfuerzo que debe ser fortalecido, sumando energía y aunando voluntades, para continuar alzando la voz y hacer visible la necesidad de esta iniciativa de largo aliento que beneficiará a la sociedad costarricense. 


\section{REFERENCIAS BIBLIOGRÁFICAS}

1. Julio Franco Corzo (2013), Diseño de políticas públicas: una guía práctica para transformar ideas en proyectos viables, México, IEXE, p. 80.

2 Ibíd., p. 86.

3. E. J. Sánchez Vanderkast (2006), "Panorama de la investigación sobre políticas de información en América latina", en Revista Interamericana de Bibliotecología, vol. 1, núm. 29, p.125.

4. Costa Rica, Constitución política (1949), San José, Imprenta Nacional, p. 5.

5. S. Córdoba González (2002), "La cultura de información", en Pensamiento actual, vol. 3, núm. 4, pp. 27-32.

6. M. Gil Calderón (2012), "Informe final de las mesas de trabajo del Congreso Nacional de Información”, en E-Ciencias de la Información (Revista electrónica), vol. 2, núm. 2.

7. R. Rosales y A. Ruiz (2013), Aproximación a los aportes bibliotecológicos a una política pública de información en Costa Rica (Tesis para obtener el grado de Licenciatura), San José, Universidad de Costa Rica: Escuela de Bibliotecología y Ciencias de la Información.

8. Universidad de Costa Rica (2014), Estatuto orgánico, San José, p. 1.

9. M. Gil Calderón (2012), Op. cit.

10. R. Rosales y A. Ruiz (2013), Op. cit.

11. M. L. Flores de la Fuente (2013), Comunidad virtual. Políticas de Información. San José. 


\title{
Archivos, bibliotecas y censura
}

\author{
ROSA MARÍA MARTÍNEZ RIDER \\ PERLA ITZAMNÁ NAVARRO SÁNCHEZ \\ ROSA MARÍA LÓPEZ MARTÍNEZ \\ Universidad Autónoma de San Luis Potosí, México
}

\section{INTRODUCCIÓN}

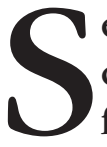

e analiza la transmisión social de las ideologías políticas y la influencia de los libros y los documentos en la formación de dos líderes políticos del siglo XX: Adolfo Hitler y José Stalin. Se revisa el impacto social de sus ideas a través de la diseminación en las bibliotecas y sus proyectos albergados en los archivos, donde los bibliotecarios y archivistas se dedicaron a organizar, difundir y censurar la información a conveniencia de los intereses políticos del nazismo y el comunismo.

Se considera la forma como se transmiten socialmente las ideas; lo que leyeron los personajes históricos aquí citados; cómo influyó su formación lectora en las propuestas ideológicas que elaboraron y en la respuesta social de su tiempo; qué políticas de información priorizaron sobre lo que se podía consultar en las bibliotecas; y qué información albergaron los archivos, que se mantuvieron en absoluta opacidad. 


\section{LAS IDEOLOGÍAS Y LA CENSURA}

Los libros y los documentos, en cualquier soporte (manuscrito, impreso, audiovisual, electrónico, digital o virtual), difunden ideas, conocimientos o información, los cuales son tan cotidianos que se asumen de forma mecánica en la vida diaria, pero toman forma dentro del proceso mismo del aprehender y comprender, porque son inherentes a la condición humana.

Estos elementos son parte de la historia, de la cultura, de la sociedad, de los proyectos personales o políticos, y se usan en función de la estructura de valores de los sujetos, para bien o para mal, aunque se parte de que su utilización debe coadyuvar en una mayor calidad en la toma de decisiones, o en la resolución de los problemas para el beneficio de la sociedad.

Las políticas de información en las bibliotecas y en los archivos (con algunas restricciones) ponen a disposición de todos los usuarios y ciudadanos lo que se ha hecho y lo que se hace en ciencia, tecnología, economía, política, técnica, arte, deporte, cultura, educación y múltiples disciplinas del saber. Son la memoria del hombre, pero además son la gama de cosmovisiones, perspectivas y ángulos que enriquecen el pensamiento humano, pues permiten, a su vez, interpretar y crear nuevas formas de comprender la realidad.

Sin embargo, además de su función y compromiso sociales, estas instituciones tienen una responsabilidad ética a través de las colecciones y los fondos que almacenan o que proporcionan a los usuarios y que, a su vez, resguardan para las próximas generaciones.

Las políticas de información hacen posible la difusión del discurso como un instrumento fundamental para la propagación de las ideologías en sus distintas variantes. Éstas 
se caracterizan por ser polisémicas y polimórficas, ya que adoptan una forma con base en el significado, sentido y dirección específica que toman, de acuerdo al contexto social en que se desarrollan y en consonancia con la lectura y las diversas interpretaciones que a partir de ésta se establecen.

Las bibliotecas son fuente para la proliferación de las prácticas lectoras y contribuyen a conformar el criterio de los sujetos; ésta es una razón por la cual se han censurado los libros y los documentos. La causa se encuentra en la función de las instituciones sobre la regulación de lo que se lee, direccionando el sentido de lo se aprende, aprehende e interpreta a través de la lectura.

En la historia, aunque no denominadas propiamente así, las políticas de información se han constituido con los actores, las instituciones, las legislaciones y los recursos, para llevar a la sociedad diversos sistemas de ideas que delinean la estructura y las relaciones entre los colectivos o los grupos sociales. En esta implantación de ideologías se encuentran inmiscuidos los grupos hegemónicos que regulan las prácticas que se llevan a cabo para generar (por medio de la escritura) y difundir (por medio de las instituciones y las formas de lectura) ciertos tipos de discursos y censurar otros.

Francia es el país que acuñó el concepto de ideología en la figura de Antoine-Louis-Claude Destutt, quien la definió como "Ciencia de las ideas" en 1801. A partir de lo anterior, el término se ha ido construyendo históricamente desde que se originó hasta nuestros días.

Por ejemplo, Marx y Engels basaron su disquisición en la premisa de la falsa conciencia ${ }^{1}$ otros autores, como Plamenat $z,{ }^{2}$ se encargaron de argumentar que ésta es parte de la conciencia global y, además, que nació de la lucha de clases.

Para Sartre, la ideología consiste en crear nuevas formas de leer la realidad. Sánchez Vázquez manifiesta que 
la ideología es un concepto más amplio que incluye "a) un conjunto de ideas acerca del mundo y la sociedad que; b) responde a intereses, aspiraciones o ideales de una clase social en un contexto social dado y que c) guían y justifican un comportamiento práctico de los hombres, acorde con esos intereses, aspiraciones o ideales."3

Althusser ${ }^{4}$ liga la ideología a las instituciones y al Estado; Gramsci, ${ }^{5}$ a las hegemonías; Lukács, ${ }^{6}$ a la conciencia de clase; Bourdieu, ${ }^{7}$ a los procesos de reproducción social; y Habermas, ${ }^{8}$ a la razón instrumental.

En otro estudio, Van Dick define las ideologías como "[...] creencias fundamentales que forman la base de las representaciones sociales de un grupo", pues dan identidad, pertenencia, origen, idioma, religión, normas, valores, posición social, relaciones con otros grupos, recursos, reproducción y medio natural, las cuales se adquieren fundamentalmente a través del discurso (texto, habla, interacción social) y abarcan una gran cantidad de conocimientos. Estas creencias influyen con determinación en lo que asumimos, asimilamos, adoptamos o modificamos, mediante una de las acciones que identifican al ser humano: la lectura. De ahí que las bibliotecas, los archivos y los medios de comunicación son agentes en la transmisión de ideas, pues, con el paso de los siglos, el libro y otros documentos han favorecido su expansión acerca del hombre y lo que le rodea.

En el acto humano de la comprensión, interpretación y creación de nuevos discursos se encuentra inmerso el cambio de ideologías y paradigmas que, como tales, cambian de acuerdo a su tiempo y, además, están sujetos a su condición de historicidad. Algunas favorecen la conservación de los libros y los documentos; otras, simplemente los destruyen para acabar con el conocimiento y ocultar, desde manejos turbios o experimentos clandestinos, hasta asesinatos masivos. 
Las ideologías políticas están estrechamente ligadas al multiculturalismo, que Hernández Reyna ${ }^{10}$ entiende como un concepto normativo sobre la regulación de la diversidad cultural y, en tanto movimiento, está entretejido con el reconocimiento de la identidad y la diferencia por parte de grupos minoritarios, siendo eminentemente político. Tal reconocimiento se distingue en las sociedades para respetar a los "otros" o, por el contrario, para tolerarlos, excluirlos y marginarlos.

Con el arribo de las Tecnologías de la Información y la Comunicación, se han modificado los estilos de difusión, sin considerar el nivel de que se traten y son un instrumento para la propagación de ideas y creencias. La computadora y las redes sociales han penetrado tanto en la vida cotidiana, que los niños y los jóvenes han creado un lenguaje particular para comunicarse y, entre otras muchas cosas, los ciudadanos han encontrado una forma de expresarse; tal es el caso del movimiento de los indignados en España, o M15, o la Primavera Árabe.

\section{IDEOLOGÍAS, MULTICULTURALISMO Y CENSURA}

Las relaciones entre los grupos multiculturales están mediadas por distintos tipos de ideologías, así como por una gama de posiciones políticas, las cuales se caracterizan por la definición de los sujetos sociales en mayorías y minorías, de las que se deriva la propagación de creencias sobre religión, raza, costumbres, hábitos y vida cotidiana, en los libros, revistas, folletos, documentos, medios masivos o Internet. Requejo y Zapata ${ }^{11}$ identifican cuatro tipos de multiculturalismo. El primero se refiere a "[...] una pluralidad de identidades culturales que tiene dificultades de expresarse 
en una esfera pública concebida tradicionalmente de forma homogénea"; por ejemplo, las corrientes feministas. El segundo está asociado a la inmigración y parte de la base inicial de la "[...] presencia de no-ciudadanos sigue una lógica de inclusión-exclusión". El tercero se relaciona con "[...] la presencia en una misma democracia de varios grupos nacionales concentrados territorialmente". El cuarto está el caracterizado por "[...] los grupos indígenas o autóctonos" en un mismo territorio geográfico.

Las ideologías tienen un impacto en las sociedades multiculturales, dadas por la mayoría que domina y las minorías que se sujetan, o las minorías que responden violentamente para defender sus creencias (como en el caso de los fundamentalismos) y derechos, en tanto se da la relación "nosotros"- "los otros" y no "nosotros y ellos con nosotros".

Varios sistemas de ideas políticas se basan en las distinciones biológicas, culturales o financieras, para crear estereotipos de superioridad racial, de estatus social o de grandeza nacional frente a otros países o regiones que han logrado solidificarse en el imaginario colectivo a través de la propagación ideológica que se da mediante la difusión de la información escrita y su correspondiente lectura. Báez destaca que "Es un error frecuente atribuir las destrucciones de libros a hombres ignorantes, inconscientes de su odio." Cuanto más culto es un pueblo o un hombre, más dispuesto está a eliminar libros bajo la presión de mitos apocalípticos.

Sobran los ejemplos de filósofos, eruditos y escritores que reivindican la biblioclastia. ${ }^{12}$ Así, la UNESCO, ${ }^{13}$ como parte del Programa "Memoria del Mundo", presentó una lista de las bibliotecas y archivos destruidos durante el siglo $\mathrm{XX}$, a partir de 1904, que incluye por ejemplo los conflictos armados en Japón, Sarajevo e Irak. La lista se publicó con la 
finalidad de proteger los libros y documentos emanados de diversas culturas.

\section{LAS IDEOLOGÍAS, LAS BIBLIOTECAS Y LOS ARCHIVOS}

El libro, los documentos de archivo y otras formas de expresión verbal o escrita como la radio, la televisión o el Internet, han influido y lo siguen haciendo en los modelos socioculturales para reafirmar los grupos hegemónicos o proponer relaciones de pluralismo, mayor equidad y justicia social en los grupos multiculturales.

Es indiscutible el papel que ha jugado la lectura durante siglos y ahora otras formas de comunicación para coadyuvar en la preservación de las monarquías, las dictaduras, los totalitarismos y otras formas de dominación. Múltiples son los ejemplos en la historia. La producción de ideas se configura del pensamiento de un autor a la imprenta o virtualmente en el Internet. Éstas se interpretan y utilizan a la luz de las ideologías que comparten los grupos sociales. Szir expresa que "[...] las prácticas inscriben al libro en el mundo social y lo relacionan con él." ${ }^{14}$

Un vínculo histórico entre los sistemas de ideas y los usuarios son las unidades de información, las cuales diseñan y estructuran políticas de información para poner las colecciones y los fondos a disposición del usuario y del ciudadano. En el caso del libro, determinan la clase de lectura a la que se tiene acceso y cómo se van internalizando las ideas en una sociedad.

Al estudiar el impacto de las ideologías, se considera la afirmación de Szir en el sentido de será necesario "[...] indagar las condiciones y modos en que esos objetos fueron producidos, las circunstancias y las vías a través de las cua- 
les llegan a los lectores y las formas a través de las cuales éstos se insertan en el proceso, con sus competencias culturales específicas y su inclusión en un complejo económico y social más amplio." 15

Así, las lecturas que llevaron a la construcción de las ideologías políticas en el siglo XX en Europa provienen de los cambios que se generaron en el siglo XIX; un ejemplo es la etnografía, que adquirió gran importancia en esa época, y las ideas del darwinismo social, de las cuales surgió la teoría "científica" de la superioridad racial.

\section{LAS POLÍTICAS DE INFORMACIÓN EN LOS TOTALITARISMOS}

Mellón y Vallbé destacan que "[...] la esencia del fascismo sería la estetización de una visión radicalmente desigualitaria y naturalista del hombre, un hombre guerrero que forma parte indisoluble de una comunidad nacional o una raza y que tiene un destino claramente marcado [...] la herencia y la raza [eran los] elementos definitorios de la comunidad". ${ }^{16}$

Partiendo de estas ideas se elaboraron múltiples escritos sobre la superioridad de la raza aria, el más popular de los cuales fue el del francés Gobineau, El ensayo sobre las desigualdades de las razas bumanas, ${ }^{17}$ difundido ampliamente en las bibliotecas. Sus ideas penetraron en distintas sociedades y diseñaron un modelo y un estereotipo racial; así, mientras Alemania enfatizaba las cuestiones culturales como el levantamiento del pueblo con base en la supremacía de la raza aria, Italia lo planteaba en términos de recuperación de la grandeza nacional. ${ }^{18}$ Cabe acotar que la obra de Gobineau fue "ajustada" por los nazis, puesto que no compartió ideas racistas contra los hebreos. 
Respecto a lo anterior, Antón ${ }^{19}$ refiere que la biblioteca personal de Hitler constó de alrededor de 16000 volúmenes y que estableció claramente en su libro Mi lucha, publicado en 1924, que "Leer no es un fin en sí mismo, sino un medio para un fin". Microlinance ${ }^{20}$ narra que "La hermana de Hitler, Paula, recordaba que siempre le recomendaba libros y que incluso le había enviado un ejemplar del Quijote de la Mancha." Además, que "Hitler había sido socio de tres bibliotecas en su Linz natal (pagando una suscripción bastante alta para la época) pues era un usuario habitual en la impresionante Hofbibliothek de Viena." La autoría del libro Raza y destino, publicado en 1928, se adjudica a Hitler sin certeza. Y se le atribuye por la inferencia del contenido, que consiste de ideas sobre la superioridad racial; la obra es conocida también como "El libro secreto de Hitler". Ryback ${ }^{21}$ afirma que los leía ávidamente, tanto, que algunos de éstos fueron decisivos en sus acciones más relevantes. Se destacó su gusto por las enciclopedias, así como por las obras de Schopenhauer, de Nietzsche, y por obras de ciencias ocultas y de la milicia.

Las ideología nazi se distribuyó socialmente en las bibliotecas y los archivos, pues "[...] el libro apunta siempre a instaurar un orden, sea el desciframiento en el cual debe ser comprendido, sea el orden deseado por la autoridad que lo ha de ejecutar", ${ }^{22}$ como es el caso de los totalitarismos. Las políticas de información desarrollaron en las bibliotecas colecciones de acuerdo a las ideas económicas, políticas y culturales desprendidas del nazismo para internalizar las ideas xenofóbicas, que repercutieron lamentablemente en "los otros", porque los libros y los documentos destacaban las desigualdades y diferencias biológicas o culturales de las raza aria respecto a las demás. 
Se generaron diversos tipos de archivos, como aquellos que contenían secretos de Estado y secretos militares. Vergonzosamente, los seres humanos fueron archivos vivientes porque fueron tatuados con un número en sus brazos. Conjuntos de documentos registraron los experimentos humanos con detalle. Además había pasaportes, visas, permisos, pases, fotografías y películas grabadas donde se muestran las atrocidades y el genocidio cometido por los nazis. Las cartas de los soldados y los recados de las familias fueron otros medios de comunicación.

Otro caso ilustrativo es el de Joseph Goebbels, quien consciente de la importancia de la diseminación social de las ideas, controló la prensa, la radio, el cine, los libros y las revistas, además de los mítines y las reuniones públicas. Así, "[...] los profesores y los bibliotecarios nazis armaron largas listas de libros que pensaban que no debían ser leídos por los alemanes."23

En el bibliocausto, se quemaron alrededor de 25000 libros de autores judíos o de autores que trataban temas que, de acuerdo al pensamiento, nazi no debían leerse. No obstante, aun con la caída del imperio alemán, la ideología nazi repercutió fuera de Europa. Los exterminadores que lograron escapar se refugiaron, por ejemplo, en América Latina y tuvieron gran influencia en algunos países; tal es el caso de Klaus Barbie, quien entrenó neonazis en Bolivia y pretendió instaurar ahí el cuarto Reich.

Del nazismo, se han derivado nuevas expresiones de la derecha en el siglo XXI que generan otras situaciones; por ejemplo, en 2014, el libro Mi lucha está en controversia, pues aunque se encuentra en Internet, en acceso abierto, en el 2015 su contenido será desclasificado en Alemania con fines educativos. Este proceso puede revisarse como una nueva etapa en la que la sociedad alemana ha encontrado 
caminos distintos para comprender el texto; ello se entiende como los naturales cambios que suelen propiciarse con el paso del tiempo en la forma de analizar un discurso escrito.

Otra ideología de gran impacto en el mundo ha sido el comunismo, que además de la URSS, se instituyó en Cuba, en China y en otros lugares, y tuvo efecto en algunos países latinoamericanos en forma de guerrillas. Ahora se aplica en Venezuela y Bolivia. En su modalidad de socialdemocracia, se ha adaptado en algunos países europeos y americanos.

El comunismo se instauró en Rusia con José Stalin, después de álgidos debates entre dos partidos: el de los mencheviques y el de los bolcheviques. De este último formaron parte Vladímir Ilich Lenin y León Trotsky, quien fue asesinado en México por el español Ramón Mercader del Río bajo las órdenes de Stalin. Pierre Broué ${ }^{24}$ señaló categóricamente que "Stalin sabía que era más fácil matar hombres que ideas, pero también que había que matar a muchos hombres para asesinar una sola idea. No escatimaba en las listas de ejecución que firmaba." Aunque Stalin fue escritor y editor, hay quienes señalan que no fue tan brillante en la construcción teórica del comunismo, como Marx, Engels, Lenin o Trotsky.

Este último criticó el modelo pragmático soviético, al establecer "[...] la degeneración del sistema hacia el burocratismo estaliniano y la teoría de la revolución permanente [así como] la negativa del partido comunista alemán a construir un frente antinazi formado por todas [las demás] izquierdas." 25 Y estos desacuerdos le costaron la vida.

Stalin, en su natal Georgia, escribió anotaciones en sus libros: "[había] referencias a las lecturas clandestinas de José y a los castigos que sufría por ello [...] Stalin tomaba prestados los libros en la biblioteca pública de la calle Kirocnaia. [Y] había leído también a Darwin, a los economistas clásicos (Smith, Ricardo, etc.), a todos los novelistas clásicos rusos 
y georgianos, y a muchos de los extranjeros." ${ }^{26}$ González Varela señala que "[...] su biblioteca contaba con todas las obras de sus rivales políticos de mayor envergadura: Trotsky, Bujarin, Kamenev, Radek [...] de los clásicos de la filosofía política, poseía un ejemplar anotado de El Príncipe de Maquiavelo." 27 Las ideas transmitidas a través del impreso influyeron en sus aportaciones a esa ideología, como es el caso de Los fundamentos del Leninismo; Sobre el materialismo dialéctico y el materialismo histórico; Cuestiones del leninismo, y Sobre el proyecto de constitución de la U.R.S.S., que fueron fundamentales en la forma práctica que dio al comunismo y a su desarrollo social. ${ }^{28}$

Así pues, toda obra intelectual fue revisada: el material impreso, el cine, la radio, porque se consideraron propiedad del Estado soviético. Además, se llevó a cabo "[...] la destrucción en masa de los libros y los periódicos pre-revolucionarios y extranjeros [que] prácticamente desaparecieron de las bibliotecas." 29 Se aplicó la censura con ferocidad, evitando a toda costa la contaminación social con las ideas del imperalismo occidental, pero, al igual que en otros casos, hubo lecturas prohibidas. González Varela afirma que:

Cada editor poseía una lista de cargos públicos claves a quienes tenía la obligación de enviar ejemplares antes de que se vendieran al lector. Se trataba de un tipo de censura especial añadida. El destinatario podía guardar el libro o devolverlo al editor con notas, sugerencias y comentarios críticos. En caso de no devolverse el editor podía suponer que la Nomenclatura no se oponía a su publicación o que le resultaba indiferente. Naturalmente Stalin también recibía ejemplares por adelantado de la mayoría de las editoriales, especialmente en su área de interés: política, economía, historia y arte. ${ }^{30}$

Se consideró tan peligroso el impacto de la lectura que hasta "Los emigrados, fusilados y encarcelados entregaban 
al Estado su biblioteca, que se almacenaban en locales donde los bibliotecarios estatales podían escoger los ejemplares que necesitaran." 31

La Biblioteca Lenin de la URSS se formó a partir del siglo XX como biblioteca pública y con Stalin creció considerablemente. En todo el mundo se conoció la cantidad de libros y manuscritos que almacenó: antes de 2010 ya tenía alrededor de 42 millones de libros. Actualmente se le conoce como la Biblioteca del Estado Ruso. Se internalizaron ideas dirigidas a engrandecer a Stalin como líder del proyecto político.

Las políticas de información tendieron al desarrollo de las bibliotecas con colecciones de acuerdo a las ideas del totalitarismo soviético, modelo alternativo al capitalismo, destacando los grandes defectos de éste y, paralelamente, enalteciendo la figura de Stalin como el gran constructor del Estado Soviético. Los archivos contenían secretos de Estado, estrategias militares, información sobre la Guerra Fría y el espionaje, experimentos médicos, archivos policíacos, asesinatos y masacres. Asimismo, contenían documentos, personales y familiares, de los niños recogidos por el Estado, y pasaportes, visas, permisos, pases, fotografías y recados de las familias que vivieron aterrorizados por la persecución cotidiana del Estado.

Como se mencionó, el comunismo se extendió a través del mundo; por ejemplo, en Cuba, con Fidel Castro y el apoyo de Ernesto "Che" Guevara, quienes por cierto tenían marcadas diferencias ideológicas. Antón y Vallbé ${ }^{32}$ refieren que el primero tenía una concepción revolucionaria basada en las tradiciones independencistas cubanas contra el imperialismo español o el norteamericano, y que simpatizaba con el modelo soviético de organización social, económica y política. En cambio, el "Ché" Guevara tuvo influencia de los elementos voluntaristas del maoísmo, con tendencia a 
crear una nueva concepción del hombre; además, fue muy crítico hacia la burocracia soviética.

El comunismo tomó su forma en China con el líder Mao Zedong y en algunas guerrillas con sus propias características. Al igual que en el nazismo, el comunismo se aplicó socialmente con excesos y abusos de poder para los sujetos que no comulgaban con esta ideología, los cuales fueron martirizados y muertos por los dictadores.

En 1991, con la caída de la URSS, quedaron expuestos los archivos soviéticos, los cuales fueron objeto de la destrucción o manipulación de propios y extranjeros. En 1997 se publicó El libro negro del comunismo: crímenes, terror $y$ represión ${ }^{33}$ escrito por autores de izquierda. La obra es controversial y polémica, pues describe las muertes de rusos, polacos, oriundos de Europa central y del sureste, China, Corea del Norte, Vietnam, Laos, Camboya, Etiopía, Angola, Mozambique, Afganistán y América Latina, conocida como "el campo de pruebas de todos los comunismos".

Se tenía conciencia de las consecuencias para un pensador o lector disidente, para aquel que no compartía la convicción de los políticos, para el que no acataba las políticas de información sobre los temas y asuntos a los que si se tenía acceso, pagando el costo de sus diferencias, biológicas, culturales y políticas. Los archivistas, al describir los documentos con fines de organización documental, conocieron su contenido y estaban al tanto de los excesos y los medios de los que se valieron los grupos hegemónicos para legitimar los modelos políticos. Todo se resguardó para el control y abuso de poder de unos cuantos. Los arrepentimientos llegaron demasiado tarde. 


\section{CONSIDERACIONES FINALES}

La investigación histórica de las políticas de información es un área que hace posible la identificación de las prácticas lectoras en diversos contextos sociales y culturales, mediante el análisis de las bibliotecas. Éstas son una fuente para internalizar las ideologías políticas en los sujetos y los colectivos, con un tipo de lectura dirigida hacia la consolidación de las hegemonías o de lecturas que han presentado alternativas a los problemas del multiculturalismo.

El análisis de las prácticas discursivas, las lecturas de ciertos actores sociales y la difusión de la información, estriba en conocer la forma en la que estos fenómenos se inscriben en determinados contextos sociales y se plantean en momentos históricos concretos en los que se puede manipular o difundir libremente la información, según sea el caso.

La reflexión acerca de las políticas de información permite estudiar los discursos, sea cual fuere el soporte en el que están albergados y las practicas que regulan su producción, conservación y distribución de acuerdo a diversas ideologías. La impresión, circulación y difusión de los libros en los totalitarismos se sujetó a las prioridades de lectura de los Estados que, en la práctica, se aplicaron en fomentar las desigualdades sociales bajo la perspectiva de un solo hombre, transformando las naciones en la cosmovisión única de sus líderes.

Los Estados distribuyeron socialmente sus ideas a través de las prácticas lectoras en las bibliotecas. La vinculación del estudio de los archivos, a los cuales no tenía acceso la población, presenta las condiciones en que las hegemonías impusieron una convicción sobre la aplicación de un modelo político y decidieron a cuáles ideas se tenía acceso y a cuáles no. Son el testimonio de lo que le sucedió a los 
"otros", así como a los que no estuvieron de acuerdo o interfirieron en los planes de grandeza.

Los libros, en el nazismo, contribuyeron al imaginario social de una estirpe racial superior, donde lo mejor era dominar y matar a todo principio de convivencia multicultural y de igualdad; todo acto se justificó por la supuesta grandeza de una raza frente a las demás. En el caso del comunismo, las ideas de Stalin representaron una alternativa social que fue atractiva en función de las condiciones sociales que prevalecieron en Rusia; el comunismo se presentó como la ideología salvadora del pueblo, como la otra, la distinta en esencia y contenido al capitalismo, considerado como el mal del mundo, pero que varió la forma del socialismo en su aplicación práctica para convertirse en un Estado policiaco. Finalmente, las diversas formas en las que se perciben las ideologías en el andar del tiempo y sus implicaciones históricas también están sujetas a una nueva crítica y a producir nuevas discusiones.

\section{REFERENCIAS BIBLIOGRÁFICAS}

1. Para Marx y Engels la falsa conciencia está integrada por creencias populares falsas, equivocadas y engañosas. Dick la interpreta como creencias populares, asimiladas de una clase dominante, para legitimar un estatus y esconder las condiciones socioeconómicas reales de los trabajadores.

C. Marx y F. Engels (1977), La ideología alemana, México, Cultura Popular, p. 37.

2. J. Plamenatz (1983), La ideología, México, Fondo de Cultura Económica, p. 28.

3. A. Sánchez Vázquez (1975), "La ideología de la neutralidad 
ideológica", en Revista Latinoamericana del pensamiento marxista, vol. 7, núm. 13-14.

4. L. Althusser (1969), Ideología y aparatos ideológicos del Estado, Buenos Aires, Nueva Visión.

5. A. Gramsci (1972), Introducción a la filosofía de la praxis, Barcelona, Península.

6. G. Lukács (1969), Historia y conciencia de clase (trad. de M. Sacristán), México, Grijalbo.

7. P. Bourdieu (2005), Capital cultural, escuela y espacio social, México, Siglo XXI.

8. J. Habermas (1984), Ciencia y técnica como ideología, Madrid, Tecnos.

9. T. A. Van Dick (2003), Ideología y discurso, México, Ariel, pp. 77.

10. M. Reyna Hernández (2007), "Sobre los sentidos de 'Multiculturalismo' e 'Interculturalismo'”, en Ra Ximbai, vol. 3, núm. 2, pp. 429-442.

11. F. Requejo y R. Zapata-Barrero (2002), "Multiculturalidad y democracia”, en J. A. Mellón (coord.), Las ideas políticas en el siglo XXI, Barcelona, Ariel, pp. 92-103.

12. "Fernando Báez: 'Sin destruir libros no se gana la guerra', en Enfoques [en línea], http://www.lanacion.com.ar/nota. asp?nota_id=694690

13. UNESCO (1996), Memory of the World: Lost Memory - Libraries and Archives Destroyed in the Twentieth Century, Paris, UNESCO.

14. S.M.Szir (2003), "El libro como objeto discursivo" [en línea], http:// www.torredepapel.com.ar/publicat/articulos/2003/10004.asp

15. Ídem. 
16. J. A. Mellón y J. J. Vallbé (2002), "Introducción a las ideas políticas del siglo XX", en J. A. Mellón (coord.), Las ideas políticas en el siglo XXI, Barcelona, Ariel, pp. 9-10.

17. J. A. De Gobineau (1853-1855), Essai sur l'inégalité des races humaines, Paris (6 vols.).

18. Ídem.

19. J.Antón (2009), "Un lector llamado Adolf Hitler" [en línea], http:// elpais.com/diario/2009/02/16/cultura/1234738801_850215. html

20. K. Microlinance (2007), "Stalin" [en línea], http://fliegeconera. blogspot.com/2007/11/Stalin-en-la-biblioteca.htlm

21. T. W. Ryback (2008), Hitler's private library, the books that shaped his life, New York, Alfred A. Knopf.

22. S. M. Szir (2003), Op. cit.

23. United States Holocaust Memorial Museum [en línea], http://www.ushmm.org/outreach/es/article. php?ModuleId=10007677

24. P. Broué, Los procesos de Moscú [en línea], http://www.marxismo.org/files/Pierre\%20Brou\%C3\%A9\%20-20Los\%20procesos\%20de\%20Mosc\%C3\%BA.pdf

25. J. A. De Gobineau (1853-1855), Op. cit.

26. C. C. del PCE (m-l) (1979), Biografía política de Stalin [en línea], http://biblio3.url.edu.gt/Libros/an_biopo_sta.pdf

27. N. González Varela, "Josef Stalin en la biblioteca" [en línea], http://es.scribd.com/doc/20750335/Josef-Stalin-en-la-Biblioteca-por-Nicolas-Gonzalez-Varela\#scribd

28. J. V. Stalin (1924), Los fundamentos del leninismo, Pravda (96, $97,103,105,107,108,111) 26$ y 30 de abril de 1924 y (1-118) 9 , 11, 14, 15 y 18 de mayo de 1924 [en línea], http://www.pcasevilla.org/images/descarga12.pdf; J. V. Stalin (1938), El materia- 
lismo dialéctico y el materialismo histórico [en línea], http:// archivo.juventudes.org/textos/Iosiv\%20Stalin/Sobre\%20el\%20 Materialismo\%20Dialectico\%20y\%20el\%20Materialismo\%20 Historico.pdf; J. V Stalin, Cuestiones del leninismo [en línea], http://www.marx2mao.com/M2M(SP)/Stalin(SP)/QL26s.html; J. V. Stalin (1936), Sobre el proyecto de constitución de la URSS. Informe ante el VIII Congreso Extraordinario de los Soviets de la URSS (pronunciado el 25 de noviembre de 1936).

29. Censura en la Unión Soviética [en línea], http://es.wikipedia. org/wiki/Censura_en_la_Uni\%C3\%B3n_Sovi\%C3\%A9tic

30. N. González Varela, Op. cit.

31. Ídem.

32. J. A. Mellón y J. J. Vallbé (2002), Op. cit., pp. 9-10.

33. N. Werth, et al. (1988), El libro negro del comunismo: crimenes, terror y represión (trad. C. Vidal), México, Planeta. 


\title{
Publicaciones oficiales, instrumento fundamental para la transparencia del Estado de Derecho
}

\author{
JUAN RICARDO MONTES GÓMEZ \\ Senado de la República, Biblioteca "Melchor Ocampo", México
}

\section{INTRODUCCIÓN}

onsidero importante, primero, denotar que la infor-
mación gubernamental puede entenderse como el
conjunto de datos y conocimientos registrados que
generan las instituciones públicas, es decir, se trata de la in-
formación que producen y poseen las estructuras de poder
del Estado, incluyendo los órganos constitucionales autó-
nomos y otras entidades que funcionan esencialmente con
recursos públicos.

Así, la información, consignada en función de su origen, describe o da cuenta del funcionamiento, procedimientos y decisiones de las burocracias al servicio del Estado, de la gestión o administración de los órganos e instituciones e, incluso, en un sentido mucho más amplio, en opinión de algunos especialistas, a últimas fechas esta información debería cubrir también la de aquellas instituciones como los partidos políticos y los sindicatos, que son financiados con recursos del Estado. En términos de su acceso, tal in- 
formación se circunscribe a la que se produce por efecto de sus actividades en diversos niveles de gobierno, ya sea el federal, el local o el municipal, y tiene como característica la máxima publicidad, con lo cual se posibilitaría una observación más nítida de la gestión del sistema en cuestión y, por supuesto, su evaluación.

Sin embargo, a contrario sensu, existe en tal conceptuación una excepción en términos de accesibilidad: la legislación exime a las instituciones públicas del Estado a la máxima publicidad de la información cuando se trata de dar a conocer datos, información o conocimientos que deben ser reservados, en razón de que tal acervo resulte ser estratégico o pudiera poner en peligro la estabilidad, la paz pública o la soberanía de la nación, incluso cuando se trate de datos personales que deben ser confidenciales, lo cual deberá estar plasmado racionalmente en las leyes correspondientes.

Desde esa perspectiva, lato sensu, ya sea que tal información gubernamental sea pública o temporalmente reservada, la condición característica para definirla en esos términos es que los datos, registros y documentos, tienen como fuente el sistema político plasmado originalmente en la Constitución del Estado.

Ya desde la Declaración de los Derechos del Hombre y del Ciudadano de 1789, el Estado, o mejor, el Estado de Derecho, es un constructo que se define por estar plasmado en la Constitución política respectiva, en cuyo texto deberán establecerse las condiciones de la división estructural de poderes y los derechos fundamentales que se garantizan. Así, a partir de esa premisa, el Estado de Derecho se legitima ante la sociedad al interior de su propia demarcación sistémica, y al exterior ante otras naciones en el contexto de la globalización. 
En el mismo sentido, dentro del conjunto de derechos garantizados en el texto constitucional de muchos países en la actualidad, está el de la libertad de información, que alude a un derecho fundamental mediante el cual se tiene la facultad de investigar y recibir informaciones y opiniones de cualquier fuente. Esto es, el derecho a la información es relativo, ya que a través de él los integrantes de la sociedad pueden, entre otros usos benéficos, comunicarse y cuestionar a las instituciones públicas observando la gestión y valorando el resultado de su funcionamiento para tomar decisiones al respecto. En relación al acceso a la información gubernamental, Mendel indica que:

[...] el derecho a la información, si se implementa correctamente, permite un diálogo entre el público y sus gobernantes, cultiva la buena gobernanza y promueve la rendición de cuentas al empoderar a los ciudadanos, los periodistas y la sociedad civil en general, con la información que requieren para luchar contra la corrupción y actuar como vigilantes contra abusos por parte de las autoridades. De manera más general, democratizar el acceso a la información, en particular la información en manos de entidades públicas, fomenta un clima político de apertura, transparencia y participación, que es la base de una democracia legítima. ${ }^{2}$

En todo caso el Derecho a la Información es de doble vía: en el plano subjetivo, mediante esa prerrogativa, los individuos y grupos de la sociedad tienen garantizado el acceso a la información pública, incluso sin necesidad de justificar ante la autoridad su requerimiento particular. En otro plano, en el de la legalidad, los sujetos obligados, en términos de responsabilidad, deben transparentar información de sus actos de conformidad con el ordenamiento jurídico establecido.

En tal argumentación, la racionalidad de la libertad de información tiene sentido cuando a nivel del Estado "[...] toda 
persona tiene derecho al libre acceso a información plural y oportuna, así como a buscar, recibir y difundir información e ideas de toda índole por cualquier medio de expresión"; ${ }^{3}$ así, el derecho humano de acceso a la información está garantizado constitucionalmente. Sin embargo, tratándose de información gubernamental, en opinión de Cossío:

[...] siempre que el derecho de petición se ejerza para solicitar información a los poderes públicos, su ámbito de aplicación podría superponerse con el del derecho a la información [...] lo que el particular tenga derecho a obtener de los poderes públicos dependerá de cuáles sean, por un lado, los contenidos del derecho a la información sobre las actividades de los poderes públicos y sus respectivas excepciones [...] y, por otro, el interés personal que tenga un particular en una situación eminentemente concreta a partir de sus características personales y su relación con la información solicitada. ${ }^{4}$

Esto circunscribe entonces al derecho o libertad de información al procedimiento mediante el cual el individuo acciona al Estado a través de una solicitud expresa, directa y materialmente pertinente al campo de actividad propia de la institución pública cuestionada. Veamos a continuación cómo el Estado, sin necesidad de un requerimiento de tal tipo, debería dar a conocer por vía de la información las acciones, los recursos y los resultados.

\section{LA TRANSPARENCIA DEL ESTADO DE DERECHO}

Entonces, en tanto que los derechos de acceso a la información o de petición hacen posible que los individuos obtengan información de los órganos de Estado que la generan, se puede deducir que la transparencia: 
[...] es una condición general del funcionamiento del Estado que se actualiza aun sin la acción directa de un individuo específicamente interesado pues de lo que se trata es de generar un amplio flujo de información [...] Lo que se presenta como el gran cambio de la transparencia es [...] que tanto cuantitativa como cualitativamente (en parte gracias al aprovechamiento tecnológico), se pone información gubernamental crecientemente importante en redes de fácil y constante acceso. ${ }^{5}$

Arribamos entonces del ejercicio de los derechos humanos de libertad de información al establecimiento de nuevas condiciones en la gestión del sistema político, de forma tal que es la operación de las estructuras del poder, propiamente las instituciones públicas, las que deben producir información gubernamental, y hacerla accesible, con criterios de pertinencia, confiabilidad, oportunidad, y periodicidad aceptables, concernientes a los resultados esperados, sin depender de acciones de sujetos interesados en la información misma. Por tanto, la transparencia del Estado de Derecho debe socializar la apertura de la información gubernamental al no hacerla depender de razones subjetivas. Y divulgarla a través de las publicaciones oficiales.

En concreto, el derecho a la información está asociado con el derecho de petición y la consecuente recepción de información por parte de los individuos solicitantes. Ésta es una garantía constitucional mediante la cual se actualiza tal precepto; sin embargo, en la actualidad un gran número de instrumentos jurídicos sobre el derecho a la información establecen también la obligación de las instituciones públicas de publicar información de manera anticipada y actualizada, aún sin que medie una solicitud de los individuos accionando a las instituciones públicas. La constante varía pero, en general, la información pública se refiere, para el caso de México, a: 
- La estructura orgánica de la institución.

- Las facultades de cada unidad administrativa.

- El directorio de servidores públicos, o sus equivalentes.

- La remuneración mensual por puesto, incluso el sistema de compensación.

- El domicilio de la unidad de enlace, además de la dirección electrónica donde podrán recibirse las solicitudes para obtener la información.

- Las metas y objetivos de las unidades administrativas de conformidad con sus programas operativos.

- Los servicios que ofrecen.

- Los trámites, requisitos y formatos. En caso de que se encuentren inscritos en el Registro Federal de Trámites y Servicios o en el Registro que para la materia fiscal establezca la Secretaría de Hacienda y Crédito Público, deberán publicarse tal y como se registraron.

- La información sobre el presupuesto asignado, así como los informes sobre su ejecución, en los términos que establezca el Presupuesto de Egresos de la Federación. En el caso del Ejecutivo Federal, dicha información será proporcionada respecto de cada dependencia y entidad por la Secretaría de Hacienda y Crédito Público, la que además informará sobre la situación económica, las finanzas públicas y la deuda pública, en los términos que establezca el propio presupuesto.

- Los resultados de las auditorías al ejercicio presupuestal de cada sujeto obligado que realicen, según corresponda, la Secretaría de la Función Pública, las contralorías internas o la Auditoría Superior de la Federación y, en su caso, las aclaraciones que correspondan.

- El diseño, ejecución, montos asignados y criterios de acceso a los programas de subsidio. Así como los padrones de beneficiarios de los programas sociales que 
establezca el Decreto del Presupuesto de Egresos de la Federación.

- Las concesiones, permisos o autorizaciones otorgados, especificando los titulares de aquéllos.

- Las contrataciones que se hayan celebrado en términos de la legislación aplicable detallando por cada contrato: a) las obras públicas, los bienes adquiridos, arrendados y los servicios contratados; en el caso de estudios o investigaciones deberá señalarse el tema específico; b) el monto; c) el nombre del proveedor, contratista o de la persona física o moral con quienes se haya celebrado el contrato y, d) los plazos de cumplimiento de los contratos.

- El marco normativo aplicable a cada sujeto obligado.

- Los informes que, por disposición legal, generen los sujetos obligados.

- En su caso, los mecanismos de participación ciudadana.

- Cualquier otra información que sea de utilidad o se considere relevante, además de la que, con base a la información estadística, responda a las preguntas hechas con más frecuencia por el público.

La información a que se refiere este parámetro normativo deberá publicarse de tal forma que facilite su uso y comprensión por las personas, y que permita asegurar su calidad, veracidad, oportunidad y confiabilidad. ${ }^{6}$

Sin duda esto puede variar en función del Estado de Derecho y del paradigma de política pública que se establezca, pero usualmente se extiende a la información sustantiva sobre cómo operan los sujetos obligados, sus políticas, las oportunidades para la participación pública, y los procedimientos sobre cómo solicitar información. 
La información gubernamental y el acceso a la información...

En términos de información gubernamental Merino considera que existen cuatro parámetros de control para la implementación y evaluación de una política de transparencia: ${ }^{7}$

- Publicidad: posibilidad efectiva de documentar y publicar toda la información sobre la forma en que la organización toma decisiones y las lleva a la práctica.

- Inclusión: importancia de incorporar e informar, de manera oportuna y accesible, a todos los actores que deben intervenir en la toma de decisiones o en su puesta en práctica, conforme a los fines que persigue una organización.

- Verificabilidad: posibilidad de constatar, por cualquier medio plausible, que las decisiones y los procesos de la organización se llevaron a cabo del mismo modo en que estaban definidos por las normas o los procedimientos aplicables o bien de la manera en que se dijo que efectivamente ocurrió.

- Responsabilidad: referida tanto a la definición formal de relaciones y papeles, como a la claridad de las decisiones que han de estar a cargo de cada uno de los actores que intervienen en la decisión o en la implementación de los fines que persigue la organización pública, así como en la producción, utilización y distribución de la información que tienen a su alcance.

Entonces, si abordamos a la transparencia como el rompimiento de la opacidad del Estado, en el que no es necesario invocar el derecho de información o el derecho de petición sino, de acuerdo con Cossío, visualizarla en dos planos, uno formal o documental y otro material, éste último buscaría la ruptura de la secrecía derivada de las condiciones burocráticas de operación en función de códigos, lenguajes y 
fórmulas, lo cual resulta tarea ardua para alcanzar que la sociedad logre entender plenamente el lenguaje técnico de la burocracia en general, situación por demás compleja y, francamente, inalcanzable. ${ }^{8}$

Importa entonces recurrir al concepto de la transparencia formal que, al ser una condicionante de operación del Estado de Derecho, en razón al continente documental y su contenido informativo, de lo que se trata es de reconocer la importancia del concepto publicación oficial como instrumento sustantivo de la transparencia en un enfoque cualitativo.

\section{LAS PUBLICACIONES OFICIALES}

Como un principio axiomático de la transparencia del Estado de Derecho debemos considerar que las instituciones públicas están obligadas, por mandato de ley, a publicar ex ante la información relevante sin menoscabo de la presencia o ausencia de solicitudes de información; los contenidos incluidos girarán en torno a las políticas, los procedimientos, los resultados, las actividades que tengan algún efecto en los miembros de la sociedad, el presupuesto, los subsidios, los beneficios y contratos, relativos a la gestión de las instituciones públicas, etcétera.

En todo caso las publicaciones oficiales son un instrumento fundamental de la transparencia del Estado de Derecho porque, en razón de la oportunidad, la pertinencia y la actualización de los contenidos permiten la divulgación proactiva consolidando la rendición de cuentas y la formación de la opinión pública; asimismo, en la reutilización de la publicación oficial la propia entidad que la genera tiene un amplio acervo de información sistematizada que permitiría la diagnosis periódica para la toma de decisiones ad intra. 
Sin duda, la redefinición de la publicación oficial estriba en la delimitación derivada de las tecnologías de la información, puesto que la información gubernamental electrónica adopta así una patente ex officio por el aumento y cobertura de contenidos, la disponibilidad e inmediatez, y la sistematicidad respecto de la propia estructura del sistema político; al respecto, es también necesario reconocer la labor bibliotecológica para la organización y evaluación de estos instrumentos para la transparencia. Al respecto la Internacional Federation of Library Associations (IFLA), en su Manifiesto sobre Transparencia, Buen Gobierno y Erradicación de la Corrupción expone que las bibliotecas, en razón de su naturaleza, son instituciones dedicadas a hacer accesible la información educativa, científica y técnica más precisa e imparcial y socialmente relevante para los individuos del grupo social, ya que a través de la organización y el acceso publicaciones oficiales se contribuye al buen gobierno, incrementando el conocimiento ciudadano sobre las acciones gubernamentales. ${ }^{\text {? }}$

Por tanto, es recomendable que las bibliotecas, en su propio ámbito territorial y de necesidades de información de la población, recopilen materiales informativos publicados por las instituciones públicas, especialmente aquellos que se relacionan con los derechos de los ciudadanos, ya sean ediciones de los poderes ejecutivo, legislativo o judicial o de otros órganos de la estructura estatal o con autonomía constitucional, mismas que se deben hacer accesibles por medio de índices, resúmenes y catálogos que apoyen la localización y consulta, ya sea en formato tradicional, digital o en línea, además de desarrollar colecciones a través de programas de preservación de la información oficial y bases de datos legislativas, de la administración pública, jurisprudenciales, electorales, sindicales, estadísticas, económicas, 
de salud pública, culturales, históricas, científicas tecnológicas, comerciales, sólo por mencionar algunas entre la infodiversidad de las instituciones públicas y de contenidos que envuelve en la cotidianidad a la ciudadanía.

\section{CONCLUSIONES}

La publicación oficial debe entenderse como un recurso documental informativo, fundamental en el contexto de transparencia del Estado de Derecho, materializado en algún tipo de soporte mediante la responsabilidad y autoridad de una institución pública, cuyo contenido, públicamente accesible, refiere objetivamente datos y conocimiento de las actividades propias de la gestión y resultados a los que está obligada dicha institución por su propia naturaleza política en el orden jurídico que la determina, que tiene por objetivo la comunicación con la ciudadanía y la justificación de la aplicación de los recursos públicos acordes a una periodicidad establecida.

\section{REFERENCIAS BIBLIOGRÁFICAS}

1. Ley General de Bienes Nacionales, publicada en el Diario Oficial de la Federación el 20 de mayo de 2004; última reforma publicada el 7 de junio de 2013.

2. T. Mendel (2009), El Derecho a la Información en América Latina, compilación jurídica, UNESCO, Quito, p. 1.

3. Constitución Política de los Estados Unidos Mexicanos. Artículo 6, publicado en el Diario Oficial de la Federación el 5 de febrero de 1917; última reforma publicada el 10 de febrero de 2014. 
4. J. R. Cossío (2008), "Transparencia y Estado de derecho", en J. M. Ackerman, Más allá del acceso a la información. Transparencia, rendición de cuentas y Estado de derecho, México: Siglo XXI, pp. 109-110.

5. Ley Federal de Transparencia y Acceso a la Información Pública Gubernamental. Nueva Ley publicada en el Diario Oficial de la Federación el 11 de junio de 2002; última reforma publicada el 8 de junio de 2012.

6. Ídem.

7. M. Merino (2008), "La transparencia como política pública", en J. M. Ackerman, Op. cit, p. 242.

8. J. R. Cossío (2008), Op. cit, pp. 109-110.

9. Manifiesto de la IFLA sobre Transparencia, Buen Gobierno y Erradicación de la Corrupción [en línea], http://www.ifla.org/ $\mathrm{ES} /$ node/7162 


\title{
La implementación de políticas de información en la diseminación de la información gubernamental
}

\author{
NAYELI GERVACIO MATEO \\ Universidad Nacional Autónoma de México
}

\section{INTRODUCCIÓN}

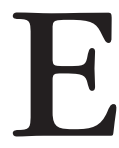

objetivo de este estudio es contribuir en la implementación de políticas de información que lleven al acceso y servicios innovadores y a la efectividad de la diseminación de la información gubernamental en sectores estratégicos, promoviendo una economía de conocimiento. Existen diversas definiciones de políticas; no obstante, para efectos de este texto y de acuerdo con el autor M. C. Sebastián, las políticas se "[...] diseñan para regular las actividades de los individuos, la industria y el comercio, de todos los tipos de instituciones, organizaciones y de gobiernos y suelen responder a estímulos concretos en un período de tiempo y por consiguiente deben ser flexibles."

Con base en lo anterior y de acuerdo con Almada, las políticas de información se definen como "[...] acciones con un propósito y dirigidas hacia un conjunto de metas identificables; tienen que ver con los patrones de comunicación, 
organización y diseminación de la información, tanto en el sector público como el privado, y por eso mismo con la infraestructura e infoestructura necesarias y organizadas para alcanzar esos objetivos."2

Otra definición es la que plantea Sánchez Vanderkast, quien define las políticas de información como: "[...] los mecanismos utilizados por la sociedad para su aplicación, para el control de los ciclos de vida tanto de la información como del documento y así como también el ciclo de transferencia de datos, información y documentos." ${ }^{3}$

Montviloff afirma que: "[...] deben normalizar la capacidad y la libertad de adquirir, poseer, guardar, usar y transmitir la propia información a través de la interacción estrechamente, no sólo con las dirigidas hacia archivos y bibliotecas, sino también con políticas de campos convergentes como la informática y las telecomunicaciones.”4

De forma concreta, las políticas de información contribuyen al desarrollo de:

[la] bibliotecología y estudios de información. Por lo tanto, es el estudio de las orientaciones y directrices que rigen la actuación de los actores, es decir, tanto los individuos como los diferentes sectores o grupos de la sociedad, en su relación con el ciclo de vida de la información: su disponibilidad, organización, transferencia, acceso y recuperación, como medio para la comunicación de la información entre personas generadoras y usuarias, así como la conservación y el retiro de la información y los documentos. ${ }^{5}$

Estela Morales, a su vez, expone que:

[...] las políticas que establezcamos en información se hallarán en estrecho vínculo con las políticas generales de un país, con las políticas públicas sobre educación y cultura y con las realidades históricas y sociales de la propia nación y de la región latinoamericana. Las políticas de información con que contamos no necesariamente son de tipo exhaustivo, ya que es posible ver esfuerzos parciales interrelacionados con las actividades y los productos 
que permiten a los habitantes de un país usar y leer información. Así, tenemos leyes, acuerdos o iniciativas de Estado correspondientes a la política que determinado país va estableciendo en el ámbito público y cultural o en el de la información y la lectura; podemos encontrar regulaciones que permiten inferir políticas sobre las bibliotecas, el libro, el derecho de autor, los recursos y sistemas informáticos. Las políticas de información han sido influidas por las guías de organismos internacionales como la UNESCO, la OEA, la IFLA, y a través de lo estipulado por estos organismos varios países han intentado crear sus propias políticas de información. ${ }^{6}$

Por otro lado, tenemos el tema de la diseminación de información. Para efectos de este capítulo, se considerará la definición que plantea Guinchat, la cual surge desde la perspectiva de servicio de información:

La diseminación de información es un procedimiento mediante el cual se suministra periódicamente a cada usuario o grupo de usuarios las referencias de los documentos que corresponden a sus intereses cognoscitivos. Este servicio puede proporcionarse a un usuario en especial basándose en un perfil de recuperación de información individual, o bien, a un conjunto de personas que tienen intereses comunes, requiriéndose para tal caso la definición de un perfil colectivo, por lo que la eficacia de este servicio depende, sobre todo, de una adecuada definición del perfil del usuario mediante la selección de un conjunto de palabras clave que reflejen la temática en cuestión. ${ }^{7}$

La diseminación de la información desde la óptica gubernamental en formatos abiertos, accesibles y estructurados, tiene el potencial de aumentar sustancialmente la transparencia y la rendición de cuentas en lo que se refiere a la elaboración y ejecución de políticas de información, además de abrir las puertas para una más amplia participación de la sociedad en la generación de nuevos servicios para los usuarios. 


\section{CASOS EN MATERIA DE DISEMINACIÓN DE INFORMACIÓN}

En México, desde 1977, el artículo sexto de la Constitución garantizaba el derecho a la información; sin embargo, se carecía de reglamentos complementarios que permitieran el ejercicio pleno de este derecho:

Se consideraba más bien una concesión, sujeta a la buena voluntad de la autoridad, y a disponibilidad física de la información. La "Ley Federal de Transparencia y Acceso a la Información Pública Gubernamental" (LFTAIPG), de junio de 2002, ha venido a modificar esta situación. Parte del principio de que toda la información gubernamental es pública, y que todos los servidores públicos deben rendir cuentas a los ciudadanos. Aquella que se clasifique como de acceso restringido debe justificar plenamente dicha condición, y las personas que solicitan documentos a través de esta disposición legal no necesitan dar ninguna razón o explicación acerca del uso que le darán. ${ }^{8}$

Para sustentar y garantizar el cumplimiento de la LFTAIP, se ha creado el Instituto Federal de Acceso a la Información y Protección de Datos (IFAI). Esto responde a la necesidad de reforzar los mecanismos y vías de diseminación de la información gubernamental, para apoyar al ciudadano cuando se presenten resistencias a la apertura.

Así, legislaciones de varios países contemplan la creación de entidades autónomas encargadas de vigilar la observancia de la ley en la materia. El IFAI empezó a operar en el año 2003, como encargado de hacer cumplir la LFTAIP en el Poder Ejecutivo Federal, y dio inicio a procesos para diseminar información en el ámbito gubernamental con el fin de promover y difundir el ejercicio del derecho a la información y resolver las negativas a las solicitudes. Como resultado, se ha logrado proteger los datos personales en manos de dependencias y entidades gubernamentales e im- 
pulsar una verdadera transformación cultural, al someter a la gestión gubernamental y a los servidores públicos.

El IFAI actualmente cuenta con autonomía operativa, presupuestaria y de decisión, lo cual le da gran fortaleza e independencia en relación con otros órganos de la administración pública. Está facultado para conocer sin restricciones toda la información que posea una entidad o dependencia gubernamental, sin importar si se trata de información confidencial o reservada, lo que implica una gran responsabilidad. Esta atribución le permite asegurar el cumplimiento puntual de la ley, ya que evita que discrecionalmente se decida qué información permanecerá restringida.

El IFAI tiene también la facultad de establecer políticas para llevar a cabo el proceso de diseminación de información, así como para la coordinación y cooperación entre todas las entidades y dependencias gubernamentales, con el propósito de que puedan hacer pública la información que poseen, siempre y cuando no afecten la seguridad nacional, la seguridad pública, la conducción de la política exterior, la estabilidad económica o financiera del país, o se ponga en riesgo la seguridad, la vida o la salud de los individuos. Asimismo, resuelve los recursos de revisión de solicitudes de información dirigidas a cualquier entidad o dependencia de gobierno. Su labor es contribuir a sustentar e incrementar la confianza pública en las instituciones, y activar los mecanismos formales de rendición de cuentas. Sin embargo, la legislación no contempla que las propias sesiones y deliberaciones del IFAI sean públicas, lo que es un punto para revisar y perfeccionar en el desarrollo de las instancias de transparencia.

Un segundo ejemplo en materia de diseminación de información es el "Acuerdo de Acceso a la Información que entró en vigencia en el 2004 aplicado en el ámbito gubernamental en Chile. Es un modelo preestablecido de validez universal 
en lo que se refiere a proceso para la diseminación de información";' sus rasgos más destacables son los siguientes:

- La inclusión de los mecanismos de solución en los que se aborde, de forma sistemática, todos los aspectos relacionados con la administración que estén enfocados en la diseminación de la información.

- La transparencia en relación con todo proyecto de medida que se adopta en el ordenamiento jurídico interno, y que pueda estar vinculada a asuntos incluidos en el acuerdo.

- La definición de un punto de contacto por cada uno de los agentes a fin de facilitar las comunicaciones.

- La inclusión de políticas detalladas para el proceso de diseminación de información, incluyendo disposiciones sobre el cumplimiento al acceso y difusión de la información gubernamental.

Como resultado de este ejercicio, se logró la cooperación y consulta entre los agentes referidos a cualquier aspecto vinculado con la aplicación en interpretación para alcanzar una solución mutuamente satisfactoria en cualquier asunto que pueda afectar el funcionamiento del proceso de diseminación de la información, así como la prevención de medios alternativos para la solución a las demandas de acceso a la información.

Otro ejemplo de diseminación de información gubernamental es el presentado en el estado de Oaxaca en 2008:

[...] se reafirmó el valor que le contribuyen los gobiernos a los mecanismos de solución en la diseminación de información a fin de tomar creíbles reglas de juego, en particular, ante quienes tienen que adoptar la toma de decisiones. Esta práctica tiende a ser cada vez más frecuente convirtiéndose en un elemento central de evaluación, en el cual predomina la libertad de organizar los 
procesos de diseminación de información de cada institución incluyendo a cada agente $\mathrm{y}$ actor que tienen precedentes que se consideran exitosos o al menos potencialmente exitosos. ${ }^{10}$

A partir de lo planteado, es conveniente estructurar políticas de información propias que coadyuven a las funciones, a las tareas y a las fases que comprende el establecimiento de una iniciativa de este tipo. Partiendo de este punto, se pueden distinguir dos etapas de implementación de políticas de información en la diseminación de la información gubernamental.

La primera es la construcción del problema que necesita ser atendido. Esto es, información que permita determinar la naturaleza del problema y los principales factores que intervienen. La segunda corresponde al esbozo o diseño de las estrategias para solucionar la problemática a la que nos enfrentamos. Aquí es necesario contar con información que tenga que ver con el análisis de posibles alternativas de solución que existen, así como de una evaluación para determinar el valor y la utilidad de cada una de las políticas que se desarrollen para lograr los resultados esperados.

La implementación de políticas de información en la diseminación de la información gubernamental se puede definir a través de tres factores principales que afectan en la generación de políticas de información en materia de la información gubernamental. Éstos pueden ayudar a entender las condiciones que se necesitan para mejorar el acceso y uso de la información.

El primer factor se refiere a la complejidad de la toma de decisión sobre la política. Dunn resalta la complejidad de los procesos para diseñar políticas de información, especialmente en el sector gubernamental. Dicha complejidad, que es determinada principalmente por factores técnicos y políticos, afecta la probabilidad de que la información tenga influencia 
en este proceso. El autor, por ejemplo, distingue cuatro problemas de políticas en función de los siguientes factores:

a) Cantidad de alternativas de políticas existentes dentro de un proceso de decisión,

b) Grado de consenso sobre el valor o utilidad de cada alternativa.

c) Número de grupo de interés y tomadores de decisión involucrados en una decisión sobre la política de información.

d) Grado de certidumbre acerca de los resultados de las alternativas de política. Este factor es el más complejo, ya que puede afectar en el uso de la información en aspectos políticos y en el uso de procedimientos racionales, tales como el análisis de políticas y la planificación estratégica, donde simplemente se signifique elegir los mejores medios para alcanzar la meta dada.

También puede influir la óptica de los distintos grupos de interés, generando conflicto acerca de cómo abordar estas políticas; por tal razón, los diseñadores de esas políticas tiendan a buscar información que apoye sus posiciones y que les permitan evaluar los mejores medios. Es necesario usar información desde un punto de vista técnico, y mientras más complejo sea el problema, más se necesita la información así como reducir la indecisión respecto a los resultados que se pretendan alcanzar.

El segundo factor se enfoca en las características del tomador de decisiones. Las características personales de los tomadores de decisiones, a menudo, determinan qué y cuántas informaciones son tomadas en consideración dentro de un proceso de construcción de políticas de infor- 
mación. Pattón ${ }^{11}$ identificó al factor personal como una variable clave para explicar la utilización de información en procesos de toma de decisiones y argumentó que, cuando hay un tomador de decisiones, hay un grupo de tomadores que están personalmente interesados en la evaluación y sus consecuencias.

La importancia del factor personal es posteriormente corroborada cuando los usurarios se involucran en la implementación y en la recolección de datos; se cree que una explicación posible a este impacto es la colaboración del usuario en la evaluación de cómo se debería realizar y operar la política de información, a medida que este enfoque pueda ser útil para ligar la problemática con la toma de decisiones y construir en la generación de conocimiento.

Por último, tenemos el factor que se refiere a las características de la información. Consiste, a su vez, en tomar en cuenta tres áreas que afectan su uso: la primera es la inteligibilidad de la información, que se refiere a facilitar o hacer fácilmente entendible ésta, pues hay mayor probabilidad de ser consultada y utilizada. Es decir, es importante cuidar que el documento sea conciso, bien organizado, simple en la presentación, fácil de leer, que maneje un lenguaje oral y menos técnico y que combine texto con graficas e ilustraciones, con la finalidad de que se tenga una mejor comprensión y apreciación de los beneficios y resultados. La segunda es la ajustabilidad de la información; se refiere a que es más probable que la información sea usada cuando apoya y no es contraria a los interese de los involucrados, lo que los lleva a tener resultados congruentes con las expectativas de los tomadores del decisión, la aceptación y la incrementación de los mismos. La tercera se refiere a los tipos de información producida: una es generada por investigación política (más pertinente para la construcción de 
políticas de información por que anticipa las consecuencias de una acción) y la otra es diseñada para entender la realidad (sólo clarifica por qué la realidad es de la manera que es, sin describir cómo podría ser hecha diferente).

Ejemplos de la implementación de políticas de información son el análisis y la evaluación sectorial y los estudios evaluativos. Los resultados de este tipo de estudios pueden producir información relevante para las diferentes etapas del proceso de construcción de políticas de información. Las dos son útiles para diagnosticar el estado de la política de información en la diseminación de información gubernamental y permiten estimar la medida en que una política de información ha alcanzado sus objetivos y qué es necesario modificar para acciones futuras.

Al contribuir con el desarrollo de políticas de la información para la diseminación de información gubernamental, se busca tener transparencia, nuevos y mejores servicios, y desarrollo equitativo en el uso y acceso a la información. Su finalidad es el acceso y la utilización óptima de los conocimientos especializados y profesionales, la información gubernamental, social y económica y las técnicas desarrolladas o disponibles en el país y en otras partes del mundo como recurso destinado a resolver problemas para el desarrollo de todos los sectores de la sociedad. Para trazar una política, se hace necesario un análisis detallado de las necesidades individuales y globales de forma tal que se tengan en cuenta los requerimientos y expectativas de aquellos que estarán regidos por tales políticas. Deberán abarcar a todos los sectores de la sociedad y la economía, que de una forma u otra estén vinculados a la investigación, la innovación, la producción y la tecnología. 


\section{CONCLUSIONES}

Una política de información para la diseminación de información gubernamental es imprescindible para lograr la armonía entre los recursos, servicios y sistemas de información; para el trabajo eficaz de todo sistema tanto económico, social como político; y para el desarrollo socioeconómico de un país. El desarrollo de este tipo políticas requiere de la participación de todas las instituciones y profesionales.

El hecho de que un país tenga su política de información es una gran señal para llevar a cabo la diseminación y la difusión de información gubernamental; sin embargo, no se debe quedar todo ahí, y es necesario que no se formalice ni esquematice. Es preciso hacer conciencia para actuar con iniciativa y creatividad. Debe satisfacer la condición de concatenar los nuevos desarrollos, en el contexto político concreto y las condiciones específicas de cada país y en función de lograr e impulsar el progreso con el objetivo de insertarse en la sociedad global de la información. Para esto, se recomienda seguir los siguientes puntos:

- Realizar un mapeo de las principales iniciativas para la diseminación de datos dispuestos en los niveles económico, social y ambiental, y desarrollar un marco metodológico que examine la relación entre la apertura de datos y la calidad de las políticas de información.

- Estudiar y discutir estrategias alternativas para fomentar la capacitación técnica en agencias gubernamentales y en los observatorios de la región, de manera de implementar repositorios de datos abiertos para el desarrollo, monitoreo y evaluación de las políticas de información. 
- Informar y sensibilizar a los gobiernos y a la sociedad civil sobre los beneficios y las potencialidades de los datos abiertos para las políticas públicas.

- Incentivar una comunidad de creadores de políticas de información, empleados públicos e investigadores, para que se sensibilicen en lo concerniente al potencial de los datos abiertos y las estrategias apropiadas para una implementación exitosa.

- Apoyar las redes de investigación para que produzcan nuevas informaciones y creen aplicaciones innovadoras y servicios basados en datos abiertos.

- Complementar el surgimiento de un interés generalizado en el tema de los datos abiertos con el desarrollo de capacidades para su gestión.

- Facilitar y apoyar la creación de estrategias de apertura de datos sustentables y durables.

- Analizar el potencial de los datos abiertos para delinear e implementar políticas de información que promuevan el crecimiento económico y la inclusión social.

\section{REFERENCIAS BIBLIOGRÁFICAS}

1. M. C. Sebastián (2000), "La necesidad de políticas de información ante la nueva sociedad globalizada. El caso español", en Ci. Inf., vol. 29, núm. 2, p. 22.

2. Elisa Margarita Almada Navarro (2008), "El análisis de actores. Metodología para el análisis contextual en Bibliotecología y estudios de la información", en F. F. Martínez Arellano y J. J. Calva González (comp.), Memoria del XXVI Coloquio de Investigación Bibliotecológica y sobre la Información, México, Universidad Nacional Autónoma de México / Centro Universitario de Investigaciones Bibliotecológicas, 2008, p. 33. 
3. Elisa Margarita Almada Navarro, "Las Políticas de Información en la enseñanza bibliotecológica. ¿Para qué enseñar el tema en la licenciatura?" [en línea], http://iibi.unam.mx/publicaciones/236/ xxvii_coloquio_cuib_elisa_margarita_almada_navarro.html

4. V. Montviloff (1990), Políticas nacionales de información: manual sobre la formulación, aprobación, aplicación y funcionamiento de una política nacional sobre la información, París: UNESCO, p. 18 [en línea], http://infolac.ucol.mx/documentos/politicas/28.pdf

5. Almada Navarro, Elisa Margarita, "Las Políticas de Información en la enseñanza bibliotecológica...”, Op. cit.

6. E. Morales (1999), "El derecho a la información y las políticas de información en América Latina”, en 65th IFLA Council and General Conference. Bangkok, Thailand, August 1999, p. 24 [en línea], http://www.ifla.org/IV/ifla65/papers/056-137s.htm

7. C. Guinchat y M. Menou (1992), Introducción general a las Ciencias y Técnicas de la Información y Documentación, Madrid, CSIC-UNESCO, pp. 371-372

8. Mauro Alberto Sánchez Hernández, "El órgano de fiscalización superior y el instituto estatal de transparencia y acceso a la información pública”, p. 4 [en línea], http://www.eumed.net/ tesisdoctorales/2008/mash/El\%20caso\%20de\%20Mexico.html

9. Félix Peña, "Una aproximación a nuevas tendencias en mecanismos de solución de controversias de acuerdos preferenciales de diseminación y difusión de información en instituciones de gobierno", p. 2 [en línea], http://infolac.ucol.mx/documentos/politicas/20.pdf

10. Ibid., p. 6

11. M. Q. Patton (1977), "In search of impact. An analysis of the utilization of federal health evaluation research", en C. Weiss (ed.), Using social research in public policy making, Lexington, Heath and Company. 
La información gubernamental y el acceso a la información pública. La edición consta de 50 ejemplares. Coordinación editorial, Carlos Ceballos Sosa; revisión especializada, formación editorial y revisión de pruebas, Servicios Profesionales de Asesoría Financiera y Administrativa (SPAFA). Instituto de Investigaciones Bibliotecológicas y de la Información/UNAM. Fue impreso en papel cultural de 90 g. en México, D.F. Se terminó de imprimir en el mes de marzo de 2015. 